\title{
Dietary assessment methods for micronutrient intake: a systematic review on vitamins
}

\author{
Patricia Henríquez-Sánchez ${ }^{1}$, Almudena Sánchez-Villegas ${ }^{1}$, Jorge Doreste-Alonso ${ }^{1}$, \\ Adriana Ortiz-Andrellucchi ${ }^{1}$, Karina Pfrimer ${ }^{2}$ and Lluis Serra-Majem ${ }^{1,3}$ \\ ${ }^{1}$ Department of Clinical Sciences, University of Las Palmas de Gran Canaria, PO Box 550, 35080 Las Palmas de Gran Canaria, \\ Spain \\ ${ }^{2}$ Division of General Internal and Geriatric Medicine, Department of Internal Medicine, School of Medicine of Ribeirão Preto, \\ University of São Paulo, Avenida Bandeirantes, 3900 Ribeirão Preto, SP, Brazil \\ ${ }^{3}$ Community Nutrition Research Centre of the Nutrition Research Foundation, University of Barcelona Science Park, Baldiri \\ Reixac 4, 08028 Barcelona, Spain
}

(Received 5 April 2009 - Revised 28 September 2009 - Accepted 15 October 2009)

The EURRECA Network of Excellence is working towards the development of aligned micronutrient recommendations across Europe. The purpose of the present study was to define how to identify dietary intake validation studies in adults pertaining to vitamins. After establishing a search strategy, we conducted a MEDLINE and EMBASE literature review. A scoring system was developed to rate the quality of each validation study according to sample size, statistical methods, data collection procedure, seasonality and vitamin supplement use. This produced a quality index with possible scores obtained ranging from 0.5 to 7 . Five thousand four-hundred and seventy-six papers were identified. The numbers meeting the inclusion criteria were: for vitamin A, 76; vitamin C, 108; vitamin D, 21; vitamin E, 75; folic acid, 47; vitamin $B_{12}$, 19; vitamin $\mathrm{B}_{6}, 21$; thiamine, 49; riboflavin, 49; and niacin, 32. The most frequently used method to ascertain dietary intake was the Food Frequency Questionnaire (FFQ), whereas dietary records (DR) and 24-h recalls were the most used reference methods. The correlation coefficients (CC) between vitamin intakes estimated by FFQ and the reference method were weighted according to the study's quality index and ranged from 0.41 to 0.53 when the reference method was the DR and from 0.43 to 0.67 when the reference was 24 -h recalls. A minority of studies ( $n 33$ ) used biomarkers for validation and in these the CC ranged from $0 \cdot 26$ to $0 \cdot 38$. The FFQ is an acceptable method of assessing vitamin intake. The present review provides new insights regarding the characteristics that assessment methods for dietary intake should fulfil.

\section{Dietary assessment: FFQ: Validation: Vitamins}

There is ample evidence regarding the role of dietary factors on the development of different chronic diseases. Nevertheless, assessing dietary patterns both at the individual and population levels is a difficult task due to the extensive variability of intake.

Multiple methods have been described to ascertain nutrient intake, with the Food Frequency Questionnaire (FFQ) being the instrument of choice in large nutritional epidemiological studies. Two other dietary instruments that are commonly used are the 24-h dietary recall and the dietary record (DR). It is generally accepted that all these methods have advantages and limitations and none of them is entirely satisfactory.

A universal epidemiological method to ascertain individual dietary intake does not exist. All methods have some kind of errors, although these are not always of a similar magnitude. Thus, it is a difficult task to know what the best method consists of if all of them are imperfect. The objective of a validation method is to compare a nutritional assessment method with another considered as superior, but never as the absolute truth ${ }^{(1)}$. One of the most important issues for avoiding false interpretations is the independence of errors among the different methods evaluated.

Numerous validation studies designed to compare the available methods to assess dietary intake are cited in the scientific literature. The most frequently applied method to ascertain dietary intake is the FFQ, whereas DR and recalls are most utilised as reference methods. The diversity of the results obtained does not allow us to draw conclusions about the selection of an ideal dietary assessment method.

Thus, the aim of this analysis was to identify the most accurate method to assess vitamin intake in the adult population through an extensive review of the literature.

Abbreviations: CC, correlation coefficients; DR, dietary records.

On behalf of EURRECA's RA.1.1 “Intake Methods" members: Serra-Majem L (Coordinator), Cavelaars A, De Groot L, De Vries J, Dhonukshe-Rutten R, Doreste JL, Frost-Andersen L, García-Álvarez A, Glibetic M, Gurinovic M, Henríquez-Sánchez P, Naska A, Ngo J, Novakovic R, Ortiz-Andrellucchi A, Øverby NC, Pijls L, Ranic M, Ribas-Barba L, Ristic-Medic D, Román-Viñas B, Ruprich J, Saavedra-Santana P, Sánchez-Villegas A, Tabacchi G, Tepsic J, Trichopoulou A, van 't Veer P, Vucic V, Wijnhoven TMA.

* Corresponding author: Patricia Henríquez-Sánchez, fax + 34 928453475, email phenriquez@dcc.ulpgc.es 


\section{Material and methods}

A MEDLINE and EMBASE literature search was carried out between July 2007 and March 2008. The procedure for the identification and selection of articles was performed in three steps:

At stage 1, a search strategy was established to identify the most relevant studies in the electronic databases.

The search terms used in the electronic databases were divided into two categorical strategies:

(1) General. The MeSH terms applied in the general search were: nutrient terms ('nutritional assessment' OR 'diet' OR 'nutritional status' OR 'dietary intake' OR 'food intake'); validity terms ('validity' OR 'validation study' OR 'reproducibility' OR 'replication study' OR 'correlation coefficient' OR 'correlation study') and human studies.

(2) Vitamin specific. The MeSH terms applied were: nutrient terms (vitamin names and synonyms) and intake terms: (intake* OR diet).

At stage 2 of the review, titles and abstracts of the selected articles were read by two independent reviewers. Only when they both determined that titles/abstracts met the exclusion criteria were the articles excluded. When a title/abstract could not be rejected with certainty, the full text of the article was obtained and further evaluated. We applied the following exclusion criteria:

(1) Articles exclusively assessing macronutrients and/or energy.

(2) Studies describing the content of foods in nutrients, additives or contaminants.

(3) Studies in diseased or institutionalised persons exclusively.

(4) Articles presenting reference values for food consumption, nutrient intake, biochemical markers and anthropometric measurements.

(5) Articles establishing associations between food consumption, nutrient intake, biological variables, biochemical markers and anthropometric measurements.

(6) Studies relating diseases to food consumption or nutrient intake.

(7) Intervention studies and other therapeutic studies with nutrients or drugs related to the metabolism of these nutrients.

(8) Calibration studies and those discussing statistical methods.
(9) Studies evaluating the physiological effects of foods, nutrients and in relation to their genetic determinants.

(10) Studies in animals and those without abstracts in PubMed.

At stage 3, the following criteria were considered to select the articles for inclusion:

(1) Studies regarding validation results for vitamin intake (those articles analysing only reproducibility or supplement use were excluded from the present analysis).

(2) Studies based on the adult population (those articles based on children, adolescents, pregnant women or the elderly were excluded from the present analysis).

The full text of all articles collected was screened for definitive exclusion or data extraction by a different reviewer from those involved in the acceptance process, with independent duplicate assessment of a random sample of $25 \%$ by a second reviewer. Where the two reviewers disagreed the study was discussed and a consensus decision reached where possible. If this was not possible, then a third reviewer was asked to arbitrate.

The articles included in the present study were categorised according to the total number of days over which the reference methods were applied:

(1) Long-term intake. If the reference method was a dietary assessment method (including 24-h recall and estimated and weighed DR) applied 7 or more days.

(2) Short-term intake. If the reference method was a dietary assessment method (including 24-h recall and estimated and weighed DR) applied less than $7 \mathrm{~d}$.

(3) Biomarker. If the reference method was a biomarker.

To assess the quality of the different validation studies, a quality score system was developed ${ }^{(2)}$. The studies were scored considering its sample size, the statistics used to validate the method, the procedure of data collection, and the inclusion or not of seasonality and vitamin supplements use, according to the values described in Table 1. The CC obtained for each study were weighed in proportion to the article quality index.

\section{Results}

Five thousand four-hundred and seventy-six articles were identified in the initial search strategy. After applying the exclusion criteria, 392 articles from the general search

Table 1. Quality criteria to score validation studies on micronutrient intake

\begin{tabular}{|c|c|c|}
\hline Variables & Specific variable & Score \\
\hline 1. Sample and sample size & $\begin{array}{l}\text { Non-homogeneous sample (sex, SES, smoking and obesity) } \\
n>100 \text { ( } n>50 \text { for biomarkers) }\end{array}$ & $\begin{array}{l}0.5 \\
0.5\end{array}$ \\
\hline \multicolumn{3}{|l|}{ 2. Statistics } \\
\hline Group level & Compare/test means or medians or differences & 1 \\
\hline Correlations. Only one selected, which with the highest score & Correlation & 0.5 \\
\hline & Adjusted correlations (energy, etc.) & 1 \\
\hline & Deattenuated or intra-class correlations & 1.5 \\
\hline Agreement & Classification or Bland and Altman plot & 0.5 \\
\hline 3. Data collection & Gathered by face to face interview & 1 \\
\hline 4. Seasonality & Considered & 0.5 \\
\hline 5. Supplements & Included and data considered in analysis & 1.5 \\
\hline
\end{tabular}

SES, Socioeconomic status. 
Table 2. Distribution of analyses by FFQ validation method and vitamin

\begin{tabular}{lcccc}
\hline & \multicolumn{4}{c}{ Gold standard } \\
\cline { 2 - 5 } & Dietary record & Recall & Biomarkers & Other methods \\
\hline Vitamin A & 46 & 24 & 2 & 8 \\
Vitamin C & 63 & 31 & 13 & 19 \\
Vitamin D & 14 & 4 & 1 & 2 \\
Vitamin E & 38 & 22 & 21 & 17 \\
Folic acid & 30 & 12 & 7 & 7 \\
Vitamin $B_{12}$ & 13 & 5 & 1 & 1 \\
Vitamin B $_{6}$ & 11 & 5 & 1 & 2 \\
Thiamine & 38 & 9 & 1 & 1 \\
Riboflavin & 39 & 9 & 1 & 1 \\
Niacin & 28 & 5 & 0 & 2 \\
\hline
\end{tabular}

remained in the review. We applied the inclusion criteria in stage 3 obtaining the following articles for each vitamin: 76 articles for vitamin A; 108 for vitamin C; 21 for vitamin D; 75 for vitamin $E ; 47$ for folic acid; 19 for vitamin $B_{12} ; 21$ for vitamin $\mathrm{B}_{6} ; 49$ for thiamine; 49 for riboflavin: 30 for niacin, extracted from a total of 124 studies.

In the present review, most of the validation studies used a FFQ as the intake assessment method. For each vitamin, the methods used as gold standards to validate the FFQ are described in Table 2.

To measure the validity of the different FFQ according to the type of reference method utilised, weighted means of the $\mathrm{CC}$ were calculated using the quality index value of each study as the weight (Table 3). Weighted CC for the FFQ ranged from 0.41 to 0.53 when the reference method was the DR, and from 0.43 to 0.67 when the recalls were utilised as the gold standard. Only a few studies ( $n$ 33) used biomarkers as a validation method, which yielded lower correlation values (coefficients between 0.26 and 0.38).

Tables 4-11 describe the purpose and scope of the literature examined in the present review: author and year of publication, population size (ranged from 20 to 860 persons) and sex (majority were females), characteristics of the FFQ (mode of administration, number of food items included in the questionnaire and reference period), characteristics of the reference method (collection of information and total number of days over which the reference method was applied), the use or not of supplements, the correlation coefficient and the quality index.

$F F Q$ v. dietary record. The DR was used as the gold standard in most of the validation studies included in the present

Table 3. Weighted mean correlation coefficients according to reference method used in FFQ validation for each vitamin

\begin{tabular}{lccc}
\hline & Dietary record & Recall & Biomarkers \\
\hline Vitamin A & 0.45 & 0.44 & 0.26 \\
Vitamin C & 0.50 & 0.51 & 0.28 \\
Vitamin D & 0.51 & 0.61 & \\
Vitamin E & 0.49 & 0.43 & 0.26 \\
Folic acid & 0.51 & 0.49 & 0.38 \\
Vitamin $B_{12}$ & 0.45 & 0.59 & \\
Vitamin $B_{6}$ & 0.50 & 0.52 & \\
Thiamine & 0.42 & 0.56 & \\
Riboflavin & 0.53 & 0.60 & \\
Niacin & 0.41 & 0.67 & \\
\hline
\end{tabular}

systematic review. In the majority of the cases, information regarding dietary intake was collected through a self-administered FFQ $(82 \%)$ to assess dietary intake in the previous 12 months $(58 \%)$. The number of food items included in the questionnaire ranged between 22 and 350. The weighted CC varied according to the number of food items $(<100$ or $\geq 100$ food items) included in the FFQ (Fig. 1).

Only $31 \%$ of the studies included the intake of vitamin supplements in their analyses. There were no large differences in $\mathrm{CC}$ between studies that did or did not include information on vitamin supplements (Fig. 2).

In $43.7 \%$ of the cases, the CC were higher when the DR used as the reference method was a weighed DR compared to the use of an estimated DR (Fig. 3).

Most of the DR used as reference methods collected dietary intake for $7 \mathrm{~d}$ or more (long-term intake; $74 \%$ of the studies). Fig. 4 shows the difference in the weighted $\mathrm{CC}$ according to the number of days included in the DR (long- $v$. short-term intake).

$F F Q$ v. recall. When the reference method was the recall, information was more frequently collected through an interviewer-administered FFQ $(50 \%)$ instead of being selfadministered by the study participants. The number of food items included in the FFQ ranged between 47 and 222. Fig. 5 shows the weighted $\mathrm{CC}$ according to the number of food items included in the FFQ.

The proportion of studies in this group including information about vitamin supplement intake was lower than that of those using DR as the gold standard (23\%). Indeed, there were no data on supplement intake for the B-complex vitamins with the exception of one study (Fig. 6).

More than half of the recalls $(55.6 \%)$ used to validate the FFQ collected dietary information during 7 days or more. When long-term intake was evaluated, the $\mathrm{CC}$ for the B-complex vitamins decreased (Fig. 7).

$F F Q$ v. biomarkers. The use of biomarkers as the reference method was less frequent, resulting in $\mathrm{CC}$ often much lower than $0 \cdot 40$. Folate intake collected through a FFQ was validated using serum folate in three studies. One study used erythrocyte folate as the reference method, and another three studies used both serum and erythrocyte folate as biomarkers. In fifteen studies, vitamin $\mathrm{C}$ intake was compared with its blood levels. Plasma concentration of vitamin E was used as the gold standard in seventeen studies validating vitamin $\mathrm{E}$ intake. Moreover, in four other studies, adipose tissue concentration was also used as biomarker.

\section{Discussion}

Our aim was to determine the comparative efficacy of available methods to validate dietary intake. The present review shows that FFQ are the most commonly used method for assessing diet in epidemiological studies. The main advantages are their low cost and their capability to characterise the usual diet in the past, as well as to minimise the risk of serious interviewer ${ }^{(1)}$ and measurement bias, given that they can be self-administered.

The drawbacks of the FFQ include the use of fixed lists of foods, the effect of memory, the difficulties in portion size estimation and the interpretation of questionnaires ${ }^{(1,3)}$. Among the available reference methods for the validation of FFQ, dietary records (DR) are likely to have the least 
Table 4. Description of validation studies regarding vitamins A, C, D and E intake (FFQ vs. dietary records)

\begin{tabular}{|c|c|c|c|c|c|c|c|c|c|c|c|c|}
\hline \multirow[b]{2}{*}{ Author and year of publication } & \multirow[b]{2}{*}{ No. } & \multicolumn{3}{|c|}{ Age (years) } & \multirow{2}{*}{$\begin{array}{l}\mathrm{FFQ} \\
\text { administration } \\
\text { method }\end{array}$} & \multirow[b]{2}{*}{$\begin{array}{l}\text { No. of } \\
\text { foods }\end{array}$} & \multirow{2}{*}{$\begin{array}{l}\mathrm{FFQ} \\
\text { reference } \\
\text { period }\end{array}$} & \multirow[b]{2}{*}{ Suppl. } & \multirow{2}{*}{$\begin{array}{l}\text { Reference method } \\
\text { (no. of records/ } \\
\text { no. of days per } \\
\text { record) }\end{array}$} & \multirow[b]{2}{*}{ Nutrient } & \multirow[b]{2}{*}{ Coefficient } & \multirow[b]{2}{*}{$\begin{array}{c}\text { Quality } \\
\text { index }\end{array}$} \\
\hline & & Mean & SD & Range & & & & & & & & \\
\hline \multicolumn{13}{|l|}{$\begin{array}{l}\text { Long-term intake } \\
\quad \text { Ambrosini et al. (2001)(7) }\end{array}$} \\
\hline Ambrosini et al. (2001) & $\begin{array}{l}26 \mathrm{~W} \\
57 \mathrm{M}\end{array}$ & & & $28-72$ & Self-administered & Unknown & 1 year & Yes & DR estimated (4/7) & Vitamin A & $0.59 \mathrm{~W}^{*} / 0.48 \mathrm{M}^{*}$ & 4 \\
\hline Andersen et al. $(1999)^{(8)}$ & $125 \mathrm{M}$ & & & $20-55$ & Self-administered & 180 & Unknown & Yes & DR weighed (5/3) & $\begin{array}{l}\text { Vitamin A } \\
\text { Vitamin C } \\
\text { Vitamin D } \\
\text { Vitamin E }\end{array}$ & $\begin{array}{l}0.62 \dagger \\
0.50 \dagger \\
0.61 \dagger \\
0.46 \dagger\end{array}$ & 4 \\
\hline Bautista et al. $(2005)^{(9)}$ & $\begin{array}{l}45 \mathrm{~W} \\
52 \mathrm{M}\end{array}$ & & & $20-40$ & Self-administered & 60 & 1 year & No & DR weighed (1/7) & $\begin{array}{l}\text { Vitamin A } \\
\text { Vitamin C }\end{array}$ & $\begin{array}{l}0.68 \neq \\
0.56 \neq\end{array}$ & 2.5 \\
\hline Blalock et al. $(2003)^{(10)}$ & $\begin{array}{l}27 \mathrm{~W} \\
30 \mathrm{M}\end{array}$ & - & & & Self-administered & 109 & 1 year & No & DR weighed $(1 / 7)$ & Vitamin D & $0.47 \dagger$ & 0.5 \\
\hline Block et al. $(1990)^{(11)}$ & $102 \mathrm{~W}$ & & & $45-70$ & Self-administered & 94 & 6 months & Yes & DR estimated (3/4) & $\begin{array}{l}\text { Vitamin A } \\
\text { Vitamin C }\end{array}$ & $\begin{array}{l}0.55 \ddagger \\
0.71 \ddagger\end{array}$ & 3.5 \\
\hline Block et al. $(1992)^{(12)}$ & 85 & & & $25-50$ & $\begin{array}{l}\text { Self-administered/ } \\
\text { interviewer }\end{array}$ & 113 & 1 year & No & $\begin{array}{l}\text { DR estimated (4/3) } \\
\quad+\text { four 24-h R }\end{array}$ & Vitamin C & $0.48 \ddagger$ & 2.5 \\
\hline Block et al. $(1992)^{(12)}$ & 85 & & & $25-50$ & Self-administered & 98 & 1 year & No & $\begin{array}{l}\text { DR estimated (4/3) } \\
\quad+\text { four 24-h R }\end{array}$ & Vitamin C & $0.54 \ddagger$ & 2.5 \\
\hline Bonifacj et al. $(1997)^{(13)}$ & $\begin{array}{l}68 \mathrm{~W} \\
30 \mathrm{M}\end{array}$ & $\begin{array}{l}42.4 \\
40.8\end{array}$ & $\begin{array}{l}12.3 \\
10.6\end{array}$ & & Interviewer & 134 & 1 year & No & DR weighed (4/7) & $\begin{array}{l}\text { Vitamin C } \\
\text { Vitamin E }\end{array}$ & $\begin{array}{l}0.35 \S \\
0.65 \S\end{array}$ & 3 \\
\hline Brunner et al. (2001) ${ }^{(14)}$ & $\begin{array}{l}403 \mathrm{~W} \\
457 \mathrm{M}\end{array}$ & & & $39-61$ & Self-administered & 127 & 1 year & No & DR estimated (1/7) & $\begin{array}{l}\text { Vitamin C } \\
\text { Vitamin E }\end{array}$ & $\begin{array}{l}0.45 \mathrm{~W}\|/ / 0.46 \mathrm{M}\| \\
0.33 \mathrm{~W}\|/\| 0.41 \mathrm{M} \|\end{array}$ & 3.5 \\
\hline Cardoso et al. $(2001)^{(15)}$ & $52 \mathrm{~W}$ & & & $21-62$ & Self-administered & 120 & 1 year & No & DR weighed (4/3) & $\begin{array}{l}\text { Vitamin A } \\
\text { Vitamin C } \\
\text { Vitamin E }\end{array}$ & $\begin{array}{l}0.32 \S \\
0.55 \S \\
0.36 \S\end{array}$ & 3.5 \\
\hline Chen et al. (2004) ${ }^{(16)}$ & $\begin{array}{l}104 \mathrm{~W} \\
85 \mathrm{M}\end{array}$ & & & $16-75$ & Interviewer & 39 & 1 year & No & DR estimated (2/7) & $\begin{array}{l}\text { Vitamin } \mathrm{C} \\
\text { Vitamin } \mathrm{E}\end{array}$ & $\begin{array}{l}0.308 \\
0.128 \\
0.168\end{array}$ & 5.5 \\
\hline Date et al. $(2005)^{(17)}$ & $\begin{array}{l}85 \mathrm{M} \\
85\end{array}$ & & & $30-69$ & Self-administered & 40 & 1 year & No & DR weighed (4/3) & $\begin{array}{l}\text { Vitamin A } \\
\text { Vitamin C }\end{array}$ & $\begin{array}{l}0.35 \| \\
0.27 \|\end{array}$ & 2.5 \\
\hline Decarli et al. $(1996)^{(18)}$ & $\begin{array}{r}265 \mathrm{~W} \\
130 \mathrm{M}\end{array}$ & & & $30-69$ & Interviewer & 77 & 1 year & No & DR weighed $(1 / 7)$ & $\begin{array}{l}\text { Vitamin C } \\
\text { Vitamin E }\end{array}$ & $\begin{array}{l}0.48 \S \\
0.34 \S\end{array}$ & 4 \\
\hline Egami et al. (1999)(19) & $\begin{array}{l}42 \mathrm{~W} \\
46 \mathrm{M}\end{array}$ & & & $41-88$ & $\begin{array}{l}\text { First FFQ } \\
\text { self-administered }\end{array}$ & 97 & 1 year & No & DR weighed (4/4) & $\begin{array}{l}\text { Vitamin A } \\
\text { Vitamin C } \\
\text { Vitamin E }\end{array}$ & $\begin{array}{l}0.56 \S \\
0.47 \S \\
0.52 \S\end{array}$ & 2.5 \\
\hline Egami et al. $(1999)^{(19)}$ & $\begin{array}{l}42 \mathrm{~W} \\
46 \mathrm{M}\end{array}$ & & & $41-88$ & $\begin{array}{l}\text { Second FFQ } \\
\text { self-administered }\end{array}$ & 97 & 1 year & No & DR weighed (4/4) & $\begin{array}{l}\text { Vitamin A } \\
\text { Vitamin C } \\
\text { Vitamin E }\end{array}$ & $\begin{array}{l}0.54 \S \\
0.61 \S \\
0.61 \S\end{array}$ & 2.5 \\
\hline Engle et al. $(1990)^{(20)}$ & $\begin{array}{l}34 \mathrm{~W} \\
16 \mathrm{M}\end{array}$ & $49 \cdot 3$ & 9.6 & & Computerised & 85 & 3 months & Yes & DR estimated (1/7) & Vitamin A & $0.40 \|$ & 3.5 \\
\hline Friis et al. $(1997)^{(21)}$ & $122 \mathrm{~W}$ & & & $20-29$ & $\begin{array}{l}\text { First FFQ } \\
\text { self-administered }\end{array}$ & 92 & 1 year & No & DR estimated (3/4) & $\begin{array}{l}\text { Vitamin A } \\
\text { Vitamin C } \\
\text { Vitamin D } \\
\text { Vitamin E }\end{array}$ & $\begin{array}{l}0.61 \S \\
0.72 \S \\
0.76 \S \\
0.37 \S\end{array}$ & 2.5 \\
\hline Friis et al. (1997) & $122 \mathrm{~W}$ & & & $20-29$ & $\begin{array}{l}\text { Second FFQ } \\
\text { self-administered }\end{array}$ & 92 & 1 year & No & DR estimated (3/4) & $\begin{array}{l}\text { Vitamin A } \\
\text { Vitamin C } \\
\text { Vitamin D }\end{array}$ & $\begin{array}{l}0.72 \S \\
0.68 \S \\
0.54 \S\end{array}$ & 2.5 \\
\hline Hodge et al. (2000) & $63 \mathrm{~W}$ & & & $16-48$ & Self-administered & 74 & 1 year & No & DR weighed $(1 / 7)$ & $\begin{array}{l}\text { Vitamin E } \\
\text { Retinol } \\
\text { Vitamin A }\end{array}$ & $\begin{array}{l}0.62 \S \\
0.45 \S \\
0.28 \S\end{array}$ & 3.5 \\
\hline Ishihara et al. (2003) & $\begin{array}{r}176 \mathrm{~W} \\
174 \mathrm{M}\end{array}$ & $\begin{array}{c}58 \\
55\end{array}$ & & & Self-administered & 180 & Unknown & No & DR weighed $(4 / 7)$ & $\begin{array}{l}\text { Vitamin C } \\
\text { Vitamin A } \\
\text { Vitamin C }\end{array}$ & $\begin{array}{l}0.60 \S \\
0.47 \mathrm{~W}\|/ / 0.35 \mathrm{M}\| \\
0.44 \mathrm{~W}\|/ / 0.46 \mathrm{M}\|\end{array}$ & 3 \\
\hline Jain et al. (1996)(24) & $\begin{array}{c}108 \mathrm{~W} \\
95 \mathrm{M}\end{array}$ & & & $35-79$ & Self-administered & 132 & 1 year & Yes & DR estimated $(1 / 7)$ & $\begin{array}{l}\text { Vitamin A } \\
\text { Retinol } \\
\text { Vitamin C } \\
\text { Vitamin E }\end{array}$ & $\begin{array}{l}0.33 \mathrm{~W} / / 0.19 \mathrm{Mq} \\
0.23 \mathrm{~W} / / 0.44 \mathrm{M} / \\
0.39 \mathrm{~W} / / 0.38 \mathrm{Mq} \\
0.39 \mathrm{~W} / 0.40 \mathrm{Mq}\end{array}$ & 4.5 \\
\hline Jain \& McLaughlin $(2000)^{(25)}$ & $\begin{array}{c}108 \mathrm{~W} \\
95 \mathrm{M}\end{array}$ & & & $35-79$ & Self-administered & 132 & 1 year & Yes & DR estimated (1/7) & $\begin{array}{l}\text { Vitamin A } \\
\text { Retinol } \\
\text { Vitamin C } \\
\text { Vitamin E }\end{array}$ & $\begin{array}{l}0.54 \mathrm{~W}^{* *} / 0.27 \mathrm{M}^{* *} \\
0.53 \mathrm{~W}^{* *} / 0.37 \mathrm{M}^{* *} \\
0.56 \mathrm{~W}^{* *} / 0.47 \mathrm{M}^{* *} \\
0.48 \mathrm{~W}^{* *} / 0.36 \mathrm{M}^{* *}\end{array}$ & 5 \\
\hline
\end{tabular}


NS British Journal of Nutrition

\begin{tabular}{|c|c|c|c|c|c|c|c|c|c|c|c|c|}
\hline \multirow[b]{2}{*}{ Author and year of publication } & \multirow[b]{2}{*}{ No. } & \multicolumn{3}{|c|}{ Age (years) } & \multirow[b]{2}{*}{$\begin{array}{l}\mathrm{FFQ} \\
\text { administration } \\
\text { method }\end{array}$} & \multirow[b]{2}{*}{$\begin{array}{l}\text { No. of } \\
\text { foods }\end{array}$} & \multirow[b]{2}{*}{$\begin{array}{l}\mathrm{FFQ} \\
\text { reference } \\
\text { period }\end{array}$} & \multirow[b]{2}{*}{ Suppl. } & \multirow{2}{*}{$\begin{array}{l}\text { Reference method } \\
\text { (no. of records/ } \\
\text { no. of days per } \\
\text { record) }\end{array}$} & \multirow[b]{2}{*}{ Nutrient } & \multirow[b]{2}{*}{ Coefficient } & \multirow[b]{2}{*}{$\begin{array}{l}\text { Quality } \\
\text { index }\end{array}$} \\
\hline & & Mean & SD & Range & & & & & & & & \\
\hline Kelemen et al. (2003) ${ }^{(26)}$ & $\begin{array}{l}58 \text { South Asians, A } \\
64 \text { Chinese, C } \\
85 \text { European, E }\end{array}$ & & & $35-75$ & Self-administered & $\begin{array}{l}163 \\
169 \\
157\end{array}$ & Unknown & Yes & DR estimated $(2 / 7)$ & $\begin{array}{l}\text { Vitamin C } \\
\text { Vitamin E }\end{array}$ & $\begin{array}{l}0.69 \mathrm{~A} \S / 0.75 \mathrm{C} S / 0.83 \mathrm{E} \S \\
0.73 \mathrm{~A} / / 0.84 \mathrm{C} \S / 0.77 \mathrm{E} \S\end{array}$ & 3.5 \\
\hline Kim et al. $(2002)^{(27)}$ & $\begin{array}{l}46 \mathrm{~W} \\
23 \mathrm{M}\end{array}$ & 38.16 & 11.7 & & Self-administered & 118 & Unknown & No & DR weighed (1/7) & $\begin{array}{l}\text { Vitamin A } \\
\text { Vitamin C } \\
\text { Vitamin E }\end{array}$ & $\begin{array}{l}0.28 \S \\
0.71 \S \\
0.58 \S\end{array}$ & 3 \\
\hline Kobayashi et al. (2003) & $\begin{array}{c}113 \mathrm{~W} \\
102 \mathrm{M}\end{array}$ & $\begin{array}{c}53.5 \\
55.6\end{array}$ & $\begin{array}{c}5 \cdot 3 \\
5 \cdot 2\end{array}$ & & Self-administered & 138 & 1 year & Yes & $\begin{array}{l}\text { DR estimated (4/7 } \\
\text { or } 2 / 7)\end{array}$ & Vitamin C & $0.22 \mathrm{~W}\|/ 0.42 \mathrm{M}\|$ & 4.5 \\
\hline Lee et al. $(2006)^{(29)}$ & $\begin{array}{l}25 \mathrm{~W} \\
58 \mathrm{M}\end{array}$ & - & & & First FFQ interviewer & 64 & 6 months & Yes & DR estimated (3/5) & $\begin{array}{l}\text { Vitamin A } \\
\text { Vitamin C } \\
\text { Vitamin E }\end{array}$ & $\begin{array}{l}0.33 \S \\
0.20 \S \\
0.35 \S\end{array}$ & 5 \\
\hline Lee et al. $(2006)^{(29)}$ & $\begin{array}{r}25 \mathrm{~W} \\
58 \mathrm{M}\end{array}$ & - & & & $\begin{array}{l}\text { Second FFQ inter- } \\
\text { viewer }\end{array}$ & 64 & 6 months & Yes & DR estimated (3/5) & $\begin{array}{l}\text { Vitamin A } \\
\text { Vitamin C } \\
\text { Vitamin E }\end{array}$ & $\begin{array}{l}0.15 \S \\
0.30 \S \\
0.53 \S\end{array}$ & 5 \\
\hline Macintyre et al. $(2001)^{(30)}$ & $\begin{array}{l}59 \mathrm{~W} \\
15 \mathrm{M}\end{array}$ & & & $15-65$ & Self-administered & 145 & Unknown & No & DR weighed $(1 / 7)$ & $\begin{array}{l}\text { Vitamin A } \\
\text { Vitamin C }\end{array}$ & $\begin{array}{l}0.35 \dagger \\
0.55 \dagger\end{array}$ & 1 \\
\hline Männistö et al. (1996) & $152 \mathrm{~W}$ & 51 & 9 & & Self-administered & 110 & 1 year & Yes & DR estimated (2/7) & $\begin{array}{l}\text { Vitamin C } \\
\text { Vitamin D } \\
\text { Vitamin E }\end{array}$ & $\begin{array}{l}0.69 \S \\
0.44 \S \\
0.64 \S\end{array}$ & 4 \\
\hline Marks et al. $(2006)^{(32)}$ & $\begin{array}{l}59 \mathrm{~W} \\
37 \mathrm{M}\end{array}$ & & & $25-75$ & Self-administered & 129 & 6 months & Yes & DR weighed (6/2) & $\begin{array}{l}\text { Retinol } \\
\text { Vitamin C }\end{array}$ & $\begin{array}{l}0.19 \mathrm{~W}\|/ 0.27 \mathrm{M}\| \\
0.20 \mathrm{~W} / / 0.63 \mathrm{M} \|\end{array}$ & 5 \\
\hline $\begin{array}{l}\text { Martín-Moreno et al. } \\
(1993)^{(33)}\end{array}$ & 147 & & & $18-74$ & $\begin{array}{l}\text { First FFQ self- } \\
\text { administered }\end{array}$ & 118 & 1 year & No & DR weighed $(4 / 4)$ & $\begin{array}{l}\text { Vitamin A } \\
\text { Vitamin C }\end{array}$ & $\begin{array}{l}0.48 \S \\
0.52 \S\end{array}$ & 3.5 \\
\hline $\begin{array}{l}\text { Martín-Moreno et al. } \\
(1993)^{(33)}\end{array}$ & 147 & & & $18-74$ & $\begin{array}{l}\text { Second FFQ self- } \\
\text { administered }\end{array}$ & 118 & 1 year & No & DR weighed (4/4) & $\begin{array}{l}\text { Vitamin A } \\
\text { Vitamin C }\end{array}$ & $\begin{array}{l}0.45 \S \\
0.71 \S\end{array}$ & 3.5 \\
\hline McKeown et al. (2001) & 118 & & & $45-74$ & Self-administered & 130 & 1 year & Yes & DR estimated (2/7) & $\begin{array}{l}\text { Vitamin C } \\
\text { Vitamin E }\end{array}$ & $\begin{array}{l}0.59 \mathrm{~W} / / 0.70 \mathrm{M} \S \\
0.60 \mathrm{~W} / 0.40 \mathrm{M} \S\end{array}$ & 5 \\
\hline McNaughton et al. $(2005)^{(35)}$ & $\begin{array}{r}17 \mathrm{~W} \\
11 \mathrm{M}\end{array}$ & 48 & 10.5 & & Self-administered & 129 & 6 months & Yes & DR weighed (6/2) & Vitamin E & $0.34 \pi$ & 2 \\
\hline Nagata et al. (1998) & 37 & & & $35-66$ & Self-administered & 169 & 1 year & No & DR estimated (12/1) & $\begin{array}{l}\text { Vitamin A } \\
\text { Retinol } \\
\text { Vitamin C } \\
\text { Vitamin E }\end{array}$ & $\begin{array}{l}0.40++\S / 0.62 \neq \neq \S \\
0.18++\S / 0.15 \neq \neq \S \\
0.17++\S / 0.69 \neq \neq \S \\
0.24++\S / 0.79 \neq \neq \S\end{array}$ & 2 \\
\hline Ogawa et al. $(2003)^{(37)}$ & $\begin{array}{l}58 \mathrm{~W} \\
55 \mathrm{M}\end{array}$ & & & $45-77$ & Self-administered & 40 & 1 year & Yes & DR estimated (4/3) & $\begin{array}{l}\text { Retinol } \\
\text { Vitamin C }\end{array}$ & $\begin{array}{l}0.30 \mathrm{~W} / / 0.38 \mathrm{MS} \\
0.43 \mathrm{~W} / 0.58 \mathrm{M} \S\end{array}$ & 4.5 \\
\hline Patterson et al. (1999) & $113 \mathrm{~W}$ & & & $50-79$ & Self-administered & 122 & 3 months & Yes & $\begin{array}{l}\text { DR estimated } \\
\text { (1/4) + four 24-h } \\
\text { (phone) R }\end{array}$ & $\begin{array}{l}\text { Vitamin A } \\
\text { Vitamin C } \\
\text { Vitamin D } \\
\text { Vitamin E }\end{array}$ & $\begin{array}{l}0.56 \S \\
0.74 \S \\
0.73 \S \\
0.83 \S\end{array}$ & 4 \\
\hline Pietinen et al. $(1988 \mathrm{a})^{(39)}$ & 190 & 59.9 & 4.0 & & $\begin{array}{l}\text { First FFQ self- } \\
\text { administered }\end{array}$ & 276 & 1 year & No & DR estimated (12/2) & $\begin{array}{l}\text { Vitamin A } \\
\text { Vitamin C } \\
\text { Vitamin D } \\
\text { Vitamin E }\end{array}$ & $\begin{array}{l}0.55 \S \\
0.70 \S \\
0.58 \S \\
0.76 \S\end{array}$ & 3 \\
\hline Pietinen et al. $(1988 \mathrm{a})^{(39)}$ & 190 & 59.9 & 4.0 & & $\begin{array}{l}\text { Second FFQ self- } \\
\text { administered }\end{array}$ & 276 & 1 year & No & DR estimated (12/2) & $\begin{array}{l}\text { Vitami A } \\
\text { Vitamin C } \\
\text { Vitamin D } \\
\text { Vitamin E }\end{array}$ & $\begin{array}{l}0.68 \S \\
0.71 \S \\
0.64 \S \\
0.82 \S\end{array}$ & 3 \\
\hline Pietinen et al. $(1988 b)^{(40)}$ & 190 & 59.9 & 4.0 & & $\begin{array}{l}\text { First FFQ self- } \\
\text { administered }\end{array}$ & 44 & 1 year & No & DR estimated (12/2) & $\begin{array}{l}\text { Vitamin E } \\
\text { Vitamin A } \\
\text { Vitamin C } \\
\text { Vitamin E }\end{array}$ & $\begin{array}{l}0.82 \S \\
0.55 \S \\
0.51 \S \\
0.59 \S\end{array}$ & 3 \\
\hline Pietinen et al. $(1988 \mathrm{~b})^{(40)}$ & 190 & 59.9 & 4.0 & & $\begin{array}{l}\text { Second FFQ self- } \\
\text { administered }\end{array}$ & 44 & 1 year & No & DR estimated (12/2) & $\begin{array}{l}\text { Vitamin A } \\
\text { Vitamin C } \\
\text { Vitamin E }\end{array}$ & $\begin{array}{l}0.53 \S \\
0.47 \S \\
0.66 \$\end{array}$ & 3 \\
\hline Potischman et al. (1999) ${ }^{(41)}$ & $219 \mathrm{~W}$ & & & $20-54$ & Self-administered & $\begin{array}{l}60 \\
100\end{array}$ & 1 year & No & $\begin{array}{l}\text { DR estimated } \\
\text { (2/3) + six 24-h } \\
\text { (phone) R }\end{array}$ & Vitamin C & $\begin{array}{l}0.39(60 \text { items }) \S \\
0.41 \text { (100 items)§ }\end{array}$ & 3 \\
\hline Potosky et al. $(1990)^{(42)}$ & $97 \mathrm{~W}$ & & & $45-70$ & Self-administered & 94 & 6 months & No & DR estimated (3/4) & $\begin{array}{l}\text { Vitamin A } \\
\text { Vitamin C }\end{array}$ & $\begin{array}{l}0.46 \ddagger \\
0.60 \ddagger\end{array}$ & 1.5 \\
\hline Riboli et al. $(1997)^{(43)}$ & $\begin{array}{r}105 \mathrm{~W} \\
101 \mathrm{M}\end{array}$ & & & $50-69$ & Self-administered & 350 & 1 year & No & DR weighed $(6 / 3)$ & $\begin{array}{l}\text { Retinol } \\
\text { Vitamin C } \\
\text { Vitamin E }\end{array}$ & $\begin{array}{l}0.44 \mathrm{~W}^{* *} / 0.58 \mathrm{M}^{* *} \\
0.85 \mathrm{~W}^{* *} / 0.62 \mathrm{M}^{* *} \\
0.69 \mathrm{~W}^{* *} / 0.70 \mathrm{M}^{* *}\end{array}$ & 2.5 \\
\hline
\end{tabular}


NS British Journal of Nutrition

Table 4. Continued

Age (years)

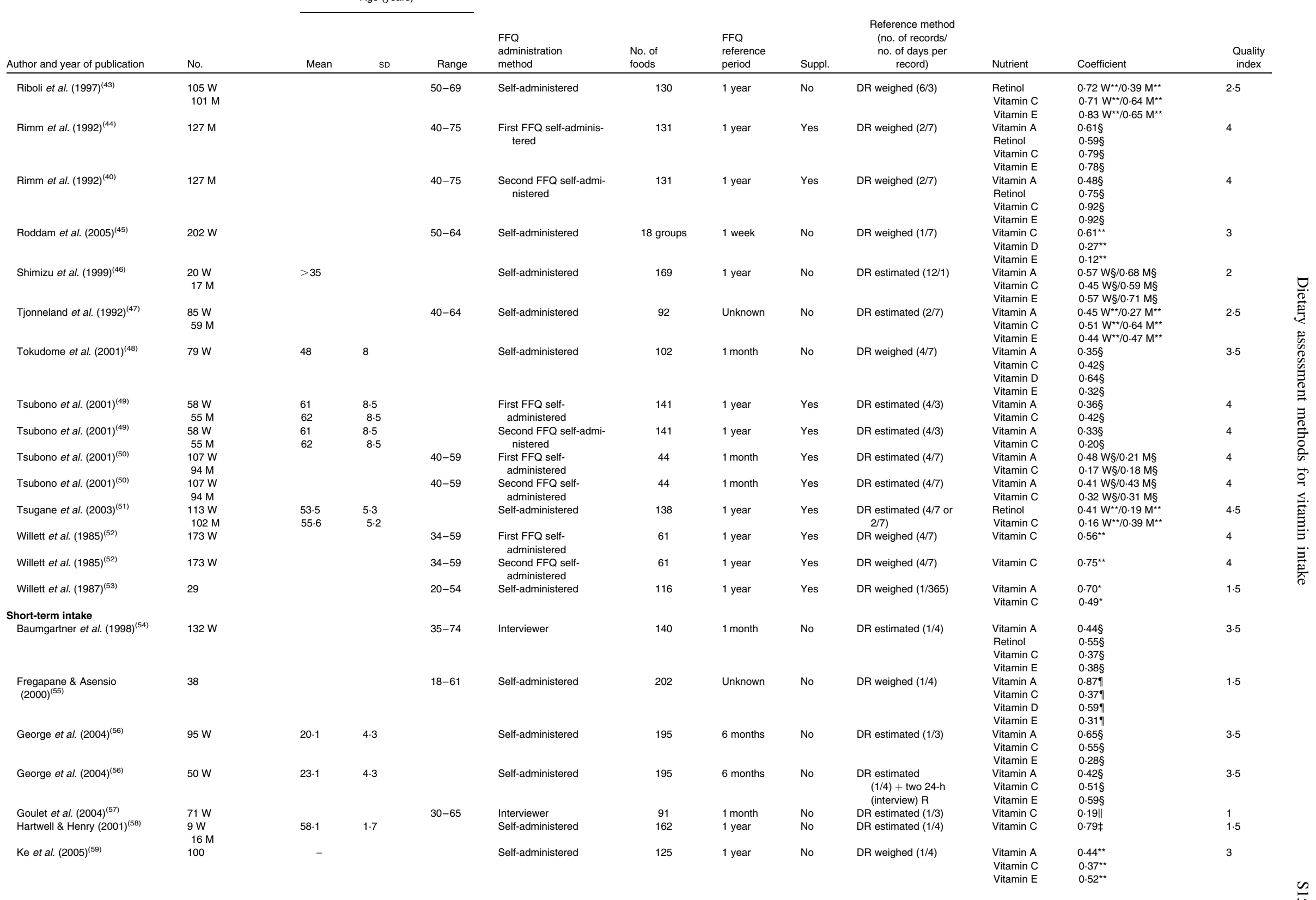


NS British Journal of Nutrition

\begin{tabular}{|c|c|c|c|c|c|c|c|c|c|c|c|c|}
\hline \multirow[b]{2}{*}{ Author and year of publication } & \multirow[b]{2}{*}{ No. } & \multicolumn{3}{|c|}{ Age (years) } & \multirow[b]{2}{*}{$\begin{array}{l}\mathrm{FFQ} \\
\text { administration } \\
\text { method }\end{array}$} & \multirow[b]{2}{*}{$\begin{array}{l}\text { No. of } \\
\text { foods }\end{array}$} & \multirow[b]{2}{*}{$\begin{array}{l}\text { FFQ } \\
\text { reference } \\
\text { period }\end{array}$} & \multirow[b]{2}{*}{ Suppl. } & \multirow{2}{*}{$\begin{array}{l}\text { Reference method } \\
\text { (no. of records/ } \\
\text { no. of days per } \\
\text { record) }\end{array}$} & \multirow[b]{2}{*}{ Nutrient } & \multirow[b]{2}{*}{ Coefficient } & \multirow[b]{2}{*}{$\begin{array}{l}\text { Quality } \\
\text { index }\end{array}$} \\
\hline & & Mean & SD & Range & & & & & & & & \\
\hline Kristal et al. (1997) $)^{(60)}$ & $829 \mathrm{~W}$ & & & $50-79$ & Self-administered & 100 & 3 months & Yes & DR estimated (1/4) & $\begin{array}{l}\text { Vitamin C } \\
\text { Vitamin E }\end{array}$ & $\begin{array}{l}0.47^{* *} \\
0.21^{* *}\end{array}$ & 2 \\
\hline Kumanyika et al. (2003) & $408 \mathrm{~W}$ & & & $21-69$ & Self-administered & 68 & 1 year & No & $\begin{array}{l}\text { DR estimated } \\
\text { (1/3) + three 24-h } \\
\text { (phone) R }\end{array}$ & $\begin{array}{l}\text { Vitamin C } \\
\text { Vitamin E }\end{array}$ & $\begin{array}{l}0.60 \S \\
0.26 \S\end{array}$ & 2.5 \\
\hline Longnecker et al. $(1993)^{(62)}$ & $\begin{array}{c}74 \mathrm{~W} \\
64 \mathrm{M}\end{array}$ & 49 & 14 & & $\begin{array}{l}\text { First FFQ self- } \\
\text { administered }\end{array}$ & 116 & 1 year & No & DR estimated (3/2) & $\begin{array}{l}\text { Vitamin A } \\
\text { Vitamin C } \\
\text { Vitamin D }\end{array}$ & $\begin{array}{l}0.60 \| \\
0.51 \| \\
0.31 \|\end{array}$ & 2.5 \\
\hline Longnecker et al. $(1993)^{(62)}$ & $\begin{array}{c}74 \mathrm{~W} \\
64 \mathrm{M}\end{array}$ & 49 & 14 & & $\begin{array}{l}\text { Second FFQ self- } \\
\text { administered }\end{array}$ & 116 & 1 year & No & DR estimated (3/2) & $\begin{array}{l}\text { Vitamin A } \\
\text { Vitamin C } \\
\text { Vitamin D }\end{array}$ & $\begin{array}{l}0.69 \S \\
0.46 \S \\
0.44 \S\end{array}$ & 2.5 \\
\hline Martínez et al. $(1999)^{(63)}$ & $\begin{array}{l}42 \mathrm{~W} \\
97 \mathrm{M}\end{array}$ & 66 & 4 & & Self-administered & 132 & 1 year & Yes & DR weighed $(1 / 4)$ & $\begin{array}{l}\text { Vitamin A } \\
\text { Vitamin C } \\
\text { Vitamin E }\end{array}$ & $\begin{array}{l}0.40 \S \\
0.63 \S \\
0.35 \S\end{array}$ & 4 \\
\hline Masson et al. (2003) & $\begin{array}{r}40 \mathrm{~W} \\
41 \mathrm{M}\end{array}$ & & & $19-58$ & Self-administered & 150 & $\begin{array}{l}2-3 \\
\text { months }\end{array}$ & No & DR weighed $(1 / 4)$ & $\begin{array}{l}\text { Vitamin A } \\
\text { Vitamin C } \\
\text { Vitamin D } \\
\text { Vitamin E }\end{array}$ & $\begin{array}{l}0.37 \mathrm{~W}^{* *} /-0.49 \mathrm{M}^{* *} \\
0.68 \mathrm{~W}^{* /} / 0.64 \mathrm{M}^{* *} \\
0.39 \mathrm{~W}^{* /} / 0.51 \mathrm{M}^{* *} \\
0.52 \mathrm{~W}^{* /} / 0.21 \mathrm{M}^{* *}\end{array}$ & 2.5 \\
\hline Moreira et al. $(2003)^{(65)}$ & $\begin{array}{l}159 \mathrm{~W} \\
87 \mathrm{M}\end{array}$ & & & $18-29$ & Interviewer & 82 & Unknown & No & DR estimated (1/4) & $\begin{array}{l}\text { Vitamin A } \\
\text { Retinol } \\
\text { Vitamin C } \\
\text { Vitamin D } \\
\text { Vitamin E }\end{array}$ & $\begin{array}{l}0.41 \mathrm{~W}^{\star \star} / 0.55 \mathrm{M}^{\star \star} \\
0.48 \mathrm{~W}^{\star \star} / 0.39 \mathrm{M}^{\star \star} \\
0.51 \mathrm{~W}^{\star /} / 0.36 \mathrm{M}^{\star \star} \\
0.21 \mathrm{~W}^{\star /} / 0.23 \mathrm{M}^{\star \star} \\
0.31 \mathrm{~W}^{\star \star} / 0.43 \mathrm{M}^{\star \star}\end{array}$ & 3 \\
\hline Paalanen et al. $(2006)^{(66)}$ & $\begin{array}{l}157 \mathrm{~W} \\
137 \mathrm{M}\end{array}$ & & & $30-79$ & Self-administered & 128 & 1 year & No & DR estimated (1/3) & $\begin{array}{l}\text { Vitamin A } \\
\text { Vitamin C } \\
\text { Vitamin D } \\
\text { Vitamin E }\end{array}$ & $\begin{array}{l}0.26 \mathrm{~W}^{\star \star} / 0.14 \mathrm{M}^{\star \star} \\
0.51 \mathrm{~W}^{\star \star} / 0.36 \mathrm{M}^{\star \star} \\
0.26 \mathrm{~W}^{\star \star} / 0.36 \mathrm{M}^{\star \star} \\
0.43 \mathrm{~W}^{\star \star} / 0.22 \mathrm{M}^{\star \star}\end{array}$ & 3.5 \\
\hline Parr et al. $(2002)^{(67)}$ & $\begin{array}{l}34 \mathrm{~W} \\
36 \mathrm{M}\end{array}$ & & & $15-45$ & Interviewer & 164 & 1 week & No & DR weighed (1/2) & $\begin{array}{l}\text { Vitamin A } \\
\text { Vitamin C }\end{array}$ & $\begin{array}{l}0.62 \dagger \\
0.49 \dagger\end{array}$ & 4 \\
\hline Sasaki et al. $(1998)^{(68)}$ & $47 \mathrm{~W}$ & & & $38-69$ & Self-administered & 110 & 1 month & No & DR estimated (1/3) & $\begin{array}{l}\text { Vitamin A } \\
\text { Vitamin C }\end{array}$ & $\begin{array}{l}0.38 \S \\
0.45 \S\end{array}$ & 3 \\
\hline Sauvaget et al. (2002) & $\begin{array}{l}1872 \mathrm{~W} \\
1133 \mathrm{M}\end{array}$ & $\begin{array}{l}57 \\
60\end{array}$ & $\begin{array}{l}7 \\
11\end{array}$ & & Self-administered & 22 & 1 year & No & DR weighed (1/1) & Vitamin C & $0.17 \dagger$ & 1.5 \\
\hline Schröder et al. $(2001)^{(70)}$ & 44 & 30.7 & $10 \cdot 4$ & & Self-administered & 157 & Unknown & No & DR weighed $(1 / 3)$ & $\begin{array}{l}\text { Vitamin C } \\
\text { Vitamin E }\end{array}$ & $\begin{array}{l}0.40 \uparrow \\
0.20 \pi\end{array}$ & 3 \\
\hline Shimizu et al. $(1999)^{(46)}$ & $\begin{array}{l}59 \mathrm{~W} \\
58 \mathrm{M}\end{array}$ & $\begin{array}{c}53 \cdot 8 \\
57.9\end{array}$ & $\begin{array}{c}11.2 \\
10 \cdot 9\end{array}$ & & Self-administered & 169 & 1 year & No & DR estimated (1/3) & $\begin{array}{l}\text { Vitamin A } \\
\text { Vitamin C } \\
\text { Vitamin E }\end{array}$ & $\begin{array}{l}0.27 \mathrm{~W}^{\star \star} / 0.42 \mathrm{M}^{\star \star} \\
0.21 \mathrm{~W}^{\star \star} / 0.21 \mathrm{M}^{\star \star} \\
0.39 \mathrm{~W}^{\star \star} / 0.29 \mathrm{M}^{\star \star}\end{array}$ & 2 \\
\hline Tokudome et al. (2005) $)^{(71)}$ & $\begin{array}{c}129 \mathrm{~W} \\
73 \mathrm{M}\end{array}$ & & & $30-70$ & Self-administered & 47 & 1 year & No & DR estimated (1/3) & $\begin{array}{l}\text { Vitamin A } \\
\text { Vitamin C } \\
\text { Vitamin E }\end{array}$ & $\begin{array}{l}0.22 \mathrm{~W} / / 0.27 \mathrm{M} \S \\
0.52 \mathrm{~W} / 0.45 \mathrm{M} \S \\
0.17 \mathrm{~W} / / 0.31 \mathrm{M} \S\end{array}$ & 3.5 \\
\hline Torheim et al. $(2001)^{(72)}$ & $\begin{array}{l}48 \mathrm{~W} \\
27 \mathrm{M}\end{array}$ & & & $15-59$ & Self-administered & 69 & 1 week & No & $\begin{array}{l}\text { DR weighed/ } \\
\text { estimated (1/2) }\end{array}$ & $\begin{array}{l}\text { Vitamin A } \\
\text { Vitamin C }\end{array}$ & $\begin{array}{l}0.46 \dagger \\
0.56 \dagger\end{array}$ & 2 \\
\hline
\end{tabular}

No., number; Suppl., supplements; W, women; M, men; DR, dietary record; 24-h R, 24-h recall.

${ }^{*}$ Age, sex and energy-adjusted, Pearson correlation coefficient.

$\dagger$ Crude, Spearman correlation coefficient.

§ Energ, Pearson correlation coefficient.
Energusted, deattenuated correlation coefficient.

|| Energy-adjusted, Spearman correlation coefficient.

ๆ Intra-class correlation coefficient.

${ }^{\star *}$ Energy-adjusted, Pearson correlation coefficient.

t† Low-food diversity.

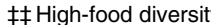


Table 5. Description of validation studies regarding vitamins A, C, D and E intake (FFQ vs. 24-h recalls)

\begin{tabular}{|c|c|c|c|c|c|c|c|c|c|c|c|c|c|c|}
\hline \multirow[b]{2}{*}{$\begin{array}{l}\text { Author and year of pub- } \\
\text { lication }\end{array}$} & \multirow[b]{2}{*}{ No. } & \multicolumn{3}{|c|}{ Age (years) } & \multirow[b]{2}{*}{$\begin{array}{l}\text { FFQ administration } \\
\text { method }\end{array}$} & \multirow[b]{2}{*}{$\begin{array}{l}\text { No. of } \\
\text { foods }\end{array}$} & \multirow{2}{*}{$\begin{array}{c}\mathrm{FFQ} \\
\text { reference } \\
\text { period }\end{array}$} & \multirow[b]{2}{*}{ Suppl. } & \multirow[b]{2}{*}{$\begin{array}{l}\text { No. of } \\
\text { recalls }\end{array}$} & \multirow{2}{*}{$\begin{array}{l}\text { Recall } \\
\text { administration } \\
\text { method }\end{array}$} & \multirow[b]{2}{*}{$\begin{array}{l}\text { Weekend } \\
\text { included }\end{array}$} & \multirow[b]{2}{*}{ Nutrient } & \multirow[b]{2}{*}{ Coefficient } & \multirow[b]{2}{*}{$\begin{array}{l}\text { Quality } \\
\text { index }\end{array}$} \\
\hline & & Mean & SD & Range & & & & & & & & & & \\
\hline \multicolumn{15}{|l|}{ Long-term intake } \\
\hline $\begin{array}{l}\text { Boeing et al. } \\
(1997)^{(72)}\end{array}$ & $\begin{array}{l}49 \mathrm{~W} \\
43 \mathrm{M}\end{array}$ & & & 35-64 & Self-administered & 158 & - & No & $\begin{array}{l}\text { Twelve, within } \\
1 \text { year }\end{array}$ & Personal interview & Yes & $\begin{array}{l}\text { Vitamin A } \\
\text { Vitamin C } \\
\text { Vitamin E }\end{array}$ & $\begin{array}{l}0.29^{\star} \\
0.69^{\star} \\
0.52^{\star}\end{array}$ & 2 \\
\hline $\begin{array}{l}\text { Fraser et al. } \\
\qquad(2005)^{(73)}\end{array}$ & 315 & - & & & Self-administered & 202 & - & No & $\begin{array}{l}\text { Eight, within } \\
6 \text { months }\end{array}$ & Phone interview & Yes & Vitamin E & $0.78^{\star}$ & 2.5 \\
\hline $\begin{array}{l}\text { Gnardellis et al. } \\
(1994)^{(74)}\end{array}$ & 80 & & & $25-67$ & $\begin{array}{l}\text { First FFQ self- } \\
\text { administered }\end{array}$ & 190 & 1 year & Yes & $\begin{array}{l}\text { Twelve, within } \\
1 \text { year }\end{array}$ & Personal interview & Yes & $\begin{array}{l}\text { Vitamin A } \\
\text { Vitamin C }\end{array}$ & $\begin{array}{l}0.17 \mathrm{~W}^{*} / 0.24 \mathrm{M}^{*} \\
0.33 \mathrm{~W}^{*} / 0.34 \mathrm{M}^{*}\end{array}$ & 4 \\
\hline $\begin{array}{l}\text { Gnardellis et al. } \\
(1994)^{(75)}\end{array}$ & 80 & & & $25-67$ & $\begin{array}{l}\text { Second FFQ self-admi- } \\
\text { nistered }\end{array}$ & 190 & 1 year & Yes & $\begin{array}{l}\text { Twelve, within } \\
1 \text { year }\end{array}$ & Personal interview & Yes & $\begin{array}{l}\text { Vitamin A } \\
\text { Vitamin C }\end{array}$ & $\begin{array}{l}0.78 \mathrm{~W}^{*} / 0.30 \mathrm{M}^{*} \\
0.17 \mathrm{~W}^{*} / 0.46 \mathrm{M}^{*}\end{array}$ & 4 \\
\hline $\begin{array}{l}\text { Hebert et al. } \\
(1998)^{(75)}\end{array}$ & $\begin{array}{l}30 \mathrm{~W} \\
30 \mathrm{M}\end{array}$ & $\begin{array}{l}43.2 \\
52.6\end{array}$ & $\begin{array}{l}13.6 \\
10.9\end{array}$ & & First FFQ interviewer & 81 & 1 year & No & $\begin{array}{l}\text { Eight, within } \\
1 \text { year }\end{array}$ & Personal interview & Yes & Vitamin C & $0.32^{\star}$ & 2.5 \\
\hline $\begin{array}{l}\text { Hebert et al. } \\
(1998)^{(75)}\end{array}$ & $\begin{array}{l}30 \mathrm{~W} \\
30 \mathrm{M}\end{array}$ & $\begin{array}{l}43.2 \\
52.6\end{array}$ & $\begin{array}{l}13 \cdot 6 \\
10 \cdot 9\end{array}$ & & $\begin{array}{l}\text { Second FFQ } \\
\text { interviewer }\end{array}$ & 81 & 1 year & No & $\begin{array}{l}\text { Eight, within } \\
1 \text { year }\end{array}$ & Personal interview & Yes & Vitamin C & $0.53^{*}$ & 2.5 \\
\hline $\begin{array}{l}\text { Hernández-Ávila } \\
\text { et al. }(1998)^{776)}\end{array}$ & $134 \mathrm{~W}$ & - & & & $\begin{array}{l}\text { First FRQ esle- } \\
\text { administered }\end{array}$ & 85 & - & No & $\begin{array}{l}\text { Sixteen, within } \\
1 \text { year }\end{array}$ & Personal interview & Yes & $\begin{array}{l}\text { Vitamin A } A \\
\text { Vitamin C } \\
\text { Vitamin D } \\
\text { Vitamin E }\end{array}$ & $\begin{array}{l}0.35^{\star} \\
0.48^{\star} \\
0.48^{*} \\
0.22^{\star}\end{array}$ & 3 \\
\hline $\begin{array}{l}\text { Hernández-Ávila } \\
\text { et al. }(1998)^{(76)}\end{array}$ & $134 \mathrm{~W}$ & - & & & $\begin{array}{l}\text { Second FFQ self-admi- } \\
\text { nistered }\end{array}$ & 85 & - & No & $\begin{array}{l}\text { Sixteen, within } \\
1 \text { year }\end{array}$ & Personal interview & Yes & $\begin{array}{l}\text { Vitamin A } \\
\text { Vitamin C } \\
\text { Vitamin D } \\
\text { Vitamin E }\end{array}$ & $\begin{array}{l}0.49^{\star} \\
0.49^{\star} \\
0.49^{\star} \\
0.12^{\star}\end{array}$ & 3 \\
\hline $\begin{array}{l}\text { Jackson et al. } \\
\qquad(2001)^{(77)}\end{array}$ & $\begin{array}{l}40 \mathrm{~W} \\
33 \mathrm{M}\end{array}$ & $\begin{array}{l}45 \cdot 4 \\
46\end{array}$ & $\begin{array}{l}13 \cdot 5 \\
15 \cdot 3\end{array}$ & & First FFQ interviewer & 70 & - & No & $\begin{array}{l}\text { Twelve, within } \\
1 \text { year }\end{array}$ & Personal interview & Yes & $\begin{array}{l}\text { Vitamin A } \\
\text { Vitamin C } \\
\text { Vitamin E }\end{array}$ & $\begin{array}{l}0.27 \dagger \\
0.43 \dagger \\
0.44 \dagger\end{array}$ & 3 \\
\hline $\begin{array}{l}\text { Jackson et al. } \\
\quad(2001)^{(77)}\end{array}$ & $\begin{array}{l}40 \mathrm{~W} \\
33 \mathrm{M}\end{array}$ & $\begin{array}{l}45 \cdot 4 \\
46\end{array}$ & $\begin{array}{l}13 \cdot 5 \\
15 \cdot 3\end{array}$ & & $\begin{array}{l}\text { Second FFQ } \\
\text { interviewer }\end{array}$ & 70 & - & No & $\begin{array}{l}\text { Twelve, within } \\
1 \text { year }\end{array}$ & Personal interview & Yes & $\begin{array}{l}\text { Vitamin A } \\
\text { Vitamin C } \\
\text { Vitamin E }\end{array}$ & $\begin{array}{l}0.19 \dagger \\
0.31 \dagger \\
0.43 t\end{array}$ & 3 \\
\hline $\begin{array}{l}\text { Johansson et al. } \\
(2001)^{(78)}\end{array}$ & $\begin{array}{l}99 \mathrm{~W} \\
99 \mathrm{M}\end{array}$ & & & $30-60$ & Self-administered & 84 & - & No & Ten, within 1 year & Phone interview & Yes & $\begin{array}{l}\text { Vitamin A } \\
\text { Vitamin C } \\
\text { Vitamin E E }\end{array}$ & $\begin{array}{l}0.3 \mathrm{~W}^{*} / 0.36 \mathrm{M}^{*} \\
0.62 \mathrm{~W}^{*} / 0.57 \mathrm{M}^{*} \\
0.42 \mathrm{~W}^{*} / 0.30 \mathrm{M}^{*}\end{array}$ & 2.5 \\
\hline $\begin{array}{l}\text { Kabagambe et al. } \\
(2001)^{(79)}\end{array}$ & $\begin{array}{l}42 \mathrm{~W} \\
78 \mathrm{M}\end{array}$ & 59 & 10 & & Interviewer & 135 & 1 year & No & $\begin{array}{l}\text { Seven, within } \\
7 \text { months }\end{array}$ & Personal interview & Yes & $\begin{array}{l}\text { Vitamin A } \\
\text { Vitamin C } \\
\text { Vitamin E E }\end{array}$ & $\begin{array}{l}0.86^{\star} \\
0.71^{\star} \\
0.48^{*}\end{array}$ & 4 \\
\hline $\begin{array}{l}\text { Katsouyanni et al. } \\
(1997)^{(80)}\end{array}$ & $\begin{array}{l}38 \mathrm{~W} \\
42 \mathrm{M}\end{array}$ & & & $25-67$ & $\begin{array}{l}\text { First FFQ self- } \\
\text { administered }\end{array}$ & 190 & 1 year & Yes & $\begin{array}{l}\text { Twelve, within } \\
1 \text { year }\end{array}$ & Personal interview & Yes & $\begin{array}{l}\text { Vitamin A } \\
\text { Vitamin C }\end{array}$ & $\begin{array}{l}0.17 \mathrm{~W}^{*} / 0.24 \mathrm{M}^{*} \\
0.33 \mathrm{~W}^{*} / 0.34 \mathrm{M}^{*}\end{array}$ & 3.5 \\
\hline $\begin{array}{c}\text { Katsouyanni et al. } \\
(1997)^{(80)}\end{array}$ & $\begin{array}{l}38 \mathrm{~W} \\
42 \mathrm{M}\end{array}$ & & & $25-67$ & $\begin{array}{l}\text { Second FFQ self-admi- } \\
\text { nistered }\end{array}$ & 190 & 1 year & Yes & $\begin{array}{l}\text { Twelve, within } \\
1 \text { year }\end{array}$ & Personal interview & Yes & $\begin{array}{l}\text { Vitamin A } \\
\text { Vitamin C }\end{array}$ & $\begin{array}{l}0.78 \mathrm{~W}^{*} / 0.30 \mathrm{M}^{*} \\
0.17 \mathrm{~W}^{*} / 0.46 \mathrm{M}^{*}\end{array}$ & 3.5 \\
\hline $\begin{array}{l}\text { Malekshah et al. } \\
(2006)^{(81)}\end{array}$ & $\begin{array}{l}82 \mathrm{~W} \\
49 \mathrm{M}\end{array}$ & $\begin{array}{l}49 \cdot 9 \\
51 \cdot 2\end{array}$ & $\begin{array}{l}9 \cdot 3 \\
13\end{array}$ & & Interviewer & 150 & 1 year & No & $\begin{array}{l}\text { Twelve, within } \\
1 \text { year }\end{array}$ & Personal interview & No & $\begin{array}{l}\text { Vitamin A } \\
\text { Vitamin C } \\
\text { Vitamin E }\end{array}$ & $\begin{array}{l}0.59 \ddagger \\
0.65 \ddagger \\
0.49 \ddagger\end{array}$ & 3 \\
\hline $\begin{array}{l}\text { Mayer-Davis et al. } \\
\quad(1999)^{(82)}\end{array}$ & $186 \mathrm{~W}$ & & & $40-69$ & Interviewer & 114 & 1 year & Yes & $\begin{array}{l}\text { Eight, within } \\
1 \text { year }\end{array}$ & Phone interview & Yes & $\begin{array}{l}\text { Vitamin A } \\
\text { Vitamin C } \\
\text { Vitamin E }\end{array}$ & $\begin{array}{l}0.40^{*} \\
0.75^{\star} \\
0.79^{*}\end{array}$ & 5 \\
\hline $\begin{array}{l}\text { Messerer et al. } \\
(2004)^{(83)}\end{array}$ & $248 \mathrm{M}$ & & & $40-74$ & Self-administered & 88 & 1 year & Yes & $\begin{array}{l}\text { Fourteen, within } \\
1 \text { year }\end{array}$ & Phone interview & Yes & $\begin{array}{l}\text { Vitamin A } \\
\text { Vitamin C } \\
\text { Vitamin D } \\
\text { Vitamin E }\end{array}$ & $\begin{array}{l}0.62^{\star} \\
0.81^{\star} \\
0.59^{\star} \\
0.57^{\star}\end{array}$ & 4.5 \\
\hline
\end{tabular}


Table 5. Continued

\begin{tabular}{|c|c|c|c|c|c|c|c|c|c|c|c|c|c|c|}
\hline \multirow[b]{2}{*}{$\begin{array}{l}\text { Author and year of pub- } \\
\text { lication }\end{array}$} & \multirow[b]{2}{*}{ No. } & \multicolumn{3}{|c|}{ Age (years) } & \multirow[b]{2}{*}{$\begin{array}{l}\text { FFQ administration } \\
\text { method }\end{array}$} & \multirow[b]{2}{*}{$\begin{array}{l}\text { No. of } \\
\text { foods }\end{array}$} & \multirow{2}{*}{$\begin{array}{c}\mathrm{FFQ} \\
\text { reference } \\
\text { period }\end{array}$} & \multirow[b]{2}{*}{ Suppl. } & \multirow[b]{2}{*}{$\begin{array}{l}\text { No. of } \\
\text { recalls }\end{array}$} & \multirow{2}{*}{$\begin{array}{l}\text { Recall } \\
\text { administration } \\
\text { method }\end{array}$} & \multirow[b]{2}{*}{$\begin{array}{l}\text { Weekend } \\
\text { included }\end{array}$} & \multirow[b]{2}{*}{ Nutrient } & \multirow[b]{2}{*}{ Coefficient } & \multirow[b]{2}{*}{$\begin{array}{l}\text { Quality } \\
\text { index }\end{array}$} \\
\hline & & Mean & so & Range & & & & & & & & & & \\
\hline $\begin{array}{l}\text { Ocké et al. } \\
\qquad(1997)^{(84)}\end{array}$ & $\begin{array}{l}58 \mathrm{~W} \\
63 \mathrm{M}\end{array}$ & & & $\begin{array}{c}20-70 \\
20-60\end{array}$ & Self-administered & 79 & 1 year & No & $\begin{array}{l}\text { Twelve, within } \\
1 \text { year }\end{array}$ & $\begin{array}{l}\text { Six personal interview + } \\
\text { six phone interview }\end{array}$ & Yes & $\begin{array}{l}\text { Vitamin C } \\
\text { Vitamin E }\end{array}$ & $\begin{array}{l}0.62 \mathrm{~W}^{*} / \\
0.29 \mathrm{M}^{*} \\
0.71 \mathrm{~W}^{*} / 0.43 \mathrm{M}^{*} \\
0.41 \mathrm{~W}^{*} / 0.58 \mathrm{M}^{*}\end{array}$ & 3 \\
\hline $\begin{array}{l}\text { Pisani et al. } \\
(1997)^{(85)}\end{array}$ & $\begin{array}{c}150 \mathrm{~W} \\
47 \mathrm{M}\end{array}$ & $\begin{array}{l}49.4 \\
50.5\end{array}$ & $\begin{array}{l}8.8 \\
8.3\end{array}$ & & Self-administered & 47 & 1 year & No & $\begin{array}{l}\text { Twelve, within } \\
1 \text { year }\end{array}$ & Personal interview & Yes & $\begin{array}{l}\text { Vitamin A } \\
\text { Vitamin C } \\
\text { Vitamin E }\end{array}$ & $\begin{array}{l}0.46 \mathrm{~W}^{*} / \\
0.37 \mathrm{M}^{*} \\
0.49 \mathrm{~W}^{*} / 0.44 \mathrm{M}^{*} \\
0.38 \mathrm{~W}^{*} / 0.48 \mathrm{M}^{*}\end{array}$ & 2.5 \\
\hline $\begin{array}{l}\text { Romieu et al. } \\
(1999)^{(86)}\end{array}$ & $110 \mathrm{~W}$ & & & $15-54$ & First FFQ interviewer & 116 & - & No & $\begin{array}{l}\text { Sixteen, within } \\
1 \text { year }\end{array}$ & Personal interview & Yes & $\begin{array}{l}\text { Vitamin A } \\
\text { Vitamin C } \\
\text { Vitamin E }\end{array}$ & $\begin{array}{l}0.35^{*} \\
0.48^{*} \\
0.22^{\star}\end{array}$ & 2.5 \\
\hline $\begin{array}{l}\text { Romieu et al. } \\
(1999)^{(86)}\end{array}$ & $110 \mathrm{~W}$ & & & $15-54$ & Second FFQ interviewer & 116 & - & No & $\begin{array}{l}\text { Sixteen, within } \\
1 \text { year }\end{array}$ & Personal interview & Yes & $\begin{array}{l}\text { Vitamin A } \\
\text { Vitamin C } \\
\text { Vitamin E }\end{array}$ & $\begin{array}{l}0.49^{\star} \\
0.49^{\star} \\
0.12^{\star}\end{array}$ & 2.5 \\
\hline $\begin{array}{l}\text { Sevak et al. } \\
\quad(1997)^{(87)}\end{array}$ & $100 \mathrm{~W}$ & $53 \cdot 5$ & 8.5 & & Interviewer & 207 & - & No & $\begin{array}{l}\text { Twelve, within } \\
1 \text { year }\end{array}$ & Phone interview & Yes & $\begin{array}{l}\text { Retinol } \\
\text { Vitamin C } \\
\text { Vitamin D }\end{array}$ & $\begin{array}{l}0.30^{*} \\
0.54^{\star} \\
0.78^{\star}\end{array}$ & 3.5 \\
\hline Shu et al. (2004) & $191 \mathrm{~W}$ & 55.4 & 9 & & Interviewer & 77 & 1 year & No & $\begin{array}{l}\text { Twenty-four, } \\
\text { within } 1 \text { year }\end{array}$ & Personal interview & Yes & $\begin{array}{l}\text { Vitamin C } \\
\text { Vitamin E }\end{array}$ & $\begin{array}{l}0.43 \ddagger \\
0.41 \ddagger\end{array}$ & 4 \\
\hline $\begin{array}{l}\text { Van Liere et al. } \\
\quad(1997)^{(89)}\end{array}$ & $115 \mathrm{~W}$ & & & $35-65$ & Self-administered & 66 & 1 year & No & $\begin{array}{l}\text { Twelve, within } \\
1 \text { year }\end{array}$ & Personal interview & Yes & $\begin{array}{l}\text { Vitamin A } \\
\text { Vitamin C } \\
\text { Vitamin E }\end{array}$ & $\begin{array}{l}0.29^{*} \\
0.69^{*} \\
0.42^{*}\end{array}$ & 4 \\
\hline $\begin{array}{l}\text { Villegas et al. } \\
\qquad(2006)^{(90)}\end{array}$ & 195 & & & $40-70$ & Interviewer & 81 & 1 year & No & $\begin{array}{l}\text { Twelve, within } \\
1 \text { year }\end{array}$ & Personal interview & Yes & $\begin{array}{l}\text { Vitamin C } \\
\text { Vitamin E }\end{array}$ & $\begin{array}{l}0.42 \S \\
0.38 \S\end{array}$ & 4 \\
\hline Short-term intake & & & & & & & & & & & & & & \\
\hline $\begin{array}{l}\text { Block et al. } \\
\quad(2006)^{(91)}\end{array}$ & 89 & 36.8 & & & Interviewer & 103 & 1 year & Yes & $\begin{array}{l}\text { Three, within } \\
2 \text { months }\end{array}$ & Personal interview & Unknown & $\begin{array}{l}\text { Vitamin A } \\
\text { Vitamin C }\end{array}$ & $\begin{array}{l}0.53^{*} \\
0.55^{*}\end{array}$ & 4.5 \\
\hline $\begin{array}{l}\text { Boucher et al. } \\
(2006)^{(92)}\end{array}$ & $96 \mathrm{~W}$ & & & $25-74$ & Self-administered & 109 & - & No & $\begin{array}{l}\text { Two, within } \\
18 \text { days }\end{array}$ & Phone interview & Yes & Vitamin C & $0.69^{*}$ & 3 \\
\hline $\begin{array}{l}\text { Flagg et al. } \\
\qquad(2000)^{(93)}\end{array}$ & $\begin{array}{l}223 \mathrm{~W} \\
216 \mathrm{M}\end{array}$ & 61 & & & Self-administered & 68 & 1 year & Yes & $\begin{array}{l}\text { Four, within } \\
1 \text { year }\end{array}$ & Personal interview & Yes & $\begin{array}{l}\text { Vitamin A } \\
\text { Vitamin C } \\
\text { Vitamin E }\end{array}$ & $\begin{array}{l}0.26 \mathrm{~W}^{*} / \\
0.45 \mathrm{M}^{*} \\
0.65 \mathrm{~W}^{*} / 0.65 \mathrm{M}^{*} \\
0.27 \mathrm{~W}^{*} / 0.23 \mathrm{M}^{*}\end{array}$ & 4 \\
\hline $\begin{array}{l}\text { Fornés et al. } \\
(2003)^{(94)}\end{array}$ & $\begin{array}{l}62 \mathrm{~W} \\
42 \mathrm{M}\end{array}$ & $\begin{array}{l}38 \\
27\end{array}$ & $\begin{array}{c}32.5 \\
23.3\end{array}$ & & First FFQ interviewer & 127 & - & No & $\begin{array}{l}\text { Six, within } \\
6 \text { months }\end{array}$ & Personal interview & Yes & $\begin{array}{l}\text { Vitamin A } \\
\text { Vitamin C }\end{array}$ & $\begin{array}{l}0.48^{*} \\
0.39^{*}\end{array}$ & 3 \\
\hline $\begin{array}{l}\text { Fornés et al. } \\
(2003)^{(94)}\end{array}$ & $\begin{array}{l}62 \mathrm{~W} \\
42 \mathrm{M}\end{array}$ & $\begin{array}{l}38 \\
27\end{array}$ & $\begin{array}{c}32.5 \\
23.3\end{array}$ & & Second FFQ interviewer & 127 & - & No & $\begin{array}{l}\text { Six, within } \\
6 \text { months }\end{array}$ & Personal interview & Yes & $\begin{array}{l}\text { Vitamin A } \\
\text { Vitamin C }\end{array}$ & $\begin{array}{l}0.47^{*} \\
0.42^{*}\end{array}$ & 3 \\
\hline Hebert et al. & $30 \mathrm{~W}$ & $\begin{array}{l}36 \cdot 1 \\
31.4\end{array}$ & 9.7 & & First FFQ interviewer & 92 & 1 year & No & Six, within 1 year & Personal interview & Yes & Vitamin C & $0.55 \ddagger$ & 2.5 \\
\hline $\begin{array}{l}\text { Hebert et al. } \\
\text { (1999)(95) }\end{array}$ & $\begin{array}{l}30 \mathrm{~W} \\
30 \mathrm{M}\end{array}$ & $\begin{array}{l}36.1 \\
31.4\end{array}$ & $\begin{array}{l}9.7 \\
7.7\end{array}$ & & $\begin{array}{l}\text { Second FFQ } \\
\text { interviewer }\end{array}$ & 92 & 1 year & No & Six, within 1 year & Personal interview & Yes & Vitamin C & $0.53 \ddagger$ & 2.5 \\
\hline $\begin{array}{l}\text { Kumanyika et al. } \\
(2003)^{(61)}\end{array}$ & $408 \mathrm{~W}$ & & & $21-69$ & Self-administered & 68 & - & Yes & $\begin{array}{l}\text { Three, within } \\
1 \text { year }\end{array}$ & Phone interview & Yes & $\begin{array}{l}\text { Vitamin C } \\
\text { Vitamin E }\end{array}$ & $\begin{array}{l}0.55^{*} \\
0.26^{*}\end{array}$ & 2.5 \\
\hline $\begin{array}{l}\text { Kusama et al. } \\
(2005)^{\left({ }^{(96)}\right)}\end{array}$ & $\begin{array}{l}62 \mathrm{~W} \\
56 \mathrm{M}\end{array}$ & & & $23-62$ & Interviewer & 116 & 3 months & No & $\begin{array}{l}\text { Three, within } \\
1 \text { month }\end{array}$ & Personal interview & Yes & $\begin{array}{l}\text { Vitamin A } \\
\text { Vitamin C }\end{array}$ & $\begin{array}{l}0.45^{*} \\
0.31^{*}\end{array}$ & 4.5 \\
\hline $\begin{array}{l}\text { Munger et al. } \\
(1992)^{(97)}\end{array}$ & $44 \mathrm{~W}$ & & & $34-59$ & Self-administered & 126 & 1 year & Yes & $\begin{array}{l}\text { Five, within } \\
1 \text { year }\end{array}$ & Phone interview & Yes & $\begin{array}{l}\text { Vitamin D } \\
\text { Vitamin E }\end{array}$ & $\begin{array}{l}0.51^{*} \\
0.26^{*}\end{array}$ & 2.5 \\
\hline $\begin{array}{l}\text { Navarro et al. } \\
(2001)^{(98)}\end{array}$ & 62 & 57 & 14 & & First FFQ interviewer & 127 & 5 years & No & $\begin{array}{l}\text { Four, within } \\
3 \text { months }\end{array}$ & Personal interview & Yes & $\begin{array}{l}\text { Vitamin C } \\
\text { Vitamin E }\end{array}$ & $\begin{array}{l}0.73^{*} \\
0.72^{*}\end{array}$ & 4 \\
\hline
\end{tabular}


Table 5. Continued

\begin{tabular}{|c|c|c|c|c|c|c|c|c|c|c|c|c|c|c|}
\hline \multirow{2}{*}{$\begin{array}{l}\text { Author and year of pub- } \\
\text { lication }\end{array}$} & \multirow[b]{2}{*}{ No. } & \multicolumn{3}{|c|}{ Age (years) } & \multirow{2}{*}{$\begin{array}{l}\text { FFQ administration } \\
\text { method }\end{array}$} & \multirow[b]{2}{*}{$\begin{array}{l}\text { No. of } \\
\text { foods }\end{array}$} & \multirow{2}{*}{$\begin{array}{c}\mathrm{FFQ} \\
\text { reference } \\
\text { period }\end{array}$} & \multirow[b]{2}{*}{ Suppl. } & \multirow{2}{*}{$\begin{array}{l}\text { No. of } \\
\text { recalls }\end{array}$} & \multirow{2}{*}{$\begin{array}{l}\text { Recall } \\
\text { administration } \\
\text { method }\end{array}$} & \multirow{2}{*}{$\begin{array}{l}\text { Weekend } \\
\text { included }\end{array}$} & \multirow[b]{2}{*}{ Nutrient } & \multirow[b]{2}{*}{ Coefficient } & \multirow[b]{2}{*}{$\begin{array}{c}\text { Quality } \\
\text { index } \\
\end{array}$} \\
\hline & & Mean & SD & Range & & & & & & & & & & \\
\hline $\begin{array}{l}\text { Navarro et al. } \\
(2001)^{(98)}\end{array}$ & 62 & 57 & 14 & & $\begin{array}{l}\text { Second FFQ } \\
\text { interviewer }\end{array}$ & 127 & 5 years & No & $\begin{array}{l}\text { Four, within } \\
3 \text { months }\end{array}$ & Personal interview & Yes & $\begin{array}{l}\text { Vitamin C } \\
\text { Vitamin E }\end{array}$ & $\begin{array}{l}0.73^{*} \\
0.67^{\star}\end{array}$ & 4 \\
\hline $\begin{array}{l}\text { Olafsdottir et al. } \\
(2006)^{(99)}\end{array}$ & $53 \mathrm{~W}$ & 36 & 5 & & Self-administered & 130 & 3 months & Yes & $\begin{array}{l}\text { Two, within } \\
1 \text { month }\end{array}$ & Phone interview & Yes & $\begin{array}{l}\text { Vitamin A } \\
\text { Vitamin C }\end{array}$ & $\begin{array}{l}0.607 \ddagger \\
0.501 \neq\end{array}$ & 3 \\
\hline $\begin{array}{l}\text { Rodríguez et al. } \\
(2002)^{(100)}\end{array}$ & $\begin{array}{l}30 \mathrm{~W} \\
43 \mathrm{M}\end{array}$ & & & $22-55$ & Self-administered & 52 & 3 months & No & $\begin{array}{l}\text { Three, within } \\
1 \text { month }\end{array}$ & Personal interview & Yes & $\begin{array}{l}\text { Vitamin A } \\
\text { Vitamin C }\end{array}$ & $\begin{array}{l}0.48^{*} \\
0.19^{\star}\end{array}$ & 3 \\
\hline $\begin{array}{l}\text { Segovia et al. } \\
(2006)^{(101)}\end{array}$ & 87 & & & $30-72$ & Self-administered & 171 & 6 months & No & $\begin{array}{l}\text { Six, within } \\
6 \text { months }\end{array}$ & Phone interview & Yes & $\begin{array}{l}\text { Vitamin A } A \\
\text { Vitamin C } \\
\text { Vitamin E }\end{array}$ & $\begin{array}{l}0.42^{\star} \\
0.96^{*} \\
0.22^{\star}\end{array}$ & 3 \\
\hline $\begin{array}{l}\text { Shai et al. } \\
\qquad(1997)^{(102)}\end{array}$ & 161 & 50 & 0.5 & & Self-administered & 126 & - & No & $\begin{array}{r}\text { Six, within } \\
1 \text { year }\end{array}$ & Personal interview & Yes & Vitamin E & $0.55^{\star}$ & 3 \\
\hline $\begin{array}{l}\text { Sichieri \& Everhart } \\
(1998)^{(103)}\end{array}$ & $\begin{array}{r}46 \mathrm{~W} \\
42 \mathrm{M}\end{array}$ & - & & & Interviewer & 61 & 1 year & No & $\begin{array}{l}\text { Four, within } \\
2 \text { months }\end{array}$ & Personal interview & Yes & $\begin{array}{l}\text { Retinol } \\
\text { Vitamin C }\end{array}$ & $\begin{array}{l}0.18 \neq \\
0.23 \ddagger\end{array}$ & 3 \\
\hline $\begin{array}{l}\text { Sudha et al. } \\
\qquad(2006)^{(104)}\end{array}$ & $\begin{array}{l}68 \mathrm{~W} \\
34 \mathrm{M}\end{array}$ & $40 \cdot 9$ & 12.8 & & First FFQ interviewer & 222 & 1 year & Yes & $\begin{array}{l}\text { Six, within } \\
1 \text { year }\end{array}$ & Personal interview & Yes & $\begin{array}{l}\text { Vitamin A } \\
\text { Vitamin C } \\
\text { Vitamin E }\end{array}$ & $\begin{array}{l}0.66^{*} \\
0.3^{*} \\
0.35^{*}\end{array}$ & 6 \\
\hline $\begin{array}{l}\text { Sudha et al. } \\
(2006)^{(104)}\end{array}$ & $\begin{array}{c}68 \mathrm{~W} \\
34 \mathrm{M}\end{array}$ & 40.9 & 12.8 & & Second FFQ interviewer & 222 & 1 year & Yes & $\begin{array}{l}\text { Six, within } \\
1 \text { year }\end{array}$ & Personal interview & Yes & $\begin{array}{l}\text { Vitamin A } A \\
\text { Vitamin C } \\
\text { Vitamin E }\end{array}$ & $\begin{array}{l}0.59^{\star} \\
0.52^{\star} \\
0.42^{\star}\end{array}$ & 6 \\
\hline
\end{tabular}

No., number; Suppl., supplements; W, women; M, men.

*Energy-adjusted deattenuated correlation coefficient.

†Energy-adjusted, Pearson correlation coefficient.

$\ddagger$ Crude, Pearson correlation coefficient.

$\S$ Crude, Spearman correlation coefficient. 
Table 6. Description of validation studies regarding vitamins A, C, D and E intake (FFQ vs. biomarkers)

\begin{tabular}{|c|c|c|c|c|c|c|c|c|c|c|c|}
\hline \multirow[b]{2}{*}{$\begin{array}{l}\text { Author and year } \\
\text { of publication }\end{array}$} & \multirow[b]{2}{*}{ No. } & \multicolumn{3}{|c|}{ Age (years) } & \multirow[b]{2}{*}{$\begin{array}{l}\text { FFQ administration } \\
\text { method }\end{array}$} & \multirow[b]{2}{*}{$\begin{array}{l}\text { No. of } \\
\text { foods }\end{array}$} & \multirow{2}{*}{$\begin{array}{l}\mathrm{FFQ} \\
\text { reference } \\
\text { period }\end{array}$} & \multirow[b]{2}{*}{ Suppl. } & \multirow[b]{2}{*}{ Biomarkers } & \multirow[b]{2}{*}{ Coefficient } & \multirow[b]{2}{*}{$\begin{array}{l}\text { Quality } \\
\text { index }\end{array}$} \\
\hline & & Mean & SD & Range & & & & & & & \\
\hline Andersen et al. $(1999)^{(8)}$ & $125 \mathrm{M}$ & & & $20-55$ & Self-administered & 180 & 1 year & Yes & $\begin{array}{l}\text { Adipose tissue vitamin } \mathrm{E} \\
\text { Serum vitamin } \mathrm{E}\end{array}$ & $\begin{array}{l}-0.10^{\star} \\
-0.05^{\star}\end{array}$ & 4 \\
\hline Ascherio et al. (1992) $)^{(105)}$ & $\begin{array}{l}162 \mathrm{~W} \\
110 \mathrm{M}\end{array}$ & $\begin{array}{l}7.2 \\
55 \cdot 7\end{array}$ & $\begin{array}{l}52 \cdot 7 \\
10\end{array}$ & & Self-administered & $\begin{array}{l}126 \\
131\end{array}$ & 1 year & Yes & $\begin{array}{l}\text { Retinol } \\
\text { Plasma vitamin E }\end{array}$ & $\begin{array}{l}0.25 \mathrm{~W}+/ 0.08 \mathrm{M} \dagger \\
0.41 \mathrm{~W}+/ 0.51 \mathrm{M} \dagger\end{array}$ & 3 \\
\hline Bingham et al. $(1997)^{(106)}$ & 156 & & & $50-65$ & Self-administered & 67 & 1 year & Yes & Blood vitamin C & $0.35^{\star}$ & 4 \\
\hline Bodner et al. $(1998)^{(107)}$ & $\begin{array}{l}155 \mathrm{~W} \\
188 \mathrm{M}\end{array}$ & & & $39-45$ & Self-administered & - & 1 year & Yes & Blood vitamin $\mathrm{C}$ & $0.41 \dagger$ & 3 \\
\hline Boeing et al. $(1997)^{(76)}$ & $\begin{array}{l}49 \mathrm{~W} \\
43 \mathrm{M}\end{array}$ & & & $35-64$ & Self-administered & 158 & - & No & $\begin{array}{l}\text { Blood retinol } \\
\text { Blood vitamin C } \\
\text { Blood vitamin E }\end{array}$ & $\begin{array}{l}0.21 \dagger \\
0.36 \dagger \\
0.18 \dagger\end{array}$ & $2 \cdot 5$ \\
\hline Bolton-Smith et al. (1991) ${ }^{(108)}$ & 196 & - & & & Self-administered & - & - & No & $\begin{array}{l}\text { Serum vitamin } C \\
\text { Serum vitamin } E\end{array}$ & $\begin{array}{l}0.56 \dagger \\
0.30 \dagger\end{array}$ & 3.5 \\
\hline Brunner et al. $(2001)^{(14)}$ & $\begin{array}{l}403 \mathrm{~W} \\
457 \mathrm{M}\end{array}$ & & & $39-61$ & Self-administered & 127 & 1 year & Yes & Plasma vitamin $\mathrm{E}$ & $-0.07 \dagger$ & 3.5 \\
\hline Coates \& Monteilh (1991) ${ }^{(109)}$ & $94 \mathrm{~W}$ & - & & & Interviewer & 98 & 1 year & Yes & Serum vitamin $\mathrm{E}$ & $0.35 t$ & 3.5 \\
\hline Dixon et al. $(2006)^{(110)}$ & $\begin{array}{l}86 \mathrm{~W} \\
44 \mathrm{M}\end{array}$ & & & $20-70$ & Self-administered & 124 & 1 year & Yes & Serum vitamin $E$ & $0.70 \dagger$ & 4.5 \\
\hline El-Sohemy et al. (2001) $)^{(111)}$ & $\begin{array}{l}121 \mathrm{~W} \\
361 \mathrm{M}\end{array}$ & $\begin{array}{l}59 \\
55\end{array}$ & $\begin{array}{l}10 \\
11\end{array}$ & & Self-administered & 135 & 1 year & Yes & $\begin{array}{l}\text { Plasma vitamin } \mathrm{E} \\
\text { Adipose tissue vitamin } \mathrm{E}\end{array}$ & $\begin{array}{l}0.16 \dagger \\
0.15 \dagger\end{array}$ & 3.5 \\
\hline Fraser et al. $(2005)^{(77)}$ & $\begin{array}{l}117 \mathrm{~W} \\
76 \mathrm{M}\end{array}$ & - & & & Self-administered & 202 & - & No & Plasma vitamin $\mathrm{E}$ & $0.45+$ & $2 \cdot 5$ \\
\hline Jacques et al. $(1993)^{(112)}$ & $\begin{array}{l}82 \mathrm{~W} \\
57 \mathrm{M}\end{array}$ & & & $40-83$ & Interviewer & 116 & 1 year & Yes & $\begin{array}{l}\text { Plasma total vitamin } C \\
\text { Plasma vitamin } D \\
\text { Plasma vitamin } E\end{array}$ & $\begin{array}{l}0.43 \dagger \\
0.35 \dagger \\
0.53 \dagger\end{array}$ & 4.5 \\
\hline Kabagambe et al. (2001) ${ }^{(79)}$ & $\begin{array}{l}42 \mathrm{~W} \\
78 \mathrm{M}\end{array}$ & 59 & 10 & & Interviewer & 135 & 1 year & No & $\begin{array}{l}\text { Plasma vitamin } \mathrm{E} \\
\text { Adipose tissue vitamin } \mathrm{E}\end{array}$ & $\begin{array}{l}0.06 \dagger \\
0.13 \dagger\end{array}$ & 4 \\
\hline Kardinaal et al. (1995) $)^{(113)}$ & $\begin{array}{l}47 \mathrm{~W} \\
38 \mathrm{M}\end{array}$ & & & $50-70$ & Self-administered & 95 & 1 year & No & $\begin{array}{l}\text { Plasma vitamin } \mathrm{E} \\
\text { Adipose tissue vitamin } \mathrm{E}\end{array}$ & $\begin{array}{l}0.11 \ddagger \\
0.20 \ddagger\end{array}$ & 2 \\
\hline Katsouyanni et al. (1997) ${ }^{(80)}$ & $\begin{array}{l}38 \mathrm{~W} \\
42 \mathrm{M}\end{array}$ & & & $25-67$ & First FFQ self-administered & 190 & 1 year & Yes & Blood vitamin C & $0.30 \dagger$ & 4 \\
\hline Katsouyanni et al. (1997) ${ }^{(80)}$ & $\begin{array}{l}38 \mathrm{~W} \\
42 \mathrm{M}\end{array}$ & & & $25-67$ & Second FFQ self-administered & 190 & 1 year & Yes & Blood vitamin C & $0.14 \dagger$ & 4 \\
\hline Knutsen et al. $(2001)^{(114)}$ & $\begin{array}{l}97 \mathrm{BI} \\
96 \mathrm{Wh}\end{array}$ & $\begin{array}{l}52 \cdot 8 \\
47 \cdot 2\end{array}$ & $\begin{array}{l}17 \\
15\end{array}$ & & Self-administered & 200 & 1 year & Yes & $\begin{array}{l}\text { Plasma vitamin } C \\
\text { Plasma vitamin } E\end{array}$ & $\begin{array}{l}0.195 \mathrm{Bl} \ddagger / 0.027 \mathrm{Wh} \ddagger \\
0.279 \mathrm{Bl} / 0.397 \mathrm{Wh} \ddagger\end{array}$ & 3 \\
\hline Kobayashi et al. (2003) & $\begin{array}{l}99 \mathrm{~W} \\
86 \mathrm{M}\end{array}$ & - & & & Self-administered & 138 & 1 year & Yes & Blood vitamin C & $-0.14 \mathrm{~W} \S /-0.20 \mathrm{M} \S$ & 4.5 \\
\hline Malekshah et al. (2006) ${ }^{(81)}$ & $\begin{array}{l}82 \mathrm{~W} \\
49 \mathrm{M}\end{array}$ & $\begin{array}{l}49 \cdot 9 \\
51 \cdot 2\end{array}$ & $\begin{array}{l}9 \cdot 3 \\
13\end{array}$ & & Interviewer & 158 & 1 year & No & $\begin{array}{l}\text { Blood retinol } \\
\text { Blood vitamin C } \\
\text { Plasma vitamin E }\end{array}$ & $\begin{array}{l}0.32 \| \\
0.35 \| \\
0.06 \dagger\end{array}$ & 3 \\
\hline Marshall et al. $(1997)^{(115)}$ & $162 \mathrm{M}$ & - & & & - & - & - & No & Blood vitamin $\mathrm{E}$ & $0 \cdot 10^{*}$ & 1 \\
\hline McKeown et al. (2001) $)^{(34)}$ & 118 & & & $45-74$ & Self-administered & 130 & 1 year & Yes & Blood vitamin C & $0.39^{*}$ & 5 \\
\hline
\end{tabular}




\begin{tabular}{|c|c|c|c|c|c|c|c|c|c|c|c|}
\hline \multirow[b]{2}{*}{$\begin{array}{l}\text { Author and year } \\
\text { of publication }\end{array}$} & \multirow[b]{2}{*}{ No. } & \multicolumn{3}{|c|}{ Age (years) } & \multirow[b]{2}{*}{$\begin{array}{l}\text { FFQ administration } \\
\text { method }\end{array}$} & \multirow[b]{2}{*}{$\begin{array}{l}\text { No. of } \\
\text { foods }\end{array}$} & \multirow{2}{*}{$\begin{array}{c}\mathrm{FFQ} \\
\text { reference } \\
\text { period }\end{array}$} & \multirow[b]{2}{*}{ Suppl. } & \multirow[b]{2}{*}{ Biomarkers } & \multirow[b]{2}{*}{ Coefficient } & \multirow[b]{2}{*}{$\begin{array}{l}\text { Quality } \\
\text { index }\end{array}$} \\
\hline & & Mean & SD & Range & & & & & & & \\
\hline McNaughton et al. (2005) ${ }^{(35)}$ & $\begin{array}{l}17 \mathrm{~W} \\
11 \mathrm{M}\end{array}$ & 48 & 10.5 & & Self-administered & 129 & 6 months & Yes & Plasma vitamin $\mathrm{E}$ & $0.31 \S$ & 2 \\
\hline Ocké et al. (1997) & $\begin{array}{l}58 \mathrm{~W} \\
63 \mathrm{M}\end{array}$ & & & $\begin{array}{l}20-70 \\
20-60\end{array}$ & Self-administered & 79 & 1 year & No & Serum vitamin $\mathrm{E}$ & $0.07 \mathrm{~W} \ddagger / 0.21 \mathrm{M} \ddagger$ & 3 \\
\hline Olafsdottir et al. (2006) ${ }^{(99)}$ & $53 \mathrm{~W}$ & 36 & 5 & & Self-administered & 130 & 3 months & Yes & Blood vitamin C & $0.32^{*}$ & 3.5 \\
\hline Porrini et al. $(1995)^{(116)}$ & $\begin{array}{l}33 \mathrm{~W} \\
11 \mathrm{M}\end{array}$ & $27 \cdot 1$ & $6 \cdot 3$ & & Self-administered & 93 & - & No & $\begin{array}{l}\text { Blood vitamin C } \\
\text { Plasma vitamin E }\end{array}$ & $\begin{array}{l}0.069^{*} \\
-0.22^{*}\end{array}$ & 1 \\
\hline Romieu et al. $(1999)^{(86)}$ & $110 \mathrm{~W}$ & & & $15-54$ & First FFQ interviewer & 116 & - & No & Plasma vitamin E & $0.07 \dagger$ & 2.5 \\
\hline Romieu et al. $(1999)^{(86)}$ & $110 \mathrm{~W}$ & & & $15-54$ & Second FFQ interviewer & 116 & - & No & Plasma vitamin $\mathrm{E}$ & $-0.01 \dagger$ & 2.5 \\
\hline Shai et al. $(1997)^{(102)}$ & 161 & 50 & 0.5 & & Self-administered & 126 & - & Yes & Plasma vitamin $\mathrm{E}$ & $0.19 \ddagger$ & 4.5 \\
\hline Sinha et al. $(1992)^{(117)}$ & $68 \mathrm{M}$ & & & $30-59$ & Self-administered & - & 1 year & Yes & Blood vitamin C & $0.43 \|$ & 2.5 \\
\hline Willett et al. $(1983)^{(118)}$ & 59 & & & $20-54$ & Self-administered & 99 & 1 year & Yes & Plasma vitamin $\mathrm{E}$ & $0.34 \dagger$ & 3 \\
\hline
\end{tabular}




\begin{tabular}{|c|c|c|c|c|c|c|c|c|c|c|}
\hline \multirow{2}{*}{$\begin{array}{l}\text { Author and year of } \\
\text { publication }\end{array}$} & \multirow[b]{2}{*}{ No. } & \multicolumn{3}{|c|}{ Age (years) } & \multirow[b]{2}{*}{ Method } & \multirow[b]{2}{*}{ Gold Standard } & \multirow[b]{2}{*}{ Suppl. } & \multirow[b]{2}{*}{ Nutrient } & \multirow[b]{2}{*}{ Coefficient } & \multirow[b]{2}{*}{$\begin{array}{l}\text { Quality } \\
\text { index }\end{array}$} \\
\hline & & Mean & SD & Range & & & & & & \\
\hline \multirow[t]{2}{*}{ Ascherio et al. (1992) $)^{(105)}$} & $162 \mathrm{~W}$ & 52.7 & $7 \cdot 2$ & & DR & Plasma vitamin $\mathrm{E}$ & No & Vitamin E & $0.51^{*}$ & 3 \\
\hline & $110 \mathrm{M}$ & 55.7 & 10.6 & & & & & & & \\
\hline \multirow[t]{2}{*}{ Bingham et al. (1994) ${ }^{(119)}$} & $127 \mathrm{~W}$ & & & $50-65$ & Oxford FFQ self-administered (127 items) & DR weighed (4/4) & No & Vitamin A & $0.55 \dagger$ & 4 \\
\hline & & & & & & & & Vitamin C & $0.54 \dagger$ & \\
\hline \multirow[t]{2}{*}{ Bingham et al. $(1994)^{(119)}$} & $127 \mathrm{~W}$ & & & $50-65$ & Cambridge FFQ & DR weighed (4/4) & No & Vitamin A & $0.32 \dagger$ & 4 \\
\hline & & & & & $\begin{array}{l}\text { self-administered } \\
\text { (130 items) }\end{array}$ & & & Vitamin C & $0.41 \dagger$ & \\
\hline \multirow[t]{2}{*}{ Bingham et al. $(1994)^{(119)}$} & $106 \mathrm{~W}$ & & & $50-65$ & Structured 24-h R & DR weighed (4/4) & No & Vitamin A & $0.33 \dagger$ & 4 \\
\hline & & & & & & & & Vitamin C & $0.35 \dagger$ & \\
\hline \multirow[t]{2}{*}{ Bingham et al. $(1994)^{(119)}$} & $73 \mathrm{~W}$ & & & $50-65$ & DR estimated (1/7) & DR weighed (4/4) & No & Vitamin A & $0.35 \dagger$ & 4 \\
\hline & & & & & & & & Vitamin C & $0.70 \dagger$ & \\
\hline Bingham et al. $(1997)^{(106)}$ & 156 & & & $50-65$ & DR weighed (4/4) & Blood vitamin C & Yes & Vitamin C & $0.51 \dagger$ & 4 \\
\hline Bingham et al. (1997) $)^{(106)}$ & 156 & & & $50-65$ & 24-h R & Blood vitamin C & Yes & Vitamin C & $0.34 \dagger$ & 4 \\
\hline Bingham et al. $(1997)^{(106)}$ & 156 & & & $50-65$ & DR estimated (1/7) & Blood vitamin C & Yes & Vitamin C & $0.22 \dagger$ & 4 \\
\hline \multirow{2}{*}{ Booth et al. $(1997)^{(120)}$} & 34 & $20-40$ & 17 & & DR weighed (3/4) & Plasma vitamin D & No & Vitamin D & $0.32^{*}$ & 0.5 \\
\hline & & $60-80$ & 17 & & & Plasma vitamin $\mathrm{E}$ & & Vitamin E & $0.08^{*}$ & \\
\hline \multirow[t]{2}{*}{ Dixon et al. $(2006)^{(110)}$} & $86 \mathrm{~W}$ & & & $20-70$ & Four personal interview 24-h R & Serum vitamin $E$ & No & Vitamin $\mathrm{E}$ & $0.72^{*}$ & 4 \\
\hline & $44 \mathrm{M}$ & & & & & & & & & \\
\hline \multirow[t]{3}{*}{ EPIC Group of Spain (1997) ${ }^{(121)}$} & 91 & & & $35-60$ & First dietary history & Twelve personal & No & Vitamin A & $0.36 \mathrm{~W} \neq / 0.30 \mathrm{M} \ddagger$ & 2 \\
\hline & & & & & & interview 24-h R & & Vitamin C & $0.79 \mathrm{~W} \neq / 0.69 \mathrm{M} \ddagger$ & \\
\hline & & & & & & & & Vitamin $\mathrm{E}$ & $0.61 \mathrm{~W} \neq / 0.64 \mathrm{M} \ddagger$ & \\
\hline \multirow[t]{3}{*}{ EPIC Group of Spain (1997) ${ }^{(121)}$} & 91 & & & $35-60$ & Second dietary history & Twelve personal & No & Vitamin A & $0.52 \mathrm{~W} \ddagger / 0.28 \mathrm{M \ddagger}$ & 2 \\
\hline & & & & & & interview 24-h R & & Vitamin C & $0.82 \mathrm{~W} \ddagger / 0.69 \mathrm{M} \ddagger$ & \\
\hline & & & & & & & & Vitamin E & $0.65 \mathrm{~W} \neq / 0.48 \mathrm{M} \ddagger$ & \\
\hline \multirow[t]{2}{*}{ EPIC Group of Spain (1997) ${ }^{(122)}$} & 72 & & & $35-60$ & Dietary history & Blood vitamin C & No & Vitamin C & $0.45 \ddagger$ & 2.5 \\
\hline & & & & & & Blood vitamin $\mathrm{E}$ & & Vitamin E & $0.33 \ddagger$ & \\
\hline \multirow[t]{2}{*}{ EPIC Group of Spain (1997) ${ }^{(122)}$} & 72 & & & $35-60$ & Twelve personal interview 24-h R & Blood vitamin C & No & Vitamin C & $0.50 \ddagger$ & 2.5 \\
\hline & & & & & & Blood vitamin $\mathrm{E}$ & & Vitamin $\mathrm{E}$ & $0.36 \ddagger$ & \\
\hline Fraser et al. (2005) ${ }^{(73)}$ & $117 \mathrm{~W}$ & - & & & Eight phone interview 24-h R & Plasma vitamin $\mathrm{E}$ & No & Vitamin $\mathrm{E}$ & $0.48^{*}$ & 2.5 \\
\hline & $76 \mathrm{M}$ & & & & & & & & & \\
\hline Hankin et al. $(1991)^{(123)}$ & 262 & & & $45-74$ & Dietary history & DR estimated (4/7) & No & Vitamin A & $0.40 \mathrm{~W} \S / 0.55 \mathrm{M} \S$ & 4 \\
\hline & & & & & & & & Vitamin C & $0.50 \mathrm{~W} \S / 0.50 \mathrm{M} \S$ & \\
\hline Hebert et al. $(1998)^{(124)}$ & $13 \mathrm{M}$ & & & $21-39$ & DR weighed $(3 / 4)$ & Ten phone interview 24-h R & No & Vitamin A & $0.68 \ddagger$ & 1 \\
\hline & & & & & & & & Vitamin C & $0.50 \ddagger$ & \\
\hline Jain et al. (1996) ${ }^{(24)}$ & $108 \mathrm{~W}$ & & & $35-79$ & Dietary history & DR estimated (1/7) & No & Vitamin C & $0.42 \mathrm{~W} \S / 0.38 \mathrm{M} \S$ & 4.5 \\
\hline & $95 \mathrm{M}$ & & & & & & & Vitamin $\mathrm{E}$ & $0.31 \mathrm{~W} \S / 0.44 \mathrm{M \S}$ & \\
\hline Kabagambe et al. (2001) ${ }^{(79)}$ & $42 \mathrm{~W}$ & 59 & 10 & & Personal interview 24-h R & Plasma vitamin E & No & Vitamin E & $0.21 \|$ & 4 \\
\hline & $78 \mathrm{M}$ & & & & & Adipose tissue vitamin $\mathrm{E}$ & & & $0.17 \|$ & \\
\hline Katsouyanni et al. $(1997)^{(80)}$ & $38 \mathrm{~W}$ & & & $25-67$ & Twelve personal & Blood vitamin C & No & Vitamin C & $0.33^{*}$ & 4 \\
\hline & $42 \mathrm{M}$ & & & & interview 24-h R & & & & & \\
\hline Knutsen et al. (2001) ${ }^{(114)}$ & $97 \mathrm{Bl}$ & $52 \cdot 8$ & 17 & & Eight phone interview 24-h R & Plasma vitamin $\mathrm{E}$ & Yes & Vitamin E & $0.52 \|$ & 3 \\
\hline & $96 \mathrm{Wh}$ & 47.2 & 15 & & & & & & & \\
\hline Kobayashi et al. (2003) & $99 \mathrm{~W}$ & - & & & DR estimated ( $4 / 7$ or $2 / 7$ ) & Blood vitamin C & Yes & Vitamin C & $-0.02 \mathrm{~W}$ / $-0.13 \mathrm{M} ף$ & 4.5 \\
\hline & $86 \mathrm{M}$ & & & & & & & & & \\
\hline Malekshah et al. $(2006)^{(85)}$ & $82 \mathrm{~W}$ & 49.9 & 9.3 & & Twelve personal interview 24-h R & Blood retinal & No & Vitamin A & $0.26^{\star \star}$ & 3 \\
\hline & $49 \mathrm{M}$ & $51 \cdot 2$ & 13 & & & Blood vitamin C & & Vitamin C & $0.37^{\star \star}$ & \\
\hline & & & & & & Plasma vitamin $\mathrm{E}$ & & Vitamin E & $0 \cdot 10^{\star *}$ & \\
\hline
\end{tabular}




\begin{tabular}{|c|c|c|c|c|c|c|c|c|c|c|}
\hline \multirow{2}{*}{$\begin{array}{l}\text { Author and year of } \\
\text { publication }\end{array}$} & \multirow[b]{2}{*}{ No. } & \multicolumn{3}{|c|}{ Age (years) } & \multirow[b]{2}{*}{ Method } & \multirow[b]{2}{*}{ Gold Standard } & \multirow[b]{2}{*}{ Suppl. } & \multirow[b]{2}{*}{ Nutrient } & \multirow[b]{2}{*}{ Coefficient } & \multirow{2}{*}{$\begin{array}{l}\text { Quality } \\
\text { index }\end{array}$} \\
\hline & & Mean & SD & Range & & & & & & \\
\hline Matthys et al. (2004) $)^{(125)}$ & $50 \mathrm{w}$ & 31 & 6 & & $\begin{array}{l}\text { Computerised self-administered } \\
\text { questionnaire }\end{array}$ & DR estimated (5/2) & No & Vitamin C & $0.60 \dagger$ & 2 \\
\hline McKeown et al. $(2001)^{(34)}$ & 118 & & & $45-74$ & DR estimated $(2 / 7)$ & Blood vitamin C & Yes & Vitamin C & $0.53 \dagger$ & 5 \\
\hline McNaughton et al. $(2005)^{(35)}$ & $\begin{array}{l}1149 \mathrm{~W} \\
1116 \mathrm{M}\end{array}$ & 43 & & & Personal interview 48-h R & DR estimated (1/5) & No & $\begin{array}{l}\text { Vitamin C } \\
\text { Vitamin E }\end{array}$ & $\begin{array}{l}0.53 \mathrm{~W}+/ 0.54 \mathrm{M} \dagger \\
0.53 \mathrm{~W}+/ 0.56 \mathrm{M}+\end{array}$ & 2 \\
\hline Olafsdottir et al. (2006) ${ }^{(99)}$ & $53 \mathrm{~W}$ & 36 & 5 & & Two phone interview 24-h R & Blood vitamin C & Yes & Vitamin C & $0.373+$ & 3.5 \\
\hline Porrini et al. $(1995)^{(116)}$ & $\begin{array}{r}33 \mathrm{~W} \\
11 \mathrm{M}\end{array}$ & $27 \cdot 1$ & $6 \cdot 3$ & & DR weighed $(1 / 7)$ & $\begin{array}{l}\text { Blood vitamin } \mathrm{C} \\
\text { Plasma vitamin } \mathrm{E}\end{array}$ & No & $\begin{array}{l}\text { Vitamin C } \\
\text { Vitamin E }\end{array}$ & $\begin{array}{l}0.437 \dagger \\
0.098 \dagger\end{array}$ & 1 \\
\hline Riboli et al. $(1997)^{(43)}$ & $\begin{array}{l}105 \mathrm{~W} \\
101 \mathrm{M}\end{array}$ & & & $50-69$ & $\begin{array}{l}\text { FFQ self-administered } \\
\quad(350 \text { items) }\end{array}$ & DR estimated (6/3) & No & Vitamin A & $0.44 \mathrm{~W} \ddagger / 0.58 \mathrm{M} \ddagger$ & 3.5 \\
\hline Riboli et al. $(1997)^{(43)}$ & $\begin{array}{r}105 \mathrm{~W} \\
101 \mathrm{M}\end{array}$ & & & $50-69$ & $\begin{array}{l}\text { FFQ self-administered } \\
\qquad(130 \text { items })\end{array}$ & DR estimated (6/3) & No & Vitamin A & $0.72 \mathrm{~W} \ddagger / 0.39 \mathrm{M} \ddagger$ & 3.5 \\
\hline Romieu et al. (1999) ${ }^{(86)}$ & $110 \mathrm{~W}$ & & & $15-54$ & Personal interview 24-h R & Plasma vitamin $\mathrm{E}$ & No & Vitamin E & $-0.06^{*}$ & 2.5 \\
\hline Sasakiet al. $(2000)^{(126)}$ & $\begin{array}{l}44 \mathrm{~W} \\
42 \mathrm{M}\end{array}$ & & & $24-67$ & Dietary history & Plasma vitamin $\mathrm{E}$ & No & Vitamin $\mathrm{E}$ & $0.17 \mathrm{~W} \neq /-0.26 \mathrm{M \ddagger}$ & 1.5 \\
\hline Schröder et al. (2001) $)^{(70)}$ & 44 & 30.7 & $10 \cdot 4$ & & Personal interview 72-h R & DR estimated (1/3) & No & $\begin{array}{l}\text { Vitamin C } \\
\text { Vitamin E }\end{array}$ & $\begin{array}{l}0.54 \S \\
0.54 \S\end{array}$ & 3 \\
\hline Shai et al. $(1997)^{(102)}$ & 161 & 50 & 0.5 & & Personal interview 24-h R & Plasma vitamin E & Yes & Vitamin $E$ & $0.33 \|$ & 4.5 \\
\hline Smith et al. $(1996)^{(127)}$ & $\begin{array}{l}302 \mathrm{~W} \\
273 \mathrm{M}\end{array}$ & & & $18-74$ & Dietary history & 24-h R & No & $\begin{array}{l}\text { Vitamin A } \\
\text { Vitamin C }\end{array}$ & $\begin{array}{l}0.36 \mathrm{~W}+/ 0.32 \mathrm{M} \dagger \\
0.35 \mathrm{~W}+/ 0.36 \mathrm{M} \dagger\end{array}$ & 3 \\
\hline Takatsuka et al. (1997) ${ }^{(128)}$ & $\begin{array}{l}18 \mathrm{~W} \\
13 \mathrm{M}\end{array}$ & $\begin{array}{c}47 \cdot 6 \\
44.2\end{array}$ & $\begin{array}{l}10 \cdot 8 \\
9 \cdot 3\end{array}$ & & Dietary history & DR weighed (12/1) & No & $\begin{array}{l}\text { Vitamin A } \\
\text { Vitamin C } \\
\text { Vitamin D } \\
\text { Vitamin E }\end{array}$ & $\begin{array}{l}0.22 \ddagger \\
0.44 \ddagger \\
0.53 \ddagger \\
0.50 \ddagger\end{array}$ & 2 \\
\hline Van Liere et al. $(1997)^{(89)}$ & $115 \mathrm{~W}$ & & & $35-65$ & Dietary history & $\begin{array}{l}\text { Twelve personal } \\
\text { interview 24-h R }\end{array}$ & No & Vitamin C & $0.69 \|$ & 4 \\
\hline
\end{tabular}

No., number; Suppl., supplements; W, women; M, men; DR, dietary record; Bl, black; Wh, white*; (24-, 48-, 72-) h R, (24-, 48-, 72-) h recall. ${ }^{*}$ Multivariable-adjusted correlation coefficient.

†Crude, Spearman correlation coefficient.

$\ddagger$ Energy-adjusted, Pearson correlation coefficient.

$\S$ Intra-class correlation coefficient.

|| Energy-adjusted, deattenuated correlation coefficient.

I Energy-adjusted, Spearman correlation coefficient.

Crude, Pearson correlation coefficient. 


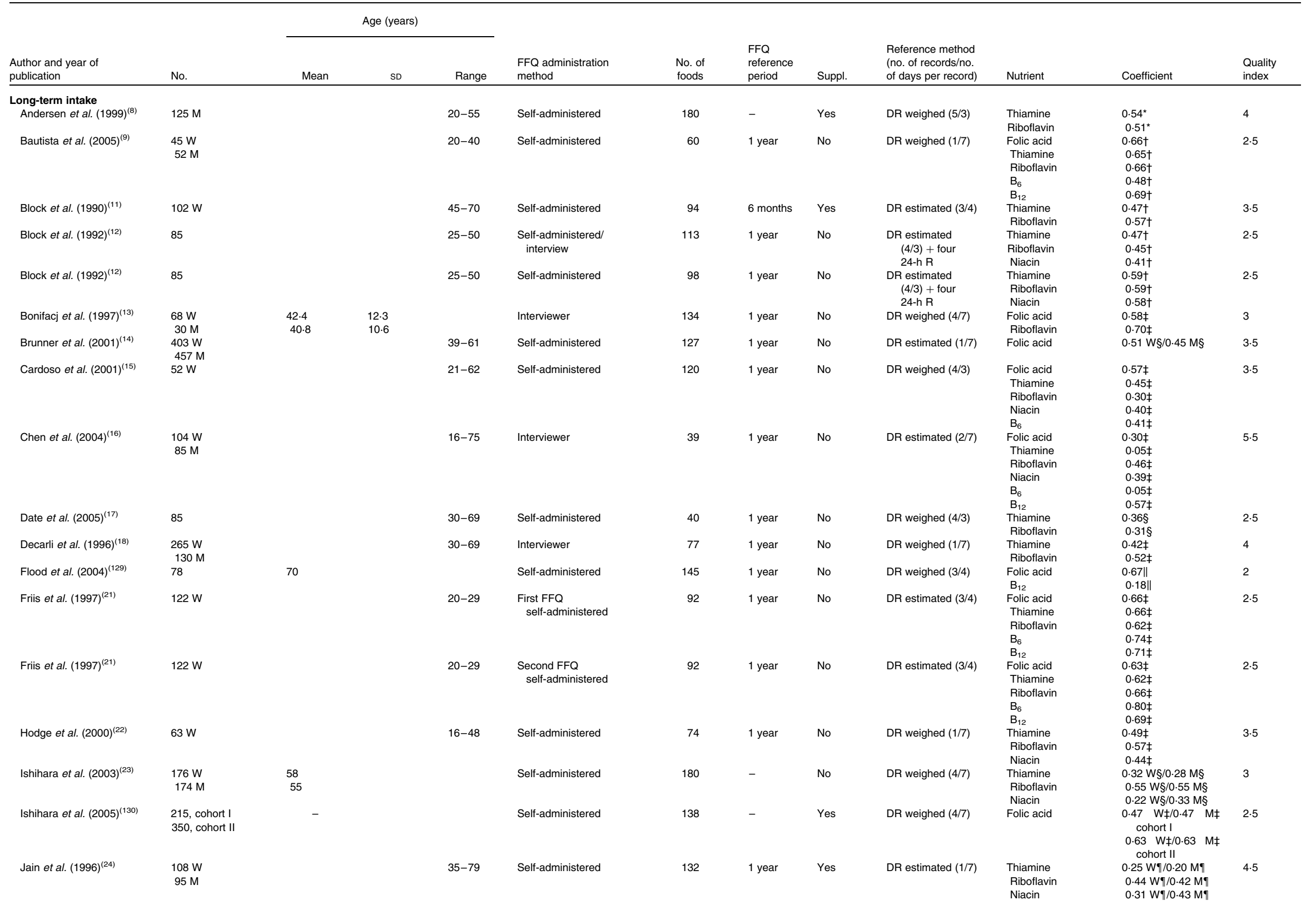


NS British Journal of Nutrition

Table 8. Continued

\begin{tabular}{|c|c|c|c|c|c|c|c|c|c|c|c|c|}
\hline \multirow[b]{2}{*}{$\begin{array}{l}\text { Author and year of } \\
\text { publication }\end{array}$} & \multirow[b]{2}{*}{ No. } & \multicolumn{3}{|c|}{ Age (years) } & \multirow[b]{2}{*}{$\begin{array}{l}\text { FFQ administration } \\
\text { method }\end{array}$} & \multirow[b]{2}{*}{$\begin{array}{l}\text { No. of } \\
\text { foods }\end{array}$} & \multirow{2}{*}{$\begin{array}{l}\mathrm{FFQ} \\
\text { reference } \\
\text { period }\end{array}$} & \multirow[b]{2}{*}{ Suppl. } & \multirow{2}{*}{$\begin{array}{l}\text { Reference method } \\
\text { (no. of records/no. } \\
\text { of days per record) }\end{array}$} & \multirow[b]{2}{*}{ Nutrient } & \multirow[b]{2}{*}{ Coefficient } & \multirow[b]{2}{*}{$\begin{array}{l}\text { Quality } \\
\text { index }\end{array}$} \\
\hline & & Mean & SD & Range & & & & & & & & \\
\hline $\begin{array}{l}\text { Jain \& McLaughlin } \\
(2000)^{(25)}\end{array}$ & $\begin{array}{c}108 \mathrm{~W} \\
95 \mathrm{M}\end{array}$ & & & $35-79$ & Self-administered & 132 & 1 year & Yes & DR estimated (1/7) & $\begin{array}{l}\text { Thiamine } \\
\text { Riboflavin } \\
\text { Niacin }\end{array}$ & $\begin{array}{c}0.41 \mathrm{~W}\|/ / 0.18 \mathrm{M}\| \\
0.57 \mathrm{~W}\|/ 0.36 \mathrm{M}\| \\
0.38 \mathrm{~W}\|/ 0.48 \mathrm{M}\|\end{array}$ & 5 \\
\hline Kelemen et al. $(2003)^{(26)}$ & $\begin{array}{l}58 \text { South Asians, A } \\
64 \text { Chinese, C, } \\
85 \text { European, E }\end{array}$ & & & $35-75$ & Self-administered & 163169157 & Unknown & Yes & DR estimated $(2 / 7)$ & $\begin{array}{l}\text { Folic acid } \\
\mathrm{B}_{6} \\
\mathrm{~B}_{12}\end{array}$ & $\begin{array}{c}0.54 \mathrm{~A} \ddagger / 0.54 \mathrm{C} \ddagger / \\
0.55 \mathrm{E \ddagger} \\
0.70 \mathrm{~A} \ddagger / 0.70 \mathrm{C} \ddagger / \\
0.59 \mathrm{E \ddagger} \\
0.70 \mathrm{~A} \ddagger / 0.67 \mathrm{C} \ddagger /\end{array}$ & 3.5 \\
\hline Kim et al. (2002) $)^{(27)}$ & $\begin{array}{l}46 \mathrm{~W} \\
23 \mathrm{M}\end{array}$ & 38.16 & 11.7 & & Self-administered & 118 & Unknown & No & DR weighed (1/7) & $\begin{array}{l}\text { Folic acid } \\
\text { Thiamine } \\
\text { Riboflavin } \\
\text { Niacin } \\
\text { B }_{6}\end{array}$ & $\begin{array}{l}0.66 \mathrm{E \ddagger} \\
0.68 \ddagger \\
0.48 \ddagger \\
0.60 \ddagger \\
0.68 \ddagger \\
0.68 \ddagger\end{array}$ & 3 \\
\hline Lee et al. (2006) & $\begin{array}{r}25 \mathrm{~W} \\
58 \mathrm{M}\end{array}$ & - & & & First FFQ interviewer & 64 & 6 months & Yes & DR estimated (3/5) & $\begin{array}{l}\text { Folic acid } \\
\text { Thiamine } \\
\text { Riboflavin } \\
\text { Niacin } \\
\mathrm{B}_{6}\end{array}$ & $\begin{array}{l}0.62 \ddagger \\
0.41 \ddagger \\
0.53 \ddagger \\
0.45 \ddagger \\
0.34 \ddagger \\
0.20 \ddagger\end{array}$ & 5 \\
\hline Lee et al. (2006) & $\begin{array}{r}25 \mathrm{~W} \\
58 \mathrm{M}\end{array}$ & - & & & $\begin{array}{l}\text { Second FFQ Inter- } \\
\text { viewer }\end{array}$ & 64 & 6 months & Yes & DR estimated (3/5) & $\begin{array}{l}\text { Folic acid } \\
\text { Thiamine } \\
\text { Riboflavin } \\
\text { Niacin } \\
\mathrm{B}_{6} \\
\mathrm{~B}_{12}\end{array}$ & $\begin{array}{l}043 \ddagger \\
0.70 \ddagger \\
0.86 \ddagger \\
0.76 \ddagger \\
0.26 \ddagger \\
0.30 \ddagger\end{array}$ & 5 \\
\hline $\begin{array}{l}\text { Männistö et al. } \\
(1996)^{(31)}\end{array}$ & $152 \mathrm{~W}$ & 51 & 9 & & Self-administered & 110 & 1 year & Yes & DR estimated (2/7) & $\begin{array}{l}\text { Thiamine } \\
\text { Riboflavin } \\
\text { Niacin }\end{array}$ & $\begin{array}{l}0.24 \ddagger \\
0.45 \ddagger \\
0.61 \ddagger\end{array}$ & 4 \\
\hline Marks et al. $(2006)^{(32)}$ & $\begin{array}{l}59 \mathrm{~W} \\
37 \mathrm{M}\end{array}$ & & & $25-75$ & Self-administered & 129 & 6 months & Yes & DR weighed (6/2) & $\begin{array}{l}\text { Thiamine } \\
\text { Riboflavin } \\
\text { Niacin }\end{array}$ & 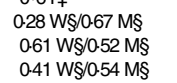 & 5 \\
\hline Nagata et al. $(1998)^{(36)}$ & 37 & & & $35-66$ & Self-administered & 169 & 1 year & No & DR estimated (12/1) & $\begin{array}{l}\text { Thiamine } \\
\text { Riboflavin }\end{array}$ & 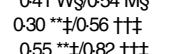 & 2 \\
\hline Ogawa et al. (2003) & $\begin{array}{l}58 \mathrm{~W} \\
55 \mathrm{M}\end{array}$ & & & $45-77$ & Self-administered & 40 & 1 year & Yes & DR estimated (4/3) & $\begin{array}{l}\text { Thiamine } \\
\text { Riboflavin } \\
\text { Niacin }\end{array}$ & $\begin{array}{l}0.31 \mathrm{~W} \neq 10.33 \mathrm{M} \neq \\
0.54 \mathrm{~W} \neq(0.43 \mathrm{M} \neq \\
0.47 \mathrm{~W} \neq 0.33 \mathrm{M} \neq\end{array}$ & 4.5 \\
\hline $\begin{array}{l}\text { Patterson et al. } \\
\qquad(1999)^{(38)}\end{array}$ & $113 \mathrm{~W}$ & & & $50-79$ & Self-administered & 122 & 3 months & Yes & $\begin{array}{l}\text { DR estimated } \\
\text { (1/4) + four } \\
24 \text {-h (phone) R }\end{array}$ & $\begin{array}{l}\text { Folic acid } \\
\text { Thiamine } \\
\text { Riboflavin } \\
\text { Niacin } \\
\mathrm{B}_{6} \\
\mathrm{~B}_{12}\end{array}$ & $\begin{array}{l}0.69 \ddagger \\
0.21 \ddagger \\
0.29 \ddagger \\
0.45 \ddagger \\
0.43 \ddagger \\
0.28 \ddagger\end{array}$ & 4 \\
\hline $\begin{array}{l}\text { Potischman et al. } \\
\quad(1999)^{(41)}\end{array}$ & $219 \mathrm{~W}$ & & & $20-54$ & Self-administered & $\begin{array}{r}60 \\
100\end{array}$ & 1 year & No & $\begin{array}{l}\text { DR estimated } \\
\text { (2/3)+ six 24-h } \\
\text { (phone) R }\end{array}$ & Folic acid & $\begin{array}{l}0.33(60 \text { items }) \ddagger \\
0.36(100 \text { items }) \ddagger\end{array}$ & 3 \\
\hline Potosky et al. $(1990)^{(42)}$ & $97 \mathrm{~W}$ & & & $45-70$ & Self-administered & 94 & 6 months & No & DR estimated (3/4) & $\begin{array}{l}\text { Thiamine } \\
\text { Riboflavin }\end{array}$ & $\begin{array}{l}0.62 \dagger \\
0.69 \dagger\end{array}$ & 1.5 \\
\hline Riboli et al. $(1997)^{(43)}$ & $\begin{array}{r}105 \mathrm{~W} \\
101 \mathrm{M}\end{array}$ & & & $50-69$ & Self-administered & 350 & 1 year & No & DR weighed (6/3) & Folic acid & $0.69 \mathrm{~W}\|/ 0.53 \mathrm{M}\|$ & 2.5 \\
\hline Riboli et al. $(1997)^{(43)}$ & $\begin{array}{l}105 \mathrm{~W} \\
101 \mathrm{M}\end{array}$ & & & $50-69$ & Self-administered & 130 & 1 year & No & DR weighed (6/3) & Folic acid & $0.71 \mathrm{~W}\|/ 0.42 \mathrm{M}\|$ & 2.5 \\
\hline Rimm et al. (1992)(44) & $127 \mathrm{M}$ & & & $40-75$ & $\begin{array}{l}\text { First FFQ self-adminis- } \\
\text { tered }\end{array}$ & 131 & 1 year & Yes & DR weighed (2/7) & $\begin{array}{l}\text { Folic acid } \\
\text { Thiamine } \\
\text { Riboflavin } \\
\mathrm{B}_{6} \\
\mathrm{~B}_{12}\end{array}$ & $\begin{array}{l}0.52 \ddagger \\
0.69 \ddagger \\
0.70 \ddagger \\
0.81 \ddagger \\
0.41 \ddagger\end{array}$ & 4 \\
\hline Rimm et al. $(1992)^{(44)}$ & $127 \mathrm{M}$ & & & $40-75$ & $\begin{array}{l}\text { Second FFQ Self-admi- } \\
\text { nistered }\end{array}$ & 131 & 1 year & Yes & DR weighed (2/7) & $\begin{array}{l}\text { Folic acid } \\
\text { Thiamine } \\
\text { Riboflavin } \\
\mathrm{B}_{6} \\
\mathrm{~B}_{12}\end{array}$ & $\begin{array}{l}0.77 \ddagger \\
0.86 \ddagger \\
0.88 \ddagger \\
0.85 \ddagger \\
0.56 \ddagger\end{array}$ & 4 \\
\hline
\end{tabular}


NS British Journal of Nutrition

Table 8. Continued

\begin{tabular}{|c|c|c|c|c|c|c|c|c|c|c|c|c|}
\hline \multirow[b]{2}{*}{$\begin{array}{l}\text { Author and year of } \\
\text { publication }\end{array}$} & \multirow[b]{2}{*}{ No. } & \multicolumn{3}{|c|}{ Age (years) } & \multirow[b]{2}{*}{$\begin{array}{l}\text { FFQ administration } \\
\text { method }\end{array}$} & \multirow[b]{2}{*}{$\begin{array}{l}\text { No. of } \\
\text { foods }\end{array}$} & \multirow{2}{*}{$\begin{array}{l}\mathrm{FFQ} \\
\text { reference } \\
\text { period }\end{array}$} & \multirow[b]{2}{*}{ Suppl. } & \multirow{2}{*}{$\begin{array}{l}\text { Reference method } \\
\text { (no. of records/no. } \\
\text { of days per record) }\end{array}$} & \multirow[b]{2}{*}{ Nutrient } & \multirow[b]{2}{*}{ Coefficient } & \multirow[b]{2}{*}{$\begin{array}{l}\text { Quality } \\
\text { index }\end{array}$} \\
\hline & & Mean & SD & Range & & & & & & & & \\
\hline Roddam et al. $(2005)^{(45)}$ & $202 \mathrm{~W}$ & & & $50-64$ & Self-administered & 18 groups & 1 week & No & DR weighed $(1 / 7)$ & $\begin{array}{l}\text { Thiamine } \\
\text { Riboflavin } \\
\text { Niacin } \\
\mathrm{B}_{6} \\
\mathrm{~B}_{12}\end{array}$ & $\begin{array}{c}0.36 \| \\
0.58 \| \\
0.40 \| \\
0.43 \| \\
0.24 \|\end{array}$ & 3 \\
\hline Tsubono et al. $(2001)^{(49)}$ & $\begin{array}{l}58 \mathrm{~W} \\
55 \mathrm{M}\end{array}$ & $\begin{array}{l}61 \\
62\end{array}$ & $\begin{array}{c}8.5 \\
8.5\end{array}$ & & $\begin{array}{l}\text { First FFQ self-adminis- } \\
\text { tered }\end{array}$ & 141 & 1 year & Yes & DR estimated (4/3) & $\begin{array}{l}\text { Thiamine } \\
\text { Riboflavin } \\
\text { Niacin }\end{array}$ & $\begin{array}{l}0.24 \neq \\
0.52 \ddagger \\
0.37 \ddagger\end{array}$ & 4 \\
\hline Tsubono et al. $(2001)^{(49)}$ & $\begin{array}{l}58 \mathrm{~W} \\
55 \mathrm{M}\end{array}$ & $\begin{array}{l}61 \\
62\end{array}$ & $\begin{array}{c}8.5 \\
8.5\end{array}$ & & $\begin{array}{l}\text { Second FFQ self-admi- } \\
\text { nistered }\end{array}$ & 141 & 1 year & Yes & DR estimated (4/3) & $\begin{array}{l}\text { Thiamine } \\
\text { Riboflavin } \\
\text { Niacin }\end{array}$ & $\begin{array}{l}0.37 \neq \\
0.40 \neq \\
0.49 \neq\end{array}$ & 4 \\
\hline Tsubono et al. $(2001)^{(50)}$ & $\begin{array}{c}107 \mathrm{~W} \\
94 \mathrm{M}\end{array}$ & & & $40-59$ & $\begin{array}{l}\text { First FFQ self-adminis- } \\
\text { tered }\end{array}$ & 44 & 1 month & Yes & DR estimated (4/7) & $\begin{array}{l}\text { Thiamine } \\
\text { Riboflavin } \\
\text { Niacin }\end{array}$ & $\begin{array}{l}0.26 \mathrm{~W} \neq / 0.29 \mathrm{M} \neq \\
0.42 \mathrm{~W} \neq / / .32 \mathrm{M} \neq \\
0.12 \mathrm{~W} \neq(0.23 \mathrm{Mt}\end{array}$ & 4 \\
\hline Tsubono et al. (2001) & $\begin{array}{c}107 \mathrm{~W} \\
94 \mathrm{M}\end{array}$ & & & $40-59$ & $\begin{array}{l}\text { Second FFQ self-admi- } \\
\text { nistered }\end{array}$ & 44 & 1 month & Yes & DR estimated (4/7) & $\begin{array}{l}\text { Thiacinine } \\
\text { Riboflavin } \\
\text { Niacin }\end{array}$ & $\begin{array}{l}0.24 \mathrm{~W} \neq / 0.41 \mathrm{M} \neq \\
0.41 \mathrm{~W} \neq / / .45 \mathrm{M} \neq \\
0.12 \mathrm{~W} \neq / 0.15 \mathrm{M} \neq\end{array}$ & 4 \\
\hline Tsugane et al. (2003) $)^{(51)}$ & $\begin{array}{r}113 \mathrm{~W} \\
102 \mathrm{M}\end{array}$ & $\begin{array}{l}53.5 \\
53.6\end{array}$ & $\begin{array}{c}5 \cdot 3 \\
5 \cdot 2\end{array}$ & & Self-administered & 138 & 1 year & Yes & $\begin{array}{l}\text { DR estimated ( } 4 / 7 \\
\text { or } 2 / 7)\end{array}$ & $\begin{array}{l}\text { Thiamine } \\
\text { Riboflavin } \\
\text { Niacin }\end{array}$ & $\begin{array}{l}0.44 \mathrm{~W} / 0.41 \mathrm{M} \S \\
0.46 \mathrm{~W} / 0.43 \mathrm{MS} \\
0.18 \mathrm{~W} / 0.35 \mathrm{M} \S\end{array}$ & 4.5 \\
\hline Willett et al. $(1985)^{(52)}$ & $173 \mathrm{~W}$ & & & $34-59$ & $\begin{array}{l}\text { First FFQ self-adminis- } \\
\text { tered }\end{array}$ & 61 & 1 year & Yes & DR weighed (4/7) & $\mathrm{B}_{6}$ & $0.47 \|$ & 4 \\
\hline Willett et al. $(1985)^{(52)}$ & $173 \mathrm{~W}$ & & & $34-59$ & $\begin{array}{l}\text { Second FFQ self-admi- } \\
\text { nistered }\end{array}$ & 61 & 1 year & Yes & DR weighed (4/7) & $\mathrm{B}_{6}$ & $0.58 \|$ & 4 \\
\hline Willett et al. (1987)(53) & 29 & & & $20-54$ & Self-administered & 116 & 1 year & Yes & DR weighed (1/365) & $\begin{array}{l}\text { Thiamine } \\
\text { Riboflavin } \\
\text { Niacin }\end{array}$ & $\begin{array}{c}0.42 \neq \ddagger \\
0.31 \neq \ddagger \\
0.37 \neq \ddagger\end{array}$ & 1.5 \\
\hline \multicolumn{13}{|l|}{ Short-term intake } \\
\hline $\begin{array}{l}\text { Bacardí-Gascón et al. } \\
(2003)^{(131)}\end{array}$ & $34 \mathrm{~W}$ & & & $18-35$ & Self-administered & 31 & 1 year & No & DR weighed (1/5) & Folic acid & $0.71^{\star}$ & 0.5 \\
\hline $\begin{array}{l}\text { Baumgartner et al. } \\
(1998)^{(54)}\end{array}$ & $132 \mathrm{~W}$ & & & $35-74$ & Interviewer & 140 & 1 month & No & DR estimated (1/4) & Folic acid & $0.41 \|$ & 3.5 \\
\hline $\begin{array}{l}\text { Fregapane \& Asensio } \\
(2000)^{(55)}\end{array}$ & 38 & & & $18-61$ & Self-administered & 202 & Unknown & No & DR weighed (1/4) & $\begin{array}{l}\text { Folic acid } \\
\text { Thiamine } \\
\text { Riboflavin } \\
\text { Niacin } \\
\mathrm{B}_{6} \\
\mathrm{~B}_{12}\end{array}$ & $\begin{array}{l}0.28 \pi \\
0.28 \pi \\
0.84 \pi \\
0.46 \pi \\
0.27 \pi \\
0.38 \pi\end{array}$ & 1.5 \\
\hline French et al. (2001) $)^{(132)}$ & $20 \mathrm{~W}$ & & & $18-45$ & Interviewer & 140 & 6 months & No & DR estimated (1/3) & Folic acid & $0.36+$ & 1 \\
\hline French et al. (2001) ${ }^{(132)}$ & $17 \mathrm{~W}$ & & & $18-45$ & Interviewer & 81 & 6 months & No & DR estimated (1/7) & Folic acid & $0.51 \dagger$ & 1 \\
\hline George et al. (2004) & $95 \mathrm{~W}$ & 20.1 & $4 \cdot 3$ & & Self-administered & 195 & $\begin{array}{l}6 \text { months } \\
\text {. }\end{array}$ & No & DR estimated (1/3) & $\begin{array}{l}\text { Folic acid } \\
\text { Thiamine } \\
\text { Riboflavin } \\
\text { Niacin } \\
B_{5}\end{array}$ & $\begin{array}{l}0.38 \ddagger \\
0.34 \ddagger \\
0.40 \ddagger \\
0.35 \ddagger \\
0.34 \ddagger\end{array}$ & 3.5 \\
\hline George et al. (2004) ${ }^{(56)}$ & $50 \mathrm{~W}$ & 23.1 & 4.3 & & Self-administered & 195 & 6 months & No & $\begin{array}{l}\text { DR estimated } \\
\text { (1/4)+ two 24-h } \\
\text { (interview) R }\end{array}$ & $\begin{array}{l}\text { P5 } \\
\text { Folic acid } \\
\text { Thiamine } \\
\text { Riboflavin } \\
\text { Niacin }\end{array}$ & $\begin{array}{l}0.04+ \\
0.41 \neq \\
0.42 \ddagger \\
0.48 \ddagger \\
0.40 \ddagger \\
0.37 \ddagger\end{array}$ & 3.5 \\
\hline Goulet et al. $(2004)^{(57)}$ & $71 \mathrm{~W}$ & & & $30-65$ & Interviewer & 91 & 1 month & No & DR estimated (1/3) & $\begin{array}{l}B_{5} \\
\text { Folic acid }\end{array}$ & $\begin{array}{l}0.37 \ddagger \\
0.39 \S\end{array}$ & 1 \\
\hline $\begin{array}{l}\text { Hartwell \& Henry } \\
(2001)^{(58)}\end{array}$ & $\begin{array}{l}9 \mathrm{~W} \\
16 \mathrm{M}\end{array}$ & 58.1 & 1.7 & & Self-administered & 162 & 1 year & No & DR estimated (1/4) & Thiamine & $0.57 \dagger$ & 1.5 \\
\hline Ke et al. $(2005)^{(59)}$ & 100 & - & & & Self-administered & 125 & 1 year & No & DR weighed (1/4) & Folic acid & $0.43 \|$ & 3 \\
\hline $\begin{array}{l}\text { Kumanyika et al. } \\
(2003)^{(61)}\end{array}$ & $408 \mathrm{~W}$ & & & $21-69$ & Self-administered & 68 & 1 year & No & $\begin{array}{l}\text { DR estimated } \\
\text { (1/3)+ three 24- } \\
\text { h (phone) } R\end{array}$ & Folic acid & $0.64 \ddagger$ & 2.5 \\
\hline $\begin{array}{l}\text { Longnecker et al. } \\
(1993)^{(62)}\end{array}$ & $\begin{array}{l}74 \mathrm{~W} \\
64 \mathrm{M}\end{array}$ & 49 & 14 & & $\begin{array}{l}\text { First FFQ self-adminis- } \\
\text { tered }\end{array}$ & 116 & 1 year & No & DR estimated (3/2) & $\begin{array}{l}\text { Folic acid } \\
\text { Thiamine } \\
\text { Riboflavin } \\
\text { Niacin } \\
\mathrm{B}_{6} \\
\mathrm{~B}_{12}\end{array}$ & $\begin{array}{l}0.42 \ddagger \\
0.50 \ddagger \\
0.63 \ddagger \\
0.29 \ddagger \\
0.43 \ddagger \\
0.72 \ddagger\end{array}$ & 2.5 \\
\hline
\end{tabular}




\begin{tabular}{|c|c|c|c|c|c|c|c|c|c|c|c|c|}
\hline \multirow{2}{*}{$\begin{array}{l}\text { Author and year of } \\
\text { publication }\end{array}$} & \multirow[b]{2}{*}{ No. } & \multicolumn{3}{|c|}{ Age (years) } & \multirow{2}{*}{$\begin{array}{l}\text { FFQ administration } \\
\text { method }\end{array}$} & \multirow{2}{*}{$\begin{array}{l}\text { No. of } \\
\text { foods }\end{array}$} & \multirow{2}{*}{$\begin{array}{l}\mathrm{FFQ} \\
\text { reference } \\
\text { period }\end{array}$} & \multirow[b]{2}{*}{ Suppl. } & \multirow{2}{*}{$\begin{array}{l}\text { Reference method } \\
\text { (no. of records/no. } \\
\text { of days per record) }\end{array}$} & \multirow[b]{2}{*}{ Nutrient } & \multirow[b]{2}{*}{ Coefficient } & \multirow{2}{*}{$\begin{array}{l}\text { Quality } \\
\text { index }\end{array}$} \\
\hline & & Mean & SD & Range & & & & & & & & \\
\hline $\begin{array}{l}\text { Longnecker et al. } \\
(1993)^{(62)}\end{array}$ & $\begin{array}{l}74 \mathrm{~W} \\
64 \mathrm{M}\end{array}$ & 49 & 14 & & $\begin{array}{l}\text { Second FFQ self-admi- } \\
\text { nistered }\end{array}$ & 116 & 1 year & No & DR estimated (3/2) & $\begin{array}{l}\text { Folic acid } \\
\text { Thiamine } \\
\text { Riboflavin } \\
\text { Niacin } \\
\mathrm{B}_{6}\end{array}$ & $\begin{array}{l}0.45 \ddagger \\
0.52 \ddagger \\
0.57 \ddagger \\
0.28 \ddagger \\
0.49 \ddagger \\
0.78 \ddagger\end{array}$ & 2.5 \\
\hline Martínez et al. (1999) & $\begin{array}{l}42 \mathrm{~W} \\
97 \mathrm{M}\end{array}$ & $66 \cdot 4$ & & & Self-administered & 132 & 1 year & Yes & DR weighed $(1 / 4)$ & $\begin{array}{l}\text { Folic acid } \\
\text { Thiamine } \\
\text { Riboflavin } \\
\text { Niacin }\end{array}$ & $\begin{array}{l}0.53 \ddagger \\
0.56 \ddagger \\
0.66 \ddagger \\
0.63 \ddagger\end{array}$ & 4 \\
\hline Masson et al. (2003) ${ }^{(64)}$ & $\begin{array}{l}40 \mathrm{~W} \\
41 \mathrm{M}\end{array}$ & & & $19-58$ & Self-administered & 150 & $\begin{array}{l}2-3 \\
\text { months }\end{array}$ & No & DR weighed $(1 / 4)$ & $\begin{array}{l}\text { Folic acid } \\
\text { Thiamine } \\
\text { Riboflavin } \\
\text { Niacin } \\
\mathrm{B}_{6} \\
\mathrm{~B}_{12}\end{array}$ & $\begin{array}{c}0.78 \mathrm{~W}\|/ / 0.56 \mathrm{M}\| \\
0.84 \mathrm{~W}\|/ / .83 \mathrm{M}\| \\
0.82 \mathrm{~W}\|/ 0.72 \mathrm{M}\| \\
0.57 \mathrm{~W}\|/ 0.51 \mathrm{M}\| \\
0.55 \mathrm{~W}\|/ 0.40 \mathrm{M}\| \\
0.39 \mathrm{~W}\|/ 0.24 \mathrm{M}\|\end{array}$ & 2.5 \\
\hline Moreira et al. $(2003)^{(65)}$ & $\begin{array}{c}159 \mathrm{~W} \\
87 \mathrm{M}\end{array}$ & & & $18-29$ & Interviewer & 82 & Unknown & No & DR estimated (1/4) & $\begin{array}{l}\text { Folic acid } \\
\text { Thiamine } \\
\text { Riboflavin } \\
\mathrm{B}_{6} \\
\mathrm{~B}_{12}\end{array}$ & $\begin{array}{c}0.53 \mathrm{~W}\|/ 0.38 \mathrm{M}\| \\
0.40 \mathrm{~W}\|/ 0.40 \mathrm{M}\| \\
0.71 \mathrm{~W}\|/ 0.59 \mathrm{M}\| \\
0.62 \mathrm{~W}\|/ 0.55 \mathrm{M}\| \\
0.26 \mathrm{~W}\|/ 0.30 \mathrm{M}\|\end{array}$ & 3 \\
\hline Paalanen et al. $(2006)^{(66)}$ & $\begin{array}{l}157 \mathrm{~W} \\
137 \mathrm{M}\end{array}$ & & & $30-79$ & Self-administered & 128 & 1 year & No & DR estimated (1/3) & $\begin{array}{l}\text { Folic acid } \\
\text { Thiamine } \\
\text { Riboflavin }\end{array}$ & $\begin{array}{l}0.46 \mathrm{~W}\|/ / 0.41 \mathrm{M}\| \\
0.49 \mathrm{~W}\|/ 0.26 \mathrm{M}\| \\
0.65 \mathrm{~W}\|/ 0.63 \mathrm{M}\|\end{array}$ & 3.5 \\
\hline Parr et al. (2002) ${ }^{(67)}$ & $\begin{array}{l}34 \mathrm{~W} \\
36 \mathrm{M}\end{array}$ & & & $15-45$ & Interviewer & 164 & 1 week & No & DR weighed (1/2) & $\begin{array}{l}\text { Thiamine } \\
\text { Riboflavin } \\
\text { Niacin }\end{array}$ & $\begin{array}{l}0.53^{*} \\
0.30^{*} \\
0.43^{*}\end{array}$ & 4 \\
\hline Sasaki et al. $(1998)^{(68)}$ & $47 \mathrm{~W}$ & & & $38-69$ & Self-administered & 110 & 1 month & No & DR estimated (1/3) & $\begin{array}{l}\text { Thiamine } \\
\text { Riboflavin } \\
\text { Niacin }\end{array}$ & $\begin{array}{l}0.46 \neq \\
0.58 \ddagger \\
0.19 \neq\end{array}$ & 3 \\
\hline Schröder et al. $(2001)^{(70)}$ & 44 & 30.7 & 10.4 & & Self-administered & 157 & Unknown & No & DR weighed $(1 / 3)$ & $\begin{array}{l}\text { Folic acid } \\
\text { Niacin } \\
\mathrm{B}_{6}\end{array}$ & $\begin{array}{l}0.21 \pi \\
0.23 \pi \\
0.48 \pi\end{array}$ & 3 \\
\hline Tokudome et al. $(2005)^{(71)}$ & $\begin{array}{l}129 \mathrm{~W} \\
73 \mathrm{M}\end{array}$ & & & $30-70$ & Self-administered & 47 & 1 year & No & DR estimated (1/3) & $\begin{array}{l}\text { Folic acid } \\
\text { Thiamine } \\
\text { Riboflavin }\end{array}$ & $\begin{array}{l}0.38 \mathrm{~W} \neq / 0.36 \mathrm{M} \neq \\
0.10 \mathrm{~W} \neq / / 2.26 \mathrm{M} \neq \\
0.43 \mathrm{~W} \neq / 0.57 \mathrm{M \ddagger}\end{array}$ & 3.5 \\
\hline Torheim et al. (2001) & $\begin{array}{l}48 \mathrm{~W} \\
27 \mathrm{M}\end{array}$ & & & $15-59$ & Self-administered & 69 & 1 week & No & $\begin{array}{l}\text { DR weighed/esti- } \\
\text { mated (1/2) }\end{array}$ & $\begin{array}{l}\text { Thiamine } \\
\text { Riboflavin } \\
\text { Niacin }\end{array}$ & $\begin{array}{l}0.40^{*} \\
0.46^{*} \\
0.38^{*}\end{array}$ & 2 \\
\hline
\end{tabular}

No., number; Suppl., supplements; M, men; DR, dietary record; W, women; 24-h R, 24-h recall.

Crude, Spearman correlation coefficient.

† Crude, Pearson correlation coefficient.

$\mp$ Energy-adjusted, deattenuated correlation coefficient.

$\S$ Energy-adjusted, Spearman correlation coefficient.

Energy-adjusted, Pearson correlation coefficient.

TIntra-class correlation coefficient.

$¥ \ddagger$ Age, sex and energy-adjusted, Pearson correlation coefficient.

t†High-food diversity. 


\begin{tabular}{|c|c|c|c|c|c|c|c|c|c|c|c|c|c|c|}
\hline \multirow{2}{*}{$\begin{array}{l}\text { Author and } \\
\text { year } \\
\text { of publication }\end{array}$} & \multirow[b]{2}{*}{ No. } & \multicolumn{3}{|c|}{ Age (years) } & \multirow{2}{*}{$\begin{array}{l}\mathrm{FFQ} \\
\text { administration } \\
\text { method }\end{array}$} & \multirow[b]{2}{*}{$\begin{array}{l}\text { No. of } \\
\text { foods }\end{array}$} & \multirow{2}{*}{$\begin{array}{l}\mathrm{FFQ} \\
\text { reference } \\
\text { period }\end{array}$} & \multirow[b]{2}{*}{ Suppl. } & \multirow[b]{2}{*}{$\begin{array}{l}\text { No. of } \\
\text { recalls }\end{array}$} & \multirow{2}{*}{$\begin{array}{l}\text { Recall } \\
\text { administration } \\
\text { method }\end{array}$} & \multirow[b]{2}{*}{$\begin{array}{l}\text { Weekend } \\
\text { included }\end{array}$} & \multirow[b]{2}{*}{ Nutrient } & \multirow[b]{2}{*}{ Coefficient } & \multirow[b]{2}{*}{$\begin{array}{l}\text { Quality } \\
\text { index }\end{array}$} \\
\hline & & Mean & sd & Range & & & & & & & & & & \\
\hline \multicolumn{15}{|l|}{ Long-term intake } \\
\hline $\begin{array}{l}\text { Fraser et al. } \\
\qquad(2005)^{(73)}\end{array}$ & 315 & - & & & Self-administered & 202 & - & No & $\begin{array}{l}\text { Eight, within } \\
6 \text { months }\end{array}$ & Phone interview & Yes & Folic acid & $0.65^{*}$ & 2.5 \\
\hline $\begin{array}{l}\text { Hebert et al. } \\
\qquad(1998)^{(75)}\end{array}$ & $\begin{array}{l}30 \mathrm{~W} \\
30 \mathrm{M}\end{array}$ & $\begin{array}{l}43 \cdot 2 \\
52 \cdot 6\end{array}$ & $\begin{array}{c}13.6 \\
10.9\end{array}$ & & $\begin{array}{l}\text { First FFQ inter- } \\
\text { viewer }\end{array}$ & 81 & 1 year & No & $\begin{array}{l}\text { Eight, within } \\
1 \text { year }\end{array}$ & Personal interview & Yes & $\begin{array}{l}\text { Thiamine } \\
\text { Riboflavin }\end{array}$ & $\begin{array}{l}0.52 \dagger \\
0.61 \dagger\end{array}$ & 2.5 \\
\hline $\begin{array}{l}\text { Hebert et al. } \\
\qquad(1998)^{(75)}\end{array}$ & $\begin{array}{l}30 \mathrm{~W} \\
30 \mathrm{M}\end{array}$ & $\begin{array}{l}43 \cdot 2 \\
52 \cdot 6\end{array}$ & $\begin{array}{l}13 \cdot 6 \\
10 \cdot 9\end{array}$ & & $\begin{array}{l}\text { Second FFQ inter- } \\
\text { viewer }\end{array}$ & 81 & 1 year & No & $\begin{array}{l}\text { Eight, within } \\
1 \text { year }\end{array}$ & Personal interview & Yes & $\begin{array}{l}\text { Thiamine } \\
\text { Riboflavin }\end{array}$ & $\begin{array}{l}0.55 \dagger \\
0.61 \dagger\end{array}$ & 2.5 \\
\hline $\begin{array}{l}\text { Hernández-Ávila } \\
\text { et al. }(1998)^{(76)}\end{array}$ & $134 \mathrm{~W}$ & - & & & $\begin{array}{l}\text { First FFQ self- } \\
\text { administered }\end{array}$ & 85 & - & No & $\begin{array}{l}\text { Sixteen, within } \\
1 \text { year }\end{array}$ & Personal interview & Yes & $\begin{array}{l}\text { Folic acid } \\
\text { Thiamine } \\
\text { Riboflavin } \\
\mathrm{B}_{6} \\
\mathrm{~B}_{12}\end{array}$ & $\begin{array}{l}0.15^{*} \\
0.43^{\star} \\
0.43^{\star} \\
0.31^{*} \\
0.23^{*}\end{array}$ & 3 \\
\hline $\begin{array}{l}\text { Hernández-Ávila } \\
\text { et al. }(1998)^{(76)}\end{array}$ & $134 \mathrm{~W}$ & - & & & $\begin{array}{l}\text { Second FFQ self- } \\
\text { administered }\end{array}$ & 85 & - & No & $\begin{array}{l}\text { Sixteen, within } \\
1 \text { year }\end{array}$ & Personal interview & Yes & $\begin{array}{l}\text { Folic acid } \\
\text { Thiamine } \\
\text { Riboflavin } \\
\mathrm{B}_{6} \\
\mathrm{~B}_{12}\end{array}$ & $\begin{array}{l}0.22^{\star} \\
0.32^{*} \\
0.51^{*} \\
0.31^{*} \\
0.29^{*}\end{array}$ & 3 \\
\hline $\begin{array}{l}\text { Kabagambe et al. } \\
(2001)^{(79)}\end{array}$ & $\begin{array}{l}42 \mathrm{~W} \\
78 \mathrm{M}\end{array}$ & 59 & 10 & & Interviewer & 135 & 1 year & No & $\begin{array}{l}\text { Seven, within } \\
7 \text { months }\end{array}$ & Personal interview & Yes & $\begin{array}{l}\text { Folic acid } \\
\mathrm{B}_{6} \\
\mathrm{~B}_{12}\end{array}$ & $\begin{array}{l}0.60^{*} \\
0.47^{*} \\
1.00^{*}\end{array}$ & 4 \\
\hline $\begin{array}{l}\text { Messerer et al. } \\
(2004)^{(83)}\end{array}$ & $248 \mathrm{M}$ & & & $40-74$ & Self-administered & 88 & 1 year & Yes & $\begin{array}{l}\text { Fourteen, } \\
\text { within } \\
1 \text { year }\end{array}$ & Phone interview & Yes & $\begin{array}{l}\text { Folic acid } \\
\mathrm{B}_{6}\end{array}$ & $\begin{array}{l}0.50^{*} \\
0.65^{*}\end{array}$ & 4.5 \\
\hline $\begin{array}{l}\text { Sevak et al. } \\
\qquad(1997)^{(87)}\end{array}$ & $100 \mathrm{~W}$ & 53.5 & 8.5 & & Interviewer & 207 & - & No & $\begin{array}{l}\text { Twelve, within } \\
1 \text { year }\end{array}$ & Phone interview & Yes & $\begin{array}{l}\text { Folic acid } \\
\mathrm{B}_{12}\end{array}$ & $\begin{array}{l}0.77^{\star} \\
0.57^{\star}\end{array}$ & 3.5 \\
\hline Shu et al. $(2004)^{(88)}$ & $191 \mathrm{~W}$ & $55 \cdot 4$ & 9 & & Interviewer & 77 & 1 year & No & $\begin{array}{l}\text { Twenty-four, } \\
\text { within } \\
1 \text { year }\end{array}$ & Personal interview & Yes & $\begin{array}{l}\text { Thiamine } \\
\text { Riboflavin } \\
\text { Niacin }\end{array}$ & $\begin{array}{l}0.59 \dagger \\
0.56 \dagger \\
0.58 \dagger\end{array}$ & 4 \\
\hline $\begin{array}{l}\text { Villegas et al. } \\
\qquad(2006)^{(90)}\end{array}$ & 195 & & & $40-70$ & Interviewer & 81 & 1 year & No & $\begin{array}{l}\text { Twelve, within } \\
1 \text { year }\end{array}$ & Personal interview & Yes & $\begin{array}{l}\text { Thiamine } \\
\text { Riboflavin } \\
\text { Niacin }\end{array}$ & $\begin{array}{l}0.58 \ddagger \\
0.46 \ddagger \\
0.52 \ddagger\end{array}$ & 4 \\
\hline $\begin{array}{l}\text { Short-term intake } \\
\text { Bacardí-Gascón } \\
\text { et al. }(2003)^{(131)}\end{array}$ & $70 \mathrm{~W}$ & & & $18-35$ & Self-administered & 31 & - & No & One & Personal interview & - & Folic acid & $0.37 \ddagger$ & 0.5 \\
\hline $\begin{array}{l}\text { Boucher et al. } \\
\text { (2006) }\end{array}$ & $96 \mathrm{~W}$ & & & $25-74$ & Self-administered & 109 & - & No & $\begin{array}{l}\text { Two, within } \\
18 \text { days }\end{array}$ & Phone interview & Yes & $\begin{array}{l}\text { Folic acid } \\
\text { Thiamine } \\
\text { Riboflavin } \\
\text { Niacin } \\
\mathrm{B}_{6} \\
\mathrm{~B}_{12}\end{array}$ & $\begin{array}{l}0.76^{*} \\
0.75^{*} \\
0.74^{*} \\
0.75^{*} \\
0.74^{*} \\
0.69^{*}\end{array}$ & 3 \\
\hline $\begin{array}{l}\text { Flagg et al. } \\
\qquad(2000)^{(93)}\end{array}$ & $\begin{array}{l}223 \mathrm{~W} \\
216 \mathrm{M}\end{array}$ & 61 & & & Self-administered & 68 & 1 year & Yes & $\begin{array}{l}\text { Four, within } \\
1 \text { year }\end{array}$ & Personal interview & Yes & Folic acid & $\begin{array}{l}0.43 \mathrm{~W}^{*} / \\
0.51 \mathrm{M}^{*}\end{array}$ & 4 \\
\hline $\begin{array}{l}\text { Hebert et al. } \\
\qquad(1999)^{(95)}\end{array}$ & $\begin{array}{l}30 \mathrm{~W} \\
30 \mathrm{M}\end{array}$ & $\begin{array}{l}36 \cdot 1 \\
31 \cdot 4\end{array}$ & $\begin{array}{l}9.7 \\
7 \cdot 7\end{array}$ & & $\begin{array}{l}\text { First FFQ inter- } \\
\text { viewer }\end{array}$ & 92 & 1 year & No & $\begin{array}{l}\text { Six, within } \\
1 \text { year }\end{array}$ & Personal interview & Yes & $\begin{array}{l}\text { Thiamine } \\
\text { Riboflavin }\end{array}$ & $\begin{array}{l}0.77 \dagger \\
0.99 \dagger\end{array}$ & 2.5 \\
\hline $\begin{array}{l}\text { Hebert et al. } \\
(1999)^{(95)}\end{array}$ & $\begin{array}{l}30 \mathrm{~W} \\
30 \mathrm{M}\end{array}$ & $\begin{array}{l}36 \cdot 1 \\
31.4\end{array}$ & $\begin{array}{l}9.7 \\
7.7\end{array}$ & & $\begin{array}{c}\text { Second FFQ } \\
\text { interviewer }\end{array}$ & 92 & 1 year & No & $\begin{array}{l}\text { Six, within } \\
1 \text { year }\end{array}$ & Personal interview & Yes & $\begin{array}{l}\text { Thiamine } \\
\text { Riboflavin }\end{array}$ & $\begin{array}{l}0.85^{*} \\
1.0^{*}\end{array}$ & 2.5 \\
\hline
\end{tabular}




\begin{tabular}{|c|c|c|c|c|c|c|c|c|c|c|c|c|c|c|}
\hline \multirow{2}{*}{$\begin{array}{l}\text { Author and } \\
\text { year } \\
\text { of publication }\end{array}$} & \multirow[b]{2}{*}{ No. } & \multicolumn{3}{|c|}{ Age (years) } & \multirow{2}{*}{$\begin{array}{l}\mathrm{FFQ} \\
\text { administration } \\
\text { method }\end{array}$} & \multirow[b]{2}{*}{$\begin{array}{l}\text { No. of } \\
\text { foods }\end{array}$} & \multirow{2}{*}{$\begin{array}{c}\mathrm{FFQ} \\
\text { reference } \\
\text { period }\end{array}$} & \multirow[b]{2}{*}{ Suppl. } & \multirow[b]{2}{*}{$\begin{array}{l}\text { No. of } \\
\text { recalls }\end{array}$} & \multirow{2}{*}{$\begin{array}{l}\text { Recall } \\
\text { administration } \\
\text { method }\end{array}$} & \multirow[b]{2}{*}{$\begin{array}{l}\text { Weekend } \\
\text { included }\end{array}$} & \multirow[b]{2}{*}{ Nutrient } & \multirow[b]{2}{*}{ Coefficient } & \multirow[b]{2}{*}{$\begin{array}{l}\text { Quality } \\
\text { index }\end{array}$} \\
\hline & & Mean & sd & Range & & & & & & & & & & \\
\hline $\begin{array}{l}\text { Kumanyika et al. } \\
(2003)^{(61)}\end{array}$ & $408 \mathrm{~W}$ & & & $21-69$ & Self-administered & 68 & - & Yes & $\begin{array}{l}\text { Three, within } \\
1 \text { year }\end{array}$ & Phone interview & Yes & Folic acid & $0.70^{*}$ & 2.5 \\
\hline $\begin{array}{l}\text { Kusama et al. } \\
\qquad(2005)^{(96)}\end{array}$ & $\begin{array}{l}62 \mathrm{~W} \\
56 \mathrm{M}\end{array}$ & & & $23-62$ & Interviewer & 116 & 3 months & No & $\begin{array}{l}\text { Three, within } \\
1 \text { month }\end{array}$ & Personal interview & Yes & $\begin{array}{l}\text { Thiamine } \\
\text { Riboflavin }\end{array}$ & $\begin{array}{l}0.38^{*} \\
0.29^{*}\end{array}$ & 4.5 \\
\hline $\begin{array}{l}\text { Navarro et al. } \\
\quad(2001)^{(98)}\end{array}$ & 62 & 57 & 14 & & $\begin{array}{l}\text { First FFQ } \\
\text { interviewer }\end{array}$ & 127 & 5 years & No & $\begin{array}{l}\text { Four, within } \\
3 \text { months }\end{array}$ & Personal interview & Yes & $\begin{array}{l}\text { Thiamine } \\
\text { Riboflavin } \\
\text { Niacin } \\
\mathrm{B}_{6}\end{array}$ & $\begin{array}{l}0.78^{*} \\
0.86^{*} \\
0.62^{*} \\
0.62^{\star}\end{array}$ & 4 \\
\hline $\begin{array}{l}\text { Navarro et al. } \\
(2001)^{(98)}\end{array}$ & 62 & 57 & 14 & & $\begin{array}{c}\text { Second FFQ } \\
\text { interviewer }\end{array}$ & 127 & 5 years & No & $\begin{array}{l}\text { Four, within } \\
3 \text { months }\end{array}$ & Personal interview & Yes & $\begin{array}{l}\text { Thiamine } \\
\text { Riboflavin } \\
\text { Niacin } \\
\mathrm{B}_{6}\end{array}$ & $\begin{array}{l}0.68^{\star} \\
0.82^{\star} \\
0.54^{\star} \\
0.57^{\star}\end{array}$ & 4 \\
\hline $\begin{array}{l}\text { Rodríguez et al. } \\
(2002)^{(100)}\end{array}$ & $\begin{array}{l}30 \mathrm{~W} \\
43 \mathrm{M}\end{array}$ & & & $22-55$ & Self-administered & 52 & 3 months & No & $\begin{array}{l}\text { Three, within } \\
1 \text { month }\end{array}$ & Personal interview & Yes & $\begin{array}{l}\text { Thiamine } \\
\text { Riboflavin } \\
\text { Niacin }\end{array}$ & $\begin{array}{l}0.26^{*} \\
0.49^{*} \\
1.00^{\star}\end{array}$ & 3 \\
\hline $\begin{array}{l}\text { Segovia et al. } \\
\qquad(2006)^{(101)}\end{array}$ & 87 & & & $30-72$ & Self-administered & 171 & 6 months & No & $\begin{array}{l}\text { Six, within } \\
6 \text { months }\end{array}$ & Phone interview & Yes & Folic acid & $0.39^{*}$ & 3 \\
\hline $\begin{array}{l}\text { Sudha et al. } \\
\qquad(2006)^{(104)}\end{array}$ & $\begin{array}{l}68 \mathrm{~W} \\
34 \mathrm{M}\end{array}$ & $40 \cdot 9$ & $12 \cdot 8$ & & $\begin{array}{l}\text { First FFQ } \\
\text { interviewer }\end{array}$ & 222 & 1 year & Yes & $\begin{array}{l}\text { Six, within } \\
1 \text { year }\end{array}$ & Personal interview & Yes & Folic acid & $0.29^{*}$ & 6 \\
\hline $\begin{array}{l}\text { Sudha et al. } \\
\qquad(2006)^{(104)}\end{array}$ & $\begin{array}{l}68 \mathrm{~W} \\
34 \mathrm{M}\end{array}$ & $40 \cdot 9$ & $12 \cdot 8$ & & $\begin{array}{l}\text { Second FFQ } \\
\text { interviewer }\end{array}$ & 222 & 1 year & Yes & $\begin{array}{l}\text { Six, within } \\
1 \text { year }\end{array}$ & Personal interview & Yes & Folic acid & $0.39^{*}$ & 6 \\
\hline $\begin{array}{l}\text { Verkleij-Hagoort } \\
\quad \text { et al. (2007) }\end{array}$ & $53 \mathrm{~W}$ & & & $24-44$ & Self-administered & 121 & 4 weeks & No & $\begin{array}{l}\text { Three, within } \\
3 \text { weeks }\end{array}$ & Phone interview & Yes & $\begin{array}{l}\text { Folic acid } \\
\mathrm{B}_{12}\end{array}$ & $\begin{array}{l}0.98^{*} \\
0.66^{*}\end{array}$ & 1.5 \\
\hline
\end{tabular}

No., number; Suppl., supplements; W, women; M, men.

*Energy-adjusted, deattenuated correlation coefficient.

† Crude, Pearson correlation coefficient.

¥Crude, Spearman correlation coefficient. 
Table 10. Description of validation studies regarding folic acid and B vitamin intake (FFQ vs. biomarkers)

\begin{tabular}{|c|c|c|c|c|c|c|c|c|c|c|c|}
\hline \multirow{2}{*}{$\begin{array}{l}\text { Author and year } \\
\text { of publication }\end{array}$} & \multirow[b]{2}{*}{ No. } & \multicolumn{3}{|c|}{ Age (years) } & \multirow{2}{*}{$\begin{array}{l}\text { FFQ administration } \\
\text { method }\end{array}$} & \multirow{2}{*}{$\begin{array}{l}\text { No. of } \\
\text { foods }\end{array}$} & \multirow{2}{*}{$\begin{array}{l}\text { FFQ reference } \\
\text { period }\end{array}$} & \multirow[b]{2}{*}{ Suppl. } & \multirow[b]{2}{*}{ Biomarkers } & \multirow[b]{2}{*}{ Coefficient } & \multirow{2}{*}{$\begin{array}{l}\text { Quality } \\
\text { index }\end{array}$} \\
\hline & & Mean & SD & Range & & & & & & & \\
\hline \multirow{2}{*}{$\begin{array}{l}\text { Drogan et al. } \\
\qquad(2004)^{(135)}\end{array}$} & $160 \mathrm{~W}$ & 160 & 10 & & Self-administered & 148 & 1 year & Yes & Plasma folate & $0.24^{*}$ & 3 \\
\hline & $203 \mathrm{M}$ & 203 & 9.4 & & & & & & RBC folate & $0.13^{*}$ & \\
\hline $\begin{array}{l}\text { Fraser et al. } \\
\qquad(2005)^{(73)}\end{array}$ & $\begin{array}{l}117 \mathrm{~W} \\
76 \mathrm{M}\end{array}$ & - & & & Self-administered & 202 & - & No & RBC folate & $0.28 \dagger$ & 2.5 \\
\hline $\begin{array}{l}\text { Hickling et al. } \\
\qquad(2005)^{(136)}\end{array}$ & $568 \mathrm{~W}$ & & & $33-83$ & Self-administered & 19 & 1 week & Yes & Serum folate & $0.49^{*}$ & 3 \\
\hline \multirow{5}{*}{$\begin{array}{l}\text { Jacques et al. } \\
\qquad(1993)^{(102)}\end{array}$} & $82 \mathrm{~W}$ & & & $40-83$ & Interviewer & 116 & 1 year & Yes & Plasma folate & $0.63 \dagger$ & 4.5 \\
\hline & $57 \mathrm{M}$ & & & & & & & & RBC thiamine & $0.02 \dagger$ & \\
\hline & & & & & & & & & RBC riboflavin & $-0.13 \dagger$ & \\
\hline & & & & & & & & & $\mathrm{RBC}_{6}$ & $-0.15 \dagger$ & \\
\hline & & & & & & & & & Plasma $B_{12}$ & $0.35 \dagger$ & \\
\hline \multirow{2}{*}{$\begin{array}{l}\text { Pufulete et al. } \\
\qquad(2002)^{(137)}\end{array}$} & $20 \mathrm{~W}$ & & & $22-65$ & Self-administered & 90 & 1 year & Yes & Serum folate & $0.69 \mathrm{~W} \ddagger / 0.85 \mathrm{M} \ddagger$ & 4 \\
\hline & $16 \mathrm{M}$ & & & & & & & & $\mathrm{RBC}$ folate & $0.41 \mathrm{~W} \ddagger / 0.69 \mathrm{M} \ddagger$ & \\
\hline \multirow{2}{*}{$\begin{array}{l}\text { Verkleij-Hagoort } \\
\text { et al. }(2007)^{(134)}\end{array}$} & $53 \mathrm{~W}$ & & & $24-44$ & Self-administered & 121 & 4 weeks & No & Serum folate & $0 \cdot 20 \ddagger$ & 2 \\
\hline & & & & & & & & & RBC folate & $0.28 \ddagger$ & \\
\hline Yen et al. (2003) & $28 \mathrm{~W}$ & & & $21-74$ & Self-administered & 122 & 1 month & Yes & Plasma folate & $-0.26 \S$ & $2 \cdot 5$ \\
\hline
\end{tabular}

No., number; Suppl., supplements; W, women; M, men; RBC, red blood cells.

* Crude, Pearson correlation coefficient.

† Multivariable-adjusted correlation coefficient.

₹Energy-adjusted, deattenuated correlation coefficient.

$\S$ Crude, Spearman correlation coefficient. 
Table 11. Description of validation studies regarding folic acid and B vitamin intake (Other methods)

\begin{tabular}{|c|c|c|c|c|c|c|c|c|c|c|}
\hline \multirow[b]{2}{*}{ Author and year of publication } & \multirow[b]{2}{*}{ No. } & \multicolumn{3}{|c|}{ Age (years) } & \multirow[b]{2}{*}{ Method } & \multirow[b]{2}{*}{ Gold standard } & \multirow[b]{2}{*}{ Suppl. } & \multirow[b]{2}{*}{ Nutrient } & \multirow[b]{2}{*}{ Coefficient } & \multirow[b]{2}{*}{ Quality index } \\
\hline & & Mean & SD & Range & & & & & & \\
\hline Bacardí-Gascón et al. (2003) ${ }^{(131)}$ & $34 \mathrm{~W}$ & & & $18-35$ & DR weighed (1/5) & Serum folate & No & Folic acid & $0.40^{\star}$ & 0.5 \\
\hline Fraser et al. $(2005)^{(73)}$ & $\begin{array}{l}117 \mathrm{~W} \\
76 \mathrm{M}\end{array}$ & - & & & Eight phone interview 24-h R & $\mathrm{RBC}$ folate & No & Folic acid & $0.51 \dagger$ & 2.5 \\
\hline Jain et al. $(1996)^{(24)}$ & $\begin{array}{l}108 \mathrm{~W} \\
95 \mathrm{M}\end{array}$ & & & $35-79$ & Dietary history & DR estimated $(1 / 7)$ & No & $\begin{array}{l}\text { Thiamine } \\
\text { Riboflavin } \\
\text { Niacin }\end{array}$ & $\begin{array}{l}0.34 \mathrm{~W} \ddagger / 0.24 \mathrm{M \ddagger} \\
0.56 \mathrm{~W} \ddagger / 0.40 \mathrm{M \ddagger} \\
0.35 \mathrm{~W} \neq / 0.46 \mathrm{M \ddagger}\end{array}$ & 4.5 \\
\hline McNaughton et al. (2005) ${ }^{(35)}$ & $\begin{array}{l}1149 \mathrm{~W} \\
1116 \mathrm{M}\end{array}$ & 43 & & & Personal interview 48-h R & DR estimated (1/5) & No & $\begin{array}{l}\text { Folic acid } \\
\mathrm{B}_{6} \\
\mathrm{~B}_{12}\end{array}$ & $\begin{array}{l}0.62 \mathrm{~W}^{*} / 0.57 \mathrm{M}^{*} \\
0.62 \mathrm{~W}^{*} / 0.58 \mathrm{M}^{*} \\
0.34 \mathrm{~W}^{*} / 0.29 \mathrm{M}^{*}\end{array}$ & 2 \\
\hline Pufulete et al. (2002) ${ }^{(137)}$ & $\begin{array}{l}20 \mathrm{~W} \\
16 \mathrm{M}\end{array}$ & & & $22-65$ & FFQ self-administered & $\begin{array}{l}\text { Serum folate } \\
\text { RBC folate }\end{array}$ & Yes & $\begin{array}{l}\text { Folic acid } \\
\text { Folic acid }\end{array}$ & $\begin{array}{l}0.69 \mathrm{~W}+/ 0.85 \mathrm{M}+ \\
0.41 \mathrm{~W}+/ 0.69 \mathrm{M}+\end{array}$ & 4 \\
\hline Pufulete et al. $(2002)^{(137)}$ & $\begin{array}{l}20 \mathrm{~W} \\
16 \mathrm{M}\end{array}$ & & & $22-65$ & DR weighed (1/7) & $\begin{array}{l}\text { Serum folate } \\
\text { RBC folate }\end{array}$ & Yes & $\begin{array}{l}\text { Folic acid } \\
\text { Folic acid }\end{array}$ & $\begin{array}{l}0.44 \mathrm{~W}+/ 0.81 \mathrm{M} \dagger \\
0.72 \mathrm{~W}+/ 1.00 \mathrm{M} \dagger\end{array}$ & 4 \\
\hline Schröder et al. $(2001)^{(70)}$ & 44 & 30.7 & $10 \cdot 4$ & & Personal interview 72-h R & DR estimated (1/3) & No & $\begin{array}{l}\text { Folic acid } \\
\text { Niacin } \\
\mathrm{B}_{6}\end{array}$ & $\begin{array}{l}0.46 \ddagger \\
0.28 \ddagger \\
0.57 \ddagger\end{array}$ & 3 \\
\hline Verkleij-Hagoort et al. (2007) ${ }^{(134)}$ & $53 \mathrm{~W}$ & & & $24-44$ & Three phone interview 24-h R & $\begin{array}{l}\text { Serum folate } \\
\text { RBC folate }\end{array}$ & No & $\begin{array}{l}\text { Folic acid } \\
\text { Folic acid }\end{array}$ & $\begin{array}{l}0.22 \S \\
0.49 \S\end{array}$ & 2 \\
\hline Yen et al. (2003) ${ }^{(138)}$ & $28 \mathrm{~W}$ & & & $21-74$ & Seven phone/mail interview 24-h R & Plasma folate & Yes & Folic acid & $0.354^{*}$ & 2.5 \\
\hline
\end{tabular}

No., number; Suppl., supplements; W, women; M, men; DR, dietary record (no. of records/no. of days per record); (24-, 48-, 72-) h R, (24-, 48-, 72-) h recall; RBC, red blood cells. *Crude, Spearman correlation coefficient.

$\dagger$ Energy-adjusted, deattenuated correlation coefficient.

Intra-Class correlation coefficient.

$\S$ Multivariable-adjusted correlation coefficient. 


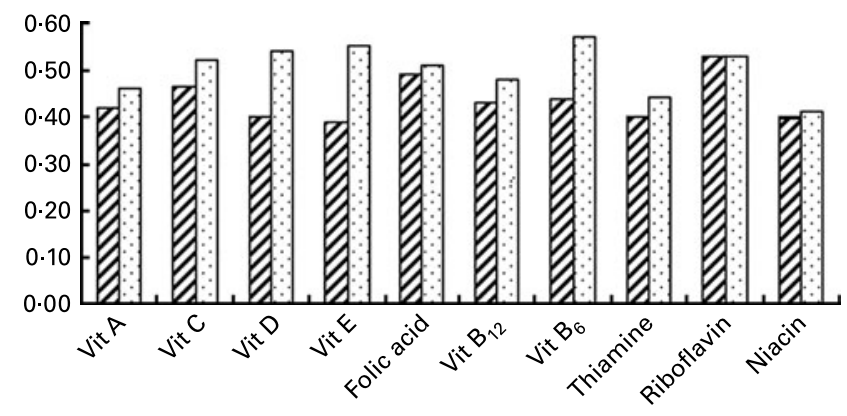

Fig. 1. Weighted correlation coefficients for $F F Q \quad v$. dietary record per vitamin and number of food items included in the FFQ. $\square$, foods $<100$; ๑., Foods $\geq 100$.

correlated errors, whereas dietary histories as gold standards are considered the least appropriate ${ }^{(1)}$.

The validity of other methods was also evaluated. However, their relatively low number and the many different reference methods that were used led us to focus on FFQ. The vast majority of FFQ were self-administered. Despite the fact that data collection was simplified, their incompleteness is a serious handicap as well as their lack of precision, given the large interpersonal variability in diet recalls ${ }^{(3)}$. In a review of FFQ validation studies, Cade et al. ${ }^{(4)}$ found that $\mathrm{CC}$ always improved, with the exception of vitamin $C$, when questionnaires were administered by an interviewer compared to those that were self-administered.

Time-frame concordance between FFQ and the reference method is even more crucial. The period of time which the dietary intake is referring to depends on the objectives of the study ${ }^{(5)}$. Usually, FFQ are designated to measure diet during the preceding year, whereas the reference methods do not cover the same time period. Multiple DR or recalls must be collected during the study period, and there is also a need to take into account seasonal variability, especially if we are interested in vitamin intakes, which are highly influenced by market availability. We have found that dietary intakes correlate better when the number of days covered by the reference method increases, except for B-complex vitamins when recall methods were used.

The order in which the FFQ and the reference method are applied is also decisive, considering that the results of the first measurement can affect those collected later on. We recommend that FFQ data be collected before gold standard measurement ${ }^{(5)}$. In many studies that were reviewed, FFQ

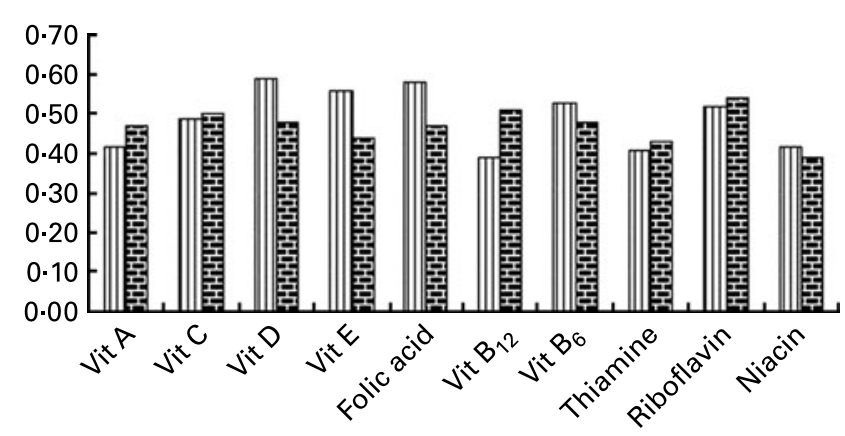

Fig. 2. Weighted correlation coefficients distributed by vitamin supplement intake. 四, Supplement; 四, no supplement.

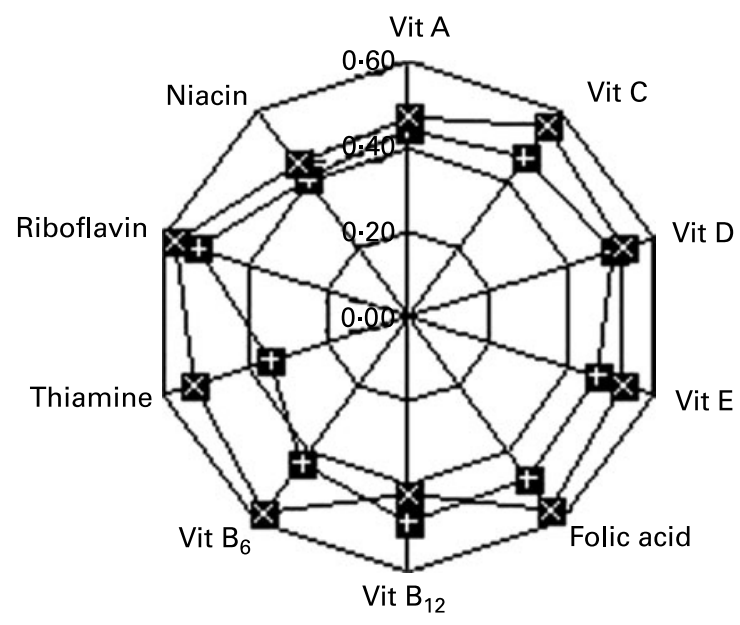

Fig. 3. Weighted correlation coefficients distributed by type of dietary record (weighed $v$. estimated dietary record). --1-, estimated dietary record; $-\mathbf{x}$ - weighed dietary record.

were applied twice, before and alter the reference period for the gold standard, in order to evaluate its reproducibility. However, the results depend on the vitamins considered.

The number of foods included in the FFQ has been classically considered as a key component to assure validity of dietary intakes. Using a meta-analysis, Molag et al. ${ }^{(6)}$ highlighted this point as the major determinant for ranking individuals according to their intakes. In the same vein, we have also found an improvement of the correlation when the numbers of food items surpassed 100: shorter questionnaires $(<100$ food items) yielded worse CC (mean 0.47) than those including more items $(0 \cdot 52)$, the latter having less variation as well.

However, it is also clear that the administration of longer FFQ is more expensive and participation rates may decrease. The use of extensive food lists is said to give less reliable results than shorter forms ${ }^{(1)}$, or even less information. The foods to be included in a FFQ should be restricted to those that are the principal source of the nutrient(s) of interest, and the frequency of their consumption must also be considered.

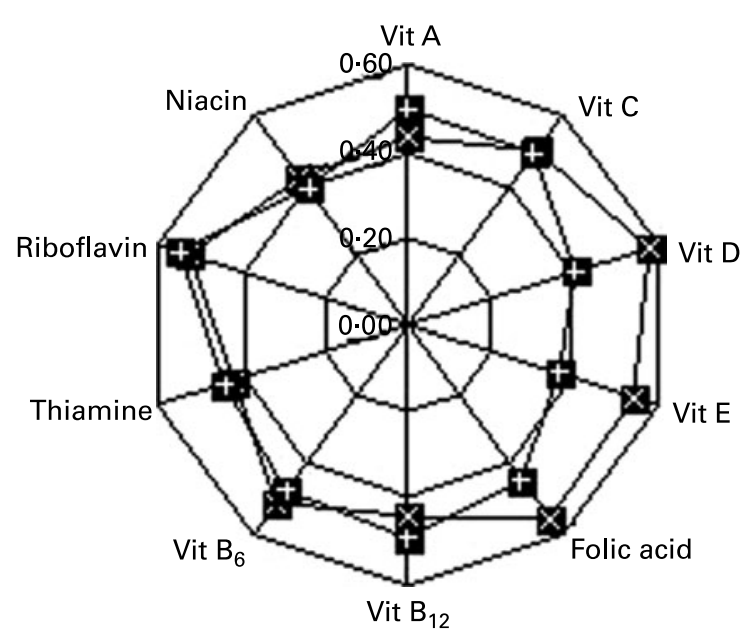

Fig. 4. Weighted correlation coefficients distributed by number of days registered. $-\mathbf{x}$-, long-term intake; $-\mathbf{t}-$-, short-term intake. 


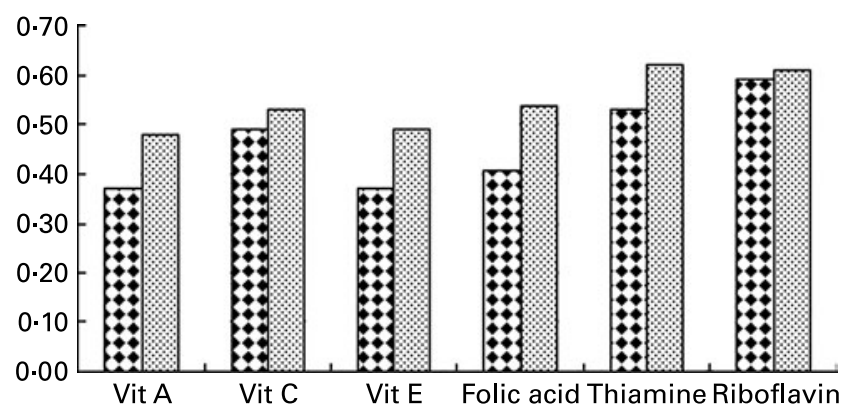

Fig. 5. Weighted correlation coefficients for FFQ $v$. recall per vitamin and number of foods items included in the FFQ. foods $<100$;. , foods $\geq 100$.

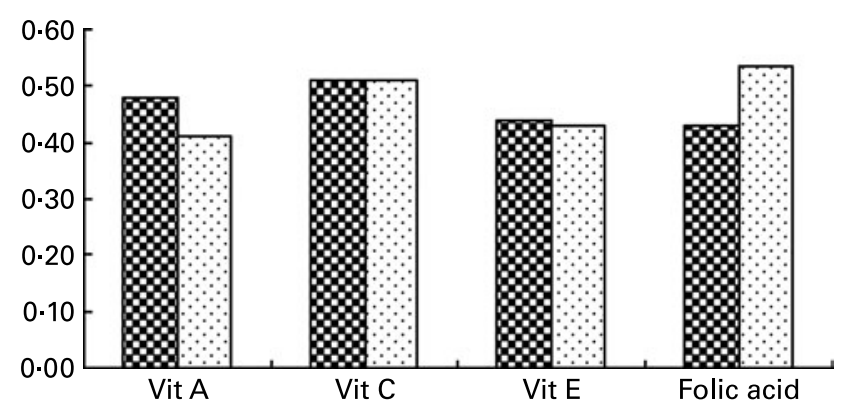

Fig. 6. Weighted correlation coefficients distributed by vitamin supplement intake. Several vitamins were not included in the figure because of the small number of studies collecting vitamin supplement use. $₫$, supplements; $\boxminus$, no supplements.

Supplements should be present in any dietary data assessment. We observed that data from FFQ and the reference method correlate better when specific questions about supplement intake are included, provided that they are asked for with the same emphasis. We stress the need to ask for the type and dosage of supplement use.

DR were the most commonly used reference method to validate the vitamin intakes measured by FFQ. We find narrower ranges of CC when DR are used, and so they may be less variable than recalls. Correlations are probably suboptimal when

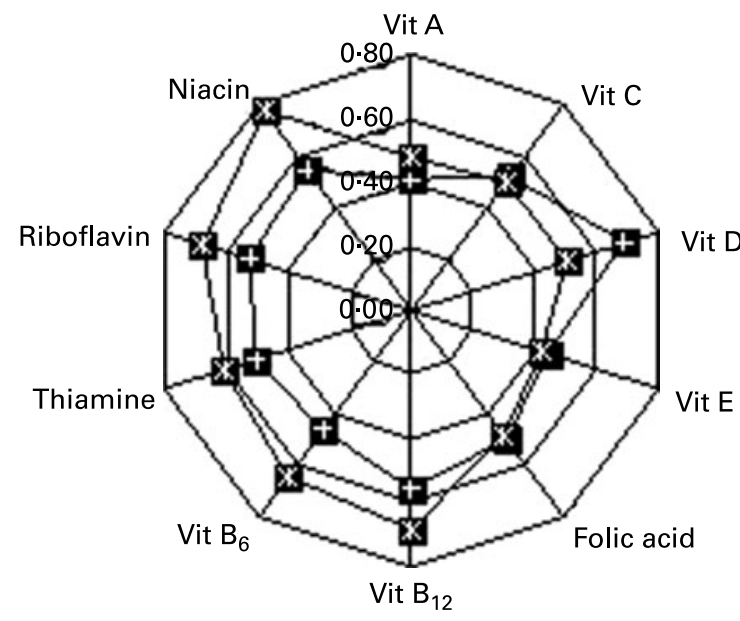

Fig. 7. Weighted correlation coefficients distributed by the number of days registered in the recalls. --- long-term intake; $-\mathbb{w}$, short-term intake. methods are used which share the inherent errors associated to FFQ, such as lack of memory and estimation of portion sizes.

Biomarker characteristics are responsible for the observed low correlations. Specifically, for vitamin C, plasma levels only show recent intake. Concerning vitamin $\mathrm{E}$, for which more biomarker-based validation studies have been done, correlation is even worse, given that only four studied its level in adipose tissue, which is the more appropriate marker for usual vitamin $\mathrm{E}$ intake.

In any case, the highest correlation coefficient observed, weighed by quality, was $0 \cdot 5$. In light of this, we recommend the application of correction factors to any population-based nutrition study.

\section{Acknowledgements}

The studies reported herein have been carried out within the EURRECA Network of Excellence (www.eurreca.org), financially supported by the Commission of the European Communities, specific Research, Technology and Development (RTD) Programme Quality of Life and Management of Living Resources, within the Sixth Framework Programme, contract no. 036196. This report does not necessarily reflect the Commission's views or its future policy in this area. P. H.-S., A. S.-V. and J. D.-A. were responsible for designing search strategies, retrieving references, critical reading and evaluation, and for writing the article. A. O.-A. participated in retrieving references. K. P. participated in data gathering. L. S.-M. designed the analysis and presentation of data and supervised the article editing, which has been read and approved by all the authors. The authors have no conflict of interests to report.

\section{References}

1. Willett WC \& Lenart E (1998) Reproducibility and validity of food-frequency questionnaires. In Nutritional Epidemiology, 2nd ed., pp. 101-147 [WC Willett, editor]. Oxford: Oxford Medical Publications.

2. Serra-Majem L, Frost Andersen L, Henriquez- Sánchez $\mathrm{P}$, et al. (2009) Evaluating the quality of dietary intake validation studies. Br J Nut 102, Suppl. 1, S3-S9.

3. Bingham SA \& Nelson M (1991) Assessment of food consumption and nutrient intake. In Design Concepts in Nutritional Epidemiology, pp. 153-191 [BM Margetts and M Nelson, editors]. Oxford: Oxford Medical Publications.

4. Cade J, Thompson R, Burley V, et al. (2001) Development validation and utilisation of a food-frequency questionnaire a review. Public Health Nutr 5, 567-587.

5. Nelson M (1991) The validation of dietary questionnaire. In Design Concepts in Nutritional Epidemiology, pp. 266-296 [BM Margetts and M Nelson, editors]. Oxford: Oxford Medical Publications.

6. Molag ML, de Vries JH, Ocké MC, et al. (2007) Design characteristics of food questionnaire in relation to their validity. Am J Epidemiol 166, 1468-1478.

7. Ambrosini GL, De Klerk NH, Musk AW, et al. (2001) Agreement between a brief food frequency questionnaire and diet records using two statistical methods. Public Health Nutr 4, $255-264$.

8. Andersen LF, Solvoll K, Johansson LR, et al. (1999) Evaluation of a food frequency questionnaire with weighed records, 
fatty acids, and alpha-tocopherol in adipose tissue and serum. Am J Epidemiol 150, 75-87.

9. Bautista L, Herrán O, Pryer J, et al. (2005) Development and simulated validation of a food-frequency questionnaire for the Colombian population. Public Health Nutr 8, 181-188.

10. Blalock SJ, Norton LL, Patel LA, et al. (2003) Development and assessment of a short instrument for assessing dietary intakes for calcium and vitamin D. J Am Pharm Assoc 43, 685-693.

11. Block G, Woods M, Potosky A, et al. (1990) Validation of a self-administered diet history questionnaire using multiple diet record. J Clin Epidemiol 43, 1327-1335.

12. Block G, Thompson FE, Hartman AM, et al. (1992) Comparison of two dietary questionnaires validated against multiple dietary records collected during a 1 -year period. J Am Diet Assoc 92, 686-693.

13. Bonifacj C, Gerber M, Scali J, et al. (1997) Comparison of dietary assessment methods in a southern French population: use of weighed records, estimated diet records and a foodfrequency questionnaire. Eur J Clin Nutr 51, 217-231.

14. Brunner E, Stallone D, Juneja M, et al. (2001) Dietary assessment in Whitehall II: comparison of $7 \mathrm{~d}$ diet diary and foodfrequency questionnaire and validity against biomarkers. $\mathrm{Br} J$ Nutr 86, 405-414.

15. Cardoso MA, Kida AA, Tomita LY, et al. (2001) Reproducibility and validity of a food frequency questionnaire among women of a Japanese ancestry living in Brazil. Nutr Res 21, $725-733$.

16. Chen Y, Ahsan H, Parvez F, et al. (2004) Validity of a foodfrequency questionnaire for a large prospective cohort study in Bangladesh. Br J Nutr 92, 851-859.

17. Date CH, Fukui M, Yamamoto A, et al. (2005) Reproducibility and validity of a self-administered food frequency questionnaire used in the JACC study. J Epidemiol 15, Suppl. 1, S9-S23.

18. Decarli A, Franceschi S, Ferraroni M, et al. (1996) Validation of a food-frequency questionnaire to assess dietary intakes in cancer studies in Italy. Results for specific nutrients. Ann Epidemiol 6, 110-118.

19. Egami I, Wakai K, Kato K, et al. (1999) A simple food frequency questionnaire for Japanese diet - Part II. Reproducibility and validity for nutrient intakes. J Epidemiol 9, 227-234.

20. Engle A, Lunn LL, Koury K, et al. (1990) Reproducibility and comparability of a computerized self-administered food frequency questionnaire. Nutr Cancer 13, 281-292.

21. Friis S, Krüger Kjaer S, Stripp C, et al. (1997) Reproducibility and relative validity of a self-administered semiquantitative food frequency questionnaire applied to younger women. $J$ Clin Epidemiol 50, 303-311.

22. Hodge A, Patterson A, Brown WJ, et al. (2000) The Anti Cancer Council of Victoria FFQ: relative validity of nutrient intakes compared with weighed food records in young to middle-aged women in a study of iron supplementation. Aust $N$ Z J Public Health 24, 576-583.

23. Ishihara J, Sobue T, Yamamoto S, et al. (2003) Validity and reproducibility of a self-administered food frequency questionnaire in the JPC Study Cohort II: study design, participant profile and results in comparison with Cohort I. J Epidemiol 13, Suppl. 1, S134-S147.

24. Jain M, Howe GR \& Rohan T (1996) Dietary assessment in epidemiology: comparison of a food frequency and diet history questionnaire with a 7-day food record. Am J Epidemiol 143, 953-960.

25. Jain M \& McLaughlin J (2000) Validity of nutrient estimates by food frequency questionnaires based either on exact frequencies or categories. Ann Epidemiol 10, 354-360.
26. Kelemen LE, Anand SS, Vuksan V, et al. (2003) Development and evaluation of cultural food frequency questionnaires for South Asians, Chinese and Europeans in North America. $J$ Am Diet Assoc 103, 1178-1184.

27. Kim J, Chan MM \& Shore RE (2002) Development and validation of a food frequency questionnaire for Korean Americans. Int J Food Sci Nutr 53, 129-142.

28. Kobayashi M, Sasaki S \& Tsugane S (2003) Validity of a selfadministered food frequency questionnaire used in the 5-year follow-up survey of the JPHC study cohort I to assess carotenoids and vitamin $\mathrm{C}$ intake: comparison with dietary records and blood level. J Epidemiol 13, Suppl. 1, S82-S91.

29. Lee MS, Pan WH, Liu KL, et al. (2006) Reproducibility and validity of a Chinese food frequency questionnaire used in Taiwan. Asia Pac J Clin Nutr 15, 161-169.

30. MacIntyre UE, Venter CS \& Vorster HH (2001) A culturesensitive quantitative food frequency questionnaire used in a African population: 2. Relative validation by 7-day weighed records and biomarkers. Public Health Nutr 4, 63-71.

31. Männistö S, Virtanen M, Mikkonen T, et al. (1996) Reproducibility and validity of a food frequency questionnaire in a case-control study on breast cancer. J Clin Epidemiol 49, 401-409.

32. Marks GC, Hughes MC \& van der Pols JC (2006) The effect of personal characteristics on the validity of nutrient intake estimates using a food-frequency questionnaire. Public Health Nutr 9, 394-402.

33. Martín-Moreno JM, Boyle P, Gorgojo L, et al. (1993) Development and validation of a food frequency questionnaire in Spain. Int J Epidemiol 22, 512-519.

34. McKeown NM, Day NE, Welch AA, et al. (2001) Use of biological markers to validate self-reported dietary intake in a random sample of the European Prospective Investigation into Cancer United Kingdom Norfolk cohort. Am J Clin Nutr 74, 188-196.

35. McNaughton SA, Marks GC, Gaffney P, et al. (2005) Validation of a food-frequency questionnaire assessment of carotenoid and vitamin E intake using weighed food records and plasma biomarkers: the method of triads model. Eur J Clin Nutr 59, 211-218.

36. Nagata C, Ohwaki A, Kurisu Y, et al. (1998) Food diversity and validity of semiquantitative food frequency questionnaire. $J$ Epidemiol 8, 297-301.

37. Ogawa K, Tsubono Y, Nishino Y, et al. (2003) Validation of a food frequency questionnaire for cohort studies in rural Japan. Public Health Nutr 6, 147-157.

38. Patterson RE, Kristal AR, Tinker LF, et al. (1999) Measurement characteristics of the Women's Health Initiative food frequency questionnaire. Ann Epidemiol 9, 178-187.

39. Pietinen P, Hartman AM, Haapa E, et al. (1998a) Reproducibility and validity of dietary assessment instruments. I. A self-administered food use questionnaire with a portion size picture booklet. Am J Epidemiol 128, 655-666.

40. Pietinen P, Hartman AM, Haapa E, et al. (1998b) Reproducibility and validity of dietary assessment instruments. II. A qualitative food frequency questionnaire. Am $J$ Epidemiol 128, 667-676.

41. Potischman N, Carroll RJ, Iturria SJ, et al. (1999) Comparison of the 60- and 100-item NCI-Block questionnaires with validation data. Nutr Cancer 34, 70-75.

42. Potosky AL, Block G \& Hartman MS (1990) The apparent validity of diet questionnaires is influenced by number of diet-records days used for comparison. J Am Diet Assoc 90, 810-813

43. Riboli E, Elmståhl S, Saracci R, et al. (1997) The Malmö Food Study: validity of two dietary assessment methods for measuring nutrient intake. Int J Epidemiol 26, Suppl. 1, S161-S173. 
44. Rimm EB, Giovannucci EL, Stampfer MJ, et al. (1992) Reproducibility and validity of an expanded self-administered semiquantitative food frequency questionnaire among male health professionals. Am J Epidemiol 135, 1114-1126.

45. Roddam AW, Spencer E, Banks E, et al. (2005) Reproducibility of a short semi-quantitative food group questionnaire and its performance in estimating nutrient intake compared with a 7-day diet diary in the Million Women Study. Public Health Nutr 8, 201-213.

46. Shimizu H, Ohwaki A, Kurisu Y, et al. (1999) Validity and reproducibility of a quantitative food frequency questionnaire for a cohort study in Japan. Jpn J Clin Oncol 29, 38-44.

47. Tjonneland A, Haraldsdottir J, Overvad K, et al. (1992) Influence of individually estimated portion size data on the validity of a semiquantitative food frequency questionnaire. Int J Epidemiol 21, 770-777.

48. Tokudome S, Imaeda N, Tokudome Y, et al. (2001) Relative validity of a semi-quantitative food frequency questionnaire versus 28 day weighed diet records in Japanese female dietitians. Eur J Clin Nutr 55, 735-742.

49. Tsubono Y, Ogawa K, Watanabe Y, et al. (2001) Food frequency questionnaire as a screening test. Nutr Cancer 39, $78-84$.

50. Tsubono Y, Sasaki S, Kobayashi M, et al. (2001) Food composition and empirical weight methods in predicting nutrient intakes from food frequency questionnaire. Ann Epidemiol 11, 213-218.

51. Tsugane S, Kobayashi M \& Sasaki S (2003) Validation of the self-administered food frequency questionnaire used in the 5 -year follow-up survey of the JPHC study cohort I: comparison with dietary records for main nutrients. J Epidemiol 13, Suppl. 1, S51-S56.

52. Willett WC, Sampson L, Stampfer MJ, et al. (1985) Reproducibility and validity of a semiquantitative food frequency questionnaire. Am J Epidemiol 122, 51-65.

53. Willett WC, Reynolds RD, Cottrell-Hoehner S, et al. (1987) Validation of a semi-quantitative food frequency questionnaire: comparison with a 1 -year diet record. J Am Diet Assoc 87, 43-47.

54. Baumgartner K, Gilliland FD, Nicholson CS, et al. (1998) Validity and reproducibility of a food frequency questionnaire among Hispanic and non-Hispanic white women in New Mexico. Ethn Dis 8, 81-92.

55. Fregapane G \& Asensio-García C (2000) Dietary assessment of an educated young Spanish population using a selfadministered meal-based food frequency questionnaire. Eur $J$ Epidemiol 16, 183-191.

56. George GC, Milani TJ, Hanss-Nuss H, et al. (2004) Development and validation of a semi-quantitative food frequency questionnaire for young adult women in the south western United States. Nutr Res 24, 29-43.

57. Goulet J, Nadeau G, Lapointe A, et al. (2004) Validity and reproducibility of an interviewer-administered food frequency questionnaire for healthy French-Canadian men and women. Nutr J 3, 13.

58. Hartwell DL \& Henry CJK (2001) Comparison of a selfadministered quantitative food amount frequency questionnaire with 4-day estimated food records. Int J Food Sci Nutr 52, $151-159$.

59. Ke L, Toshiro T, Fengyan S, et al. (2005) Relative validity of a semi-quantitative food frequency questionnaire versus 3 day weighed diet records in middle-aged inhabitants in Chaoshan area, China. Asian Pac J Cancer Prev 6, 376-381.

60. Kristal AR, Feng Z, Coates RJ, et al. (1997) Associations of race/ethnicity education and dietary intervention with the validity and reliability of a food frequency questionnaire. Am J Epidemiol 146, 856-869.
61. Kumanyika SK, Mauger D, Mitchell DC, et al. (2003) Relative validity of food frequency questionnaire nutrient estimates in the Black Women's Health Study. Ann Epidemiol 13, 111-118

62. Longnecker M, Lissner L, Holden J, et al. (1993) The reproducibility and validity of a self-administered semiquantitative food frequency questionnaire in subjects from south Dakota and Wyoming. Epidemiology 4, 356-365.

63. Martínez ME, Marshall JR, Graver E, et al. (1999) Reliability and validity of a self-administered food frequency questionnaire in a chemoprevention trial of adenoma recurrence. Cancer Epidemiol Biomarkers Prev 8, 941-946.

64. Masson LF, McNeill G, Tomany JO, et al. (2003) Statistical approaches for assessing the relative validity of a foodfrequency questionnaire: use of correlation coefficients and the kappa statistic. Public Health Nutr 6, 313-321.

65. Moreira P, Sampaio D \& Almeida MD (2003) Validity assessment of a food frequency questionnaire by comparison with a 4-day diet record. Acta Med Port 16, 412-420.

66. Paalanen L, Männistö S, Virtanen MJ, et al. (2006) Validity of a food frequency questionnaire varied by age and body mass index. J Clin Epidemiol 59, 994-1001.

67. Parr CL, Barikmon I, Torheim LE, et al. (2002) Validation of the second version of a quantitative food-frequency questionnaire for use in Western Mali. Public Health Nutr 5, 769-781.

68. Sasaki S, Yanagibori R, Amano K, et al. (1998) Selfadministered diet history questionnaire developed for health education: a relative validation of the test-version by comparison with 3-day diet record in women. J Epidemiol 8, $203-215$.

69. Sauvaget C, Allen N, Hayashi M, et al. (2002) Validation of a food frequency questionnaire in the Hiroshima/Nagasaki life span study. J Epidemiol 12, 394-401.

70. Schröder H, Covas MI, Marrugat J, et al. (2001) Use of a three-day estimated food record, a 72-hour recall and a foodfrequency questionnaire for dietary assessment in a Mediterranean Spanish population. Clin Nutr 20, 429-437.

71. Tokudome S, Goto Ch, Imaeda N, et al. (2005) Relative validity of a short food frequency questionnaire for assessing nutrient intake versus three-day weighed diet records in middle-aged Japanese. J Epidemiol 15, 135-145.

72. Boeing H, Bohlscheid-Thomas S, Voss S, et al. (1997) The relative validity of vitamin intakes derived from a food frequency questionnaire compared to 24-hour recalls and biological measurements: results from the EPIC Pilot Study in Germany. Int J Epidemiol 26, Suppl. 1, S62-S90.

73. Fraser GE, Butler TL, Shavlik D, et al. (2005) Correlations between estimated and true dietary intakes: using two instrumental variables. Ann Epidemiol 15, 509-518.

74. Gnardellis C, Trichopoulou A, Katsouyanni K, et al. (1994) Reproducibility and validity of an extensive semiquantitative food frequency questionnaire among Greek school teachers. Epidemiology 6, 74-77.

75. Hebert JR, Gupta PC, Bhonsle RB, et al. (1998) Development and testing of a quantitative food frequency questionnaire for use in Kerala, India. Public Health Nutr 1, 123-130.

76. Hernández-Ávila M, Romieu I, Parra S, et al. (1998) Validity and reproducibility of a food frequency questionnaire to assess dietary intake of women living in Mexico City. Salud Publica Mex 40, 133-140.

77. Jackson M, Walker S, Cade J, et al. (2001) Reproducibility and validity of a quantitative food-frequency questionnaire among Jamaicans of Africa origin. Public Health Nutr 4, 971-980.

78. Johansson I, Hallmans G, Biessy C, et al. (2001) Validation and calibration of food-frequency questionnaire measurements in the Northern Sweden Health and Disease cohort. Public Health Nutr 5, 487-496. 
79. Kabagambe EK, Baylin A, Allan DA, et al. (2001) Application of the method of triads to evaluate the performance of food frequency questionnaires and biomarkers as indicators of long-term dietary intake. Am J Epidemiol 154, 1126-1135.

80. Katsouyanni K, Rimm EB, Gnardellis CH, et al. (1997) Reproducibility and relative validity of an extensive semiquantitative food frequency questionnaire using dietary records and biochemical markers among Greek schoolteachers. Int $J$ Epidemiol 26, Suppl. 1, S118-S127.

81. Malekshah AF, Kimiagar M, Saadatian-Elahi M, et al. (2006) Validity and reliability of a new food frequency questionnaire compared to $24 \mathrm{~h}$ recalls and biochemical measurements: pilot phase of Golestan cohort study of esophageal cancer. Eur $J$ Clin Nutr 60, 971-977.

82. Mayer-Davis EJ, Vitolins MZ, Carmichael SL, et al. (1999) Validity and reproducibility of a food frequency interview in a multi-cultural epidemiologic study. Ann Epidemiol 9, $314-324$.

83. Messerer M, Johansson SE \& Wolk A (2004) The validity of questionnaire-based micronutrient intake estimates is increased by including dietary supplement use in Swedish men. $J$ Nutr 134, 1800-1805.

84. Ocké MC, Bueno-de-Mesquita HB, Pols MA, et al. (1997) The Dutch EPIC food frequency questionnaire. II. Relative validity and reproducibility for nutrients. Int J Epidemiol 26, Suppl. 1, S49-S58.

85. Pisani P, Faggiano F, Krogh V, et al. (1997) Relative validity and reproducibility of a food frequency dietary questionnaire for use in the Italian EPIC centres. Int $J$ Epidemiol 26, Suppl. 1, S152-S160.

86. Romieu I, Parra S, Hernández JF, et al. (1999) Questionnaire assessment of antioxidant and retinol intakes in Mexican women. Arch Med Res 30, 224-239.

87. Sevak L, Mangtani P, McCormack V, et al. (2004) Validation of a food frequency questionnaire to assess macro- and micronutrient intake among South Asians in the United Kingdom. Eur J Nutr 43, 160-168.

88. Shu O, Yang G, Jin F, et al. (2004) Validity and reproducibility of the food frequency questionnaires used in the Shanghai Women's Health Study. Eur J Clin Nutr 58, 17-23.

89. Van Liere MJ, Lucas F, Clavel F, et al. (1997) Relative validity and reproducibility of a French dietary history questionnaire. Int J Epidemiol 26, Suppl. 1, S128-S136.

90. Villegas R, Yang G, Liu D, et al. (2006) Validity and reproducibility of the food frequency questionnaire used in the Shangai Men's Health Study. Br J Nutr 97, 993-1000.

91. Block G, Wakimoto P, Jensen C, et al. (2006) Validation of a food frequency questionnaire for Hispanics. Prev Chronic Dis 3, 77A.

92. Boucher B, Cotterchio M, Kreiger N, et al. (2006) Validity and reliability of the Block98 food-frequency questionnaire in a sample of Canadian women. Public Health Nutr 9, 84-93.

93. Flagg EW, Coates RJ, Calle EE, et al. (2000) Validation of the American Cancer Society Cancer Prevention Study II Nutrition Survey Cohort Food Frequency Questionnaire. Epidemiology 11, 462-468.

94. Fornés NS, Stringhini ML \& Elias BM (2003) Reproducibility and validity of a food-frequency questionnaire for use among low-income Brazilian workers. Public Health Nutr 6, 821-827.

95. Hebert JR, Gupta PC, Bhonsle RB, et al. (1999) Development and testing of a quantitative food frequency questionnaire for use in Gujarat, India. Public Health Nutr 2, 39-50.

96. Kusama K, Le DS, Hanh TT, et al. (2005) Reproducibility and validity of a food frequency questionnaire among Vietnamese in Ho Chi Minh City. J Am Coll Nutr 24, 466-473.

97. Munger RG, Folsom AR, Kushi LH, et al. (1992) Dietary assessment of older Iowa women with a food frequency questionnaire: nutrient intake, reproducibility, and comparison with 24-hour dietary recall interviews. Am J Epidemiol 136, 192-200.

98. Navarro A, Osella AR, Guerra V, et al. (2001) Reproducibility and validity of a food-frequency questionnaire in assessing dietary intakes and food habits in epidemiological cancer studies in Argentina. J Exp Clin Cancer Res 20, 365-370.

99. Olafsdottir AS, Thorsdottir I, Gunnarsdottir I, et al. (2006) Comparison of women's diet assessed by FFQs and 24-hour recalls with and without underreporters: associations with biomarkers. Ann Nutr Metab 50, 450-460.

100. Rodríguez MM, Méndez H, Torún B, et al. (2002) Validation of a semi-quantitative food-frequency questionnaire for use among adults in Guatemala. Public Health Nutr 5, 691-698.

101. Segovia-Siapco G, Singh P, Jaceldo-Siegl K, et al. (2007) Validation of a food-frequency questionnaire for measurement of nutrient intake in a dietary intervention study. Public Health Nutr 10, 177-184.

102. Shai I, Rosner BA, Shahar DR, et al. (2005) Dietary evaluation and attenuation of relative risk: multiple comparisons between blood and urinary biomarkers, food frequency, and 24-hour recall questionnaires: the DEARR study. J Nutr 135, 573-579.

103. Sichieri R \& Everhart JE (1998) Validity of a Brazilian food frequency questionnaire against dietary recalls and estimated energy intakes. Nutr Res 18, 1649-1659.

104. Sudha V, Radhika G, Sathya RM, et al. (2006) Reproducibility and validity of an interviewer-administered semi-quantitative food frequency questionnaire to assess dietary intake of urban adults in southern India. Int J Food Sci Nutr 57, 481-493.

105. Ascherio A, Stampfer MJ, Colditz GA, et al. (1992) Correlations of vitamin $\mathrm{A}$ and $\mathrm{E}$ intakes with the plasma concentrations of carotenoids and tocopherols among American men and women. $J$ Nutr 122, 1792-1801.

106. Bingham SA, Gill C, Welch A, et al. (1997) Validation of dietary assessment methods in the UK arm of EPIC using weighed records, and 24-hour urinary nitrogen and potassium and serum vitamin $\mathrm{C}$ and carotenoids and biomarkers. Int J Epidemiol 26, Suppl. 1, S137-S151.

107. Bodner CH, Soutar A, New SA, et al. (1998) Validation of a food frequency questionnaire for use in a Scottish population: correlation of antioxidant vitamin intakes with biochemical measures. J Hum Nutr Diet 11, 373-380.

108. Bolton-Smith C, Casey CE, Gey KF, et al. (1991) Antioxidant vitamin intakes assessed using a food frequency questionnaire: correlation with biochemical status in smokers and nonsmokers. Br J Nutr 65, 337-436.

109. Coates RJ \& Monteilh CP (1997) Assessment of food frequency questionnaires in minority populations. Am J Clin Nutr 65, Suppl. 4, S1108-S1115.

110. Dixon LB, Subar AF, Wideroff L, et al. (2006) Carotenoid and tocopherol estimates from the NCI diet history questionnaire are valid compared with multiple recalls and serum biomarkers. J Nutr 136, 3054-3061.

111. El-Sohemy A, Baylin A, Ascherio A, et al. (2001) Populationbased study of $\alpha$ - and $\gamma$-tocopherol in plasma and adipose tissue as biomarkers of intake in Costa Rica adults. Am J Clin Nutr 74, 356-363.

112. Jacques PF, Sulsky SI, Sadowski JA, et al. (1993) Comparison of micronutrient intake measured by a dietary questionnaire and biochemical indicators of micronutrient status. Am J Clin Nutr 57, 182-189.

113. Kardinaal AF, van't Veer P, Brants HA, et al. (1995) Relations between antioxidant vitamins in adipose tissue, plasma, and diet. Am J Epidemiol 141, 440-450.

114. Knutsen SF, Fraser GE, Linsted KD, et al. (2001) Comparing biological measurements of vitamin $\mathrm{C}$, folate, alpha-tocopherol and carotene with 24-hour dietary recall information in nonhispanic blacks and whites. Ann Epidemiol 11, 406-416. 
115. Marshall JR, Lanza E, Bloch A, et al. (1997) Indexes of food nutrient intakes as predictors of serum concentrations of nutrients: the problem of inadequate discriminant validity. Am J Clin Nutr 65, Suppl. 4, S1269-S1274.

116. Porrini M, Gentile MG \& Fidanza F (1995) Biochemical validation of a self-administered semi-quantitative food-frequency questionnaire. Br J Nutr 74, 323-333.

117. Sinha R, Block G \& Taylor PR (1992) Determinants of plasma ascorbic acid in a healthy male population. Cancer Epidemiol Biomarkers Prev 1, 297-302.

118. Willet WC, Stampfer MJ \& Underwood BA (1983) Validation of a dietary questionnaire with plasma carotenoid and (alpha)tocopherol levels. Am J Clin Nutr 38, 631-639.

119. Bingham SA, Gill C, Welch A, et al. (1994) Comparison of dietary assessment methods in nutritional epidemiology: weighed records v. $24 \mathrm{~h}$ recalls, food-frequency questionnaires and estimated-diet records. Br J Nutr 72, 619-643.

120. Booth SL, Tucker KL, McKeown NM, et al. (1997) Relationships between dietary intakes and fasting plasma concentrations of fat-soluble vitamins in humans. J Nutr 127, 587-592.

121. EPIC Group of Spain (1997) Relative validity and reproducibility of a diet history questionnaire in Spain. II. Nutrients. Int J Epidemiol 26, Suppl. 1, S100-S109.

122. EPIC Group of Spain (1997) Relative validity and reproducibility of a diet history questionnaire in Spain. III. Biochemical markers. Int J Epidemiol 26, Suppl. 1, S110-S117.

123. Hankin JH, Wilkens LR, Kolonel LN, et al. (1991) Validation on a quantitative diet history method in Hawaii. Am J Epidemiol 133, 616-628.

124. Hebert JR, Hurley T, Chiriboga D, et al. (1998) A comparison of selected nutrient intakes derived from three diet assessment methods used in a low-fat maintenance trial. Public Health Nutr 1, 207-214.

125. Matthys C, Pynaert I, Roe M, et al. (2004) Validity and reproducibility of a computerised tool for assessing the iron, calcium and vitamin C intake of Belgian women. Eur J Clin Nutr 58, 1297-1305.

126. Sasaki S, Ushio F, Amano K, et al. (2000) Serum biomarkerbased validation of a self-administered diet history questionnaire for Japanese subjects. J Nutr Sci Vitaminol (Tokyo) 46, 285-296.
127. Smith CJ, Nelson RG, Hardy SA, et al. (1996) Survey of the diet of Pima Indians using quantitative food frequency assessment and 24-hour recall. J Am Diet Assoc 96, 778-784.

128. Takatsuka N, Kurisu Y, Nagata C, et al. (1997) Validation of simplified diet history questionnaire. $J$ Epidemiol 7, 33-41.

129. Flood V, Smith WT, Webb KL, et al. (2004) Issues in assessing the validity of nutrient data obtained from a foodfrequency questionnaire: folate and vitamin B12 examples. Public Health Nutr 7, 751-756.

130. Ishihara J, Yamamoto S, Iso H, et al. (2005) Validity of a self-administered food frequency questionnaire (FFQ) and its generalizability to the estimation of dietary folate intake in Japan. Nutr J 4, 26.

131. Bacardi-Gascón M, Ley y de Góngora S, Castro-Vázquez BY, et al. (2003) Validation of a semiquantitative food frequency questionnaire to assess folate status. Results discriminate a high-risk group of women residing on the Mexico-U.S. border. Arch Med Res 34, 325-330.

132. French MR, Langdon C, Levy-Milne R, et al. (2001) Development of a validated food frequency questionnaire to determine folate intake. Can J Diet Pract Res 62, 82-86.

133. Torheim LE, Barikmo I, Hatloy A, et al. (2001) Validation of a quantitative food frequency questionnaire for use in western Mali. Public Health Nutr 4, 1267-1277.

134. Verkleij-Hagoort AC, de Vries JHM, Stegers MPG, et al. (2007) Validation of the assessment of folate and vitamin B12 intake in women of reproductive age: the method of triads. Eur J Clin Nutr 61, 610-615.

135. Drogan D, Klipstein-Grobusch K, Wans S, et al. (2004) Plasma folate as marker of folate status in epidemiological studies: the European Investigation into Cancer and Nutrition (EPIC)Postdam study. Br J Nutr 92, 489-496.

136. Hickling S, Knuiman M, Jamrozik K, et al. (2005) A rapid dietary assessment to determine intake of folate was developed and validated. J Clin Epidemiol 58, 802-808.

137. Pufulete M, Emery PW, Nelson M, et al. (2002) Validation of a short food frequency questionnaire to assess folate intake. $\mathrm{Br}$ J Nutr 87, 383-390.

138. Yen J, Zoumas-Mourse C, Pakiz B, et al. (2003) Folate intake assessment: validation of a new approach. J Am Diet Assoc 103, 991-1000. 